ÊNIO JOSÉ BASSI

\title{
PROPRIEDADES IMUNOMODULADORAS DAS CÉLULAS-TRONCO MESENQUIMAIS DO TECIDO ADIPOSO NO TRATAMENTO DO DIABETES AUTOIMUNE EXPERIMENTAL
}

Tese apresentada ao Programa de PósGraduação em Imunologia do Instituto de Ciências Biomédicas da Universidade de São Paulo, para a obtenção do Título de Doutor em Ciências. 


\section{PROPRIEDADES IMUNOMODULADORAS DAS CÉLULAS-TRONCO MESENQUIMAIS DO TECIDO ADIPOSO NO TRATAMENTO DO DIABETES AUTOIMUNE EXPERIMENTAL}

Tese apresentada ao Programa de PósGraduação em Imunologia do Instituto de Ciências Biomédicas da Universidade de São Paulo para a obtenção do Título de Doutor em Ciências.

Área de concentração: Imunologia

Orientador: Prof. Dr. Niels Olsen Saraiva Câmara

Versão original 
DADOS DE CATALOGAÇĀO NA PUBLICAÇÃO (CIP)

Serviço de Biblioteca e Informação Biomédica do

Instituto de Ciências Biomédicas da Universidade de São Paulo

reproduçăo năo autorizada pelo autor

\section{Bassi, Ênio José.}

Propriedades imunomoduladoras das células-tronco mesenquimais do tecido adiposo no tratamento do diabetes autoimune experimental / Énio José Bassi. -- Säo Paulo, 2012.

Orientador. Prof. Dr.Niels Olsen Saraiva Câmara.

Tese (Doutorado) - Universidade de Säo Paulo. Instituto de Cièncias Biomédicas. Departamento de Imunologia. Área de concentração: Imunologia. Linha de pesquisa: Imunorregulaçäo e tolerância imunológica.

Versão do título para o inglês: Immune regulatory properties of adipose-derived mesenchymal stem cells in the treatment of experimental autoimmune diabetes.

$\begin{array}{llll}\text { 1. Imunologia celular 2. Células-tronco } 3 \text {. Diabetes mellitus } & \end{array}$ 4. Autoimunidade I. Câmara, Prof. Dr. Niels Olsen Saraiva II. Universidade de São Paulo. Instituto de Ciências Biomédicas. Programa de Pós-Graduaçäo em Imunologia III. Título. 


\title{
UNIVERSIDADE DE SÃO PAULOO \\ INSTITUTO DE CIÉNCIAS BIOMÉDICAS
}

\begin{abstract}
Candidato(a): Énio José Bassi.
Título da Tese: $\quad$ Propriedades imunomoduladoras das células-tronco mesenquimais do tecido adiposo no tratamento do diabetes autoimune experimental.
\end{abstract}

Orientador(a)

Prof. Dr. Niels Olsen Saraiva Câmara.

A Comissão Julgadora dos trabalhos de Defesa da Tese de Doutorado, em sessão pública realizada a $J$ considerou
( ) Aprovado(a)
( ) Reprovado(a)

\begin{tabular}{|c|c|}
\hline Examinador(a): & Assinatura: .. \\
\hline & Nome: ........ \\
\hline & Instituiça:o: \\
\hline Examinador(a): & Assinatura: \\
\hline & Nome: ...... \\
\hline & Instituiç̧̃o: \\
\hline Examinador(a): & Assinatura: \\
\hline & Nome: ...... \\
\hline & Instituição: \\
\hline Examinador(a): & Assinatura: \\
\hline & Nome: ........ \\
\hline & Instituilgão: . \\
\hline Presidente: & Assinatura: \\
\hline & Nome: ............ \\
\hline & Instituięấc \\
\hline
\end{tabular}




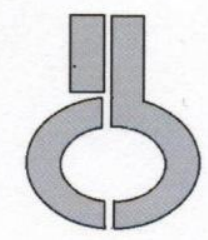

UNIVERSIDADE DE SÃO PAULO INSTITUTO DE CIÊNCIAS BIOMÉDICAS

Cidade Universitária "Armando de Salles Oliveira"

Av. Prof. Lineu Prestes, 2415 - CEP. 05508-000 São Paulo, SP - Brasil

Telefone :(55) (011) 3091.7733 - telefax : (55) (011) 3091.7438

e-mail: cep@icb.usp.br

\section{Certificado}

Certificamos que o protocolo registrado sob $\mathrm{n}^{\circ} \mathbf{9 2}$ nas fls. $\mathbf{7 3}$ do livro $\mathbf{0 2}$ para uso de animais em experimentação, sob a responsabilidade do Prof(a) $\operatorname{Dr}(a)$ Niels Olsen Saraiva Câmara, Coordenador(a) da Linha de pesquisa Estudo das propriedades imunomoduladoras das células-tronco mesenquimais sobre a geração, expansão e diferenciação de células TCD4+CD25+Foxp3+e cêlulas Th17 do qual participou(aram) o(s) alunos Ênio José Bassi, está de acordo com os Princípios Éticos de Experimentação Animal adotado pela Sociedade Brasileira de Ciência de Animais de Laboratório (SBCAL) e foi aprovado pela COMISSÃO DE ÉTICA EM EXPERIMENTAÇÃO ANIMAL (CEEA) em $\mathbf{3 0 . 0 6 . 0 9}$, com validade de 3 anos.

São Paulo, 01 de julho de 2009.

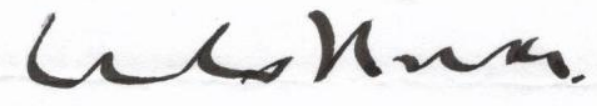

Prof.Dr.WOTHAN TAVARES DE LIMA Coordenador CEEA - ICB/USP

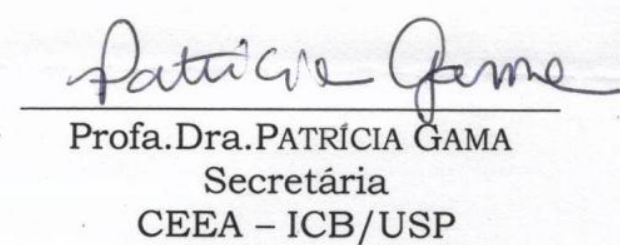

CEEA - ICB/USP 
Ao Amor da Minha Vida, Letícia Anderson, por estar sempre ao meu lado... "Feliz o dia que os meus olhos nos teus se encontraram..."

A minha amada mãe Zilma, pelo apoio, carinho $e$ amor de mãe incondicional 


\section{AGRADECIMENTOS}

Agradeço a Deus, pelo dom da vida e por estar sempre ao meu lado iluminando cada passo da minha caminhada, sorrindo comigo nos momentos felizes e sendo meu ombro amigo fiel nas horas em que mais precisei...

Ao amor da minha vida, Letícia Anderson, pelo amor, carinho, cumplicidade, dedicação e por sempre estar ao meu lado, me apoiando em todos os momentos de minha vida

A minha mãe, Zilma, ao meu irmão Denis, e a toda minha família, por me apoiarem, pelas orações $e$ por sempre estarem presentes torcendo pela minha felicidade

Ao meu pai, Jayme Bassi (in memorian) pela proteção que me concede todos os dias

Ao professor e amigo, Niels Olsen Saraiva Câmara, pela acolhida como seu aluno em seu laboratório, pela orientação, amizade, confiança, preocupação, incentivo e por sempre me ajudar quando mais precisei

Àos amigos Pedro, Danilo e Vinícius pela amizade, companheirismo, apoio e ajuda no desenvolvimento deste trabalho e pelos momentos que passamos juntos durante esses anos

Aos amigos do Laboratório de Imunobiologia dos Transplantes, pela convivência e momentos agradáveis que passamos juntos

Aos amigos Carla e Leonardo, pela ajuda com os experimentos

Ao professor Alexandre Basso pelo apoio e disponibilidade dos camundongos Foxp3 GFP

A todos os professores das disciplinas que cursei por todos os ensinamentos, em especial a professora Vera Calich pela oportunidade de ser seu aluno $\mathscr{P A E}$

À Secretaria do Programa de Pós-Graduação em Imunologia, em especial a Eni

Ao Paulo Albe pela ajuda com a parte de análise fistológica

A FAPESP pelo apoio financeiro sem o qual não seria possível a realização deste trabalho

Ao Departamento de Imunologia, ao Instituto de Ciências Biomédicas e a Universidade de São Paulo

A todas as pessoas que contribuíram para o desenvolvimento desse trabalho, as quais, direta ou indiretamente, participaram da construção da minha história como profissional e ser humano, a minha eterna gratidão

MUITO OBRIGADO

Ênio José Bassi 
O presente trabalho foi desenvolvido com apoio da Fundação de Amparo a Pesquisa do Estado de São Paulo (FAPESP) e do Conselho Nacional de Desenvolvimento Científico e Tecnológico (CNPq). 
"Quando a noite esconde a luz, Deus acende as estrelas"

Pe. Fábio de Melo 


\section{RESUMO}

Bassi EJ. Propriedades imunomoduladoras das células-tronco mesenquimais do tecido adiposo no tratamento do diabetes autoimune experimental. [tese (Doutorado em Imunologia)]. São Paulo: Instituto de Ciências Biomédicas, Universidade de São Paulo; 2012.

As células-tronco isoladas a partir do tecido adiposo (ADMSCs) se tornaram promissoras para o tratamento de diversas doenças autoimunes devido a suas propriedades imunomoduladoras. No entanto, o seu papel imunomodulador no diabetes autoimune tipo 1 (DMT1) permanece amplamente inexplorado. $\mathrm{O}$ objetivo deste estudo foi avaliar o potencial terapêutico das ADMSCs em modular a resposta imune no diabetes autoimune experimental em camundongos NOD. ADMSCs alogenêicas foram administradas em camundongos NOD diabéticos (glicemia > $240 \mathrm{mg} / \mathrm{dl}$ ) nos dias 0, 7 e 14 sendo então a glicemia monitorada por 12 semanas. A administração de ADMSCs resultou na reversão da hiperglicemia em $78 \%$ dos animais por até 8 semanas após o tratamento sendo esse efeito acompanhado de uma melhora significativa na resposta ao teste de tolerância a glicose e em aumento nos níveis de insulina, amilina e GLP-1 no soro. A presença das ADMSCs pôde ser detectada 72h após administração intraperitoneal nos linfonodos pancreáticos e pâncreas dos animais. Esse efeito terapêutico foi associado, nos linfonodos pancreáticos, a um aumento na frequência de células $\mathrm{T}$ CD4+CD25+Foxp3+ ( $\mathrm{T}$ reguladoras, ou Tregs) e a uma diminuição de linfócitos CD4+ produtores de IFN- $\gamma$ e TNF- $\alpha 35$ dias após o tratamento. Além disso, no pâncreas, uma redução do infiltrado celular inflamatório e nos níveis de IFN- $\gamma$ e aumento de TGF- $\beta 1$ biologicamente ativo, assim como uma maior expressão de insulina e PDX-1 nas ilhotas pancreáticas foram observados. De forma interessante, uma maior frequência de células T CD4+CD25+Foxp3+Helios+ pode ser observada 12 semanas após o tratamento. In vitro, as ADMSCs promoveram a expansão de Tregs em um mecanismo dependente de contato celular e mediado pela molécula PD-L1. Em suma, o tratamento com ADMSCs pôde melhorar de forma efetiva o diabetes autoimune em camundongos NOD pela atenuação da resposta autoimune concomitante a expansão de células Tregs, provendo o desenvolvimento futuro de novas perspectivas de estratégias terapêuticas de terapia celular para o DMT1.

Palavras-chave: Células-tronco mesenquimais do tecido adiposo. Imunomodulação. Diabetes autoimune experimental. Células T reguladoras. 


\begin{abstract}
Bassi EJ. Immune regulatory properties of adipose-derived mesenchymal stem cells in the treatment of experimental autoimmune diabetes. [Ph. D. thesis (Immunology)]. São Paulo: Instituto de Ciências Biomédicas, Universidade de São Paulo; 2012.

Adipose-derived mesenchymal stem cells (ADMSCs) display immunomodulatory properties representing a promising therapeutic approach for several autoimmune diseases, but their role in autoimmune type 1 diabetes (T1D) remains largely unexplored. The aim of this study was to investigate the immune regulatory properties of allogeneic ADMSCs therapy in $\mathrm{T}$ cellmediated experimental autoimmune diabetes in NOD mice. Diabetic NOD mice (blood glucose $>240 \mathrm{mg} / \mathrm{dl}$ ) were treated or not with ADMSC at days 0, 7 and 14 and blood glucose was monitored once a week for 12 weeks after treatment. ADMSCs reversed the hyperglycemia levels of early onset T1D in $78 \%$ of diabetic-treated mice for 8 weeks after treatment and this effect was related with higher serum insulin, amylin and glucagon-like peptide (GLP-1) levels and a significant improvement to intraperitoneal (i.p.) glucose tolerance test. Interestingly, ADMSCs could be detected 72h after i.p. administration in both pancreas and pancreatic lymph nodes (PLN) of treated mice. This improved outcome was associated with down regulation of Th1-biased immune response $\left(\mathrm{CD} 4+\mathrm{IFN}-\gamma^{+}\right.$and CD4+TNF- $\alpha+$ cells) and expansion of Tregs (CD4+CD25+Foxp3+) in PLN verified 35 days after treatment. Moreover, insulitis and IFN- $\gamma$ levels were also reduced while insulin, PDX-1 and active TGF- $\beta 1$ were increased within the pancreas. Interestingly, a higher frequency of CD4+CD25+Foxp3+Helios+ $T$ cells could be observed in PLN of ADMSCstreated mice 12 weeks after treatment. In vitro, ADMSCs induced expansion/proliferation of Tregs in a cell contact-dependent manner in a mechanism mediated by PD-L1 and higher TGF- $\beta 1$ levels. ADMSCs therapy efficiently ameliorates T1D pathogenesis in diabetic NOD mice by attenuating the Th1 immune response concomitantly with the expansion of Tregs, thereby contributing to maintenance of functional $\beta$-cells. This study may thus provide a new therapeutic perspective for the development of ADMSCs-based cellular therapies for T1D.
\end{abstract}

Keywords: Adipose-derived mesenchymal stem cells. Immuneregulation. Experimental autoimmune diabetes. Regulatory T cells. 


\section{LISTA DE ABREVIATURAS}

ADMSCs: células-tronco derivadas de tecido adiposo

ADP: adenosina difosfato

AMP: adenosina monofosfato

APCs: células apresentadoras de antígeno

ATP: adenosina trifosfato

BM-MSCs: células-tronco mesenquimais obtidas a partir da medula óssea

cAMP: AMP cíclico

CCL-2: "CC-chemokine ligand-2"

CD: molécula CD (Clusters Differentiation)

CFUs: unidades formadoras de colônia fibrobastóide

CTAs: células-tronco adultas

CTEs: células-tronco embrionárias

CTLA-4: "cytotoxic T-lymphocyte antigen 4"

DCs: células dendríticas

dl: decilitro

DMEM: meio de cultura

EAE: encefalomielite autoimune experimental

Foxp3: "Forkhead Box P3"

FSC: "Forward scatter"

GIP: polipeptídeo inibitório gástrico

GLP-1: "glucagon like-peptide 1"

HE: Hematoxilina e Eosina

HGF: fator de crescimento de hepatócitos ( "hepatocyte growth factor")

HLA-G5: "human leucocyte antige- G5"

HO-1: heme oxigenase-1

i.p.: intraperitoneal

IDO: "Idoleamina 2,3 - deoxygenase"

IFN- $\gamma$ : interferon- $\gamma$

IgG: Imunoglobulina G

IGTT: teste de tolerância a glicose intraperitoneal

IL-10: interleucina-10

IL-12: interleucina-12

IL-17: interleucina-17

IL-2: interleucina-2

IL-4: interleucina-4

IL-6: interleucina-6

KI: "knockin"

KO: "knockout"

LPs: linfonodos pancreáticos

MHC: complexo principal de histocompatibilidade 
MMPs: metaloproteinases ("matrix metalloproteinases")

MSCs: células-tronco mesenquimais

NO: óxido nítrico

NOD: non-obese diabetic

NOR: non-obese resistant

PBMCs: células mononucleares do sangue periférico

PBS: Solução salina de tampão fosfato

PGE2: prostaglandina E2

PHA: fitohemaglutinina

REVH: reação do enxerto versus hospedeiro

SBF: soro fetal bovino

SCID: imunodeficiência severa combinada

SSC: "side scatter"

TCR: receptor de células $\mathrm{T}$

TGF- $\beta$ : fator transformador de crescimento - $\beta$

Th: célula $\mathrm{T}$ auxiliar

TLR: receptor do tipo Toll

TNF- $\alpha$ : fator de necrose tumoral $\alpha$

Tregs: células $T$ reguladoras

$\mu \mathrm{g}$ : micrograma

$\mu \mathrm{l}$ : microlitro 


\section{SUMÁRIO}

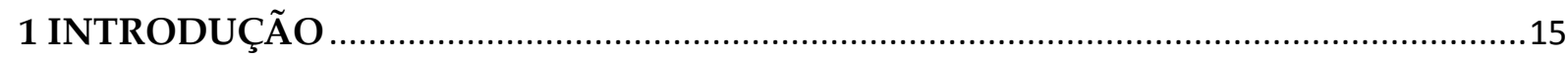

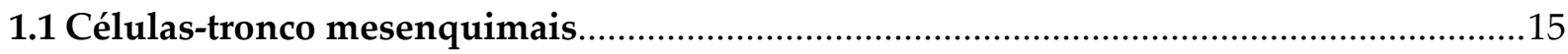

1.2 Células-tronco mesenquimais do tecido adiposo (ADMSCs) .......................................17

1.3 Propriedades imunomoduladoras das MSCs..............................................................18

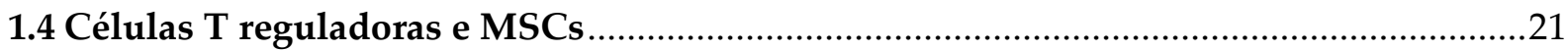

1.5 MSCs, doenças autoimunes e células Tregs................................................................25

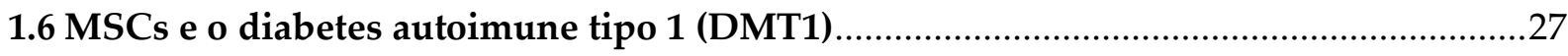

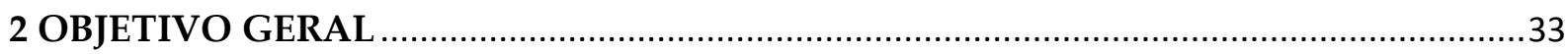

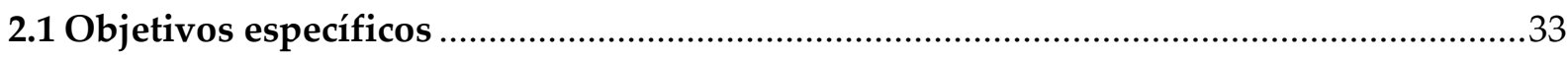

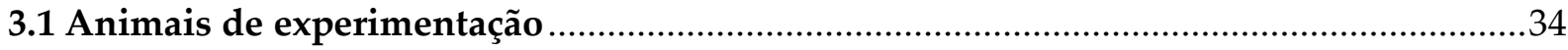

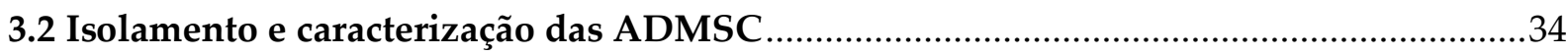

3.2.1 Isolamento das ADMSC a partir de tecido adiposo murino .....................................................34

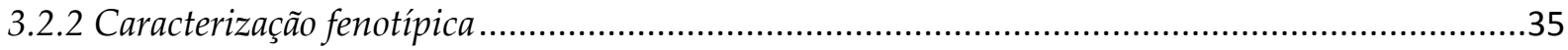

3.3.3 Diferenciação adipogênica, osteogênica e condrogênica .........................................................35

3.3.4 Inibição da proliferação de células T CD4+ por ADMSC ........................................................36

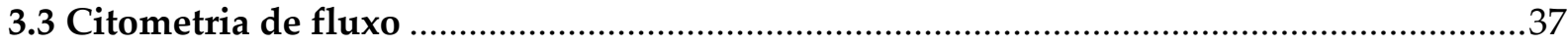

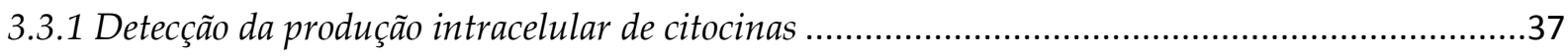

3.3.2 Imunofenotipagem de células T reguladoras..........................................................................38

3.4 Modelo de diabetes autoimune experimental em camundongos NOD e protocolo

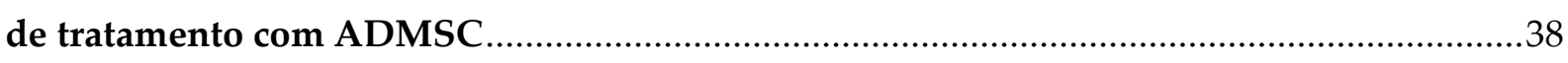

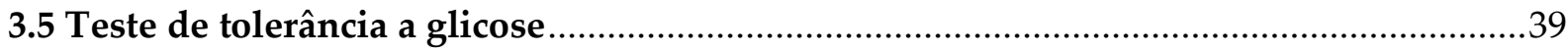

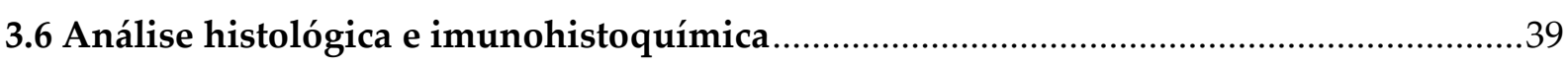

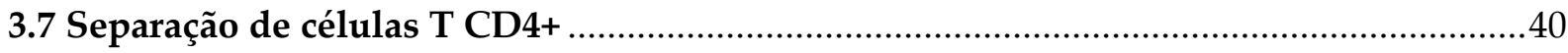

3.8 Separação de células T CD4+62L+Foxp3- e CD4+Foxp3+ por FACS ("fluorescence

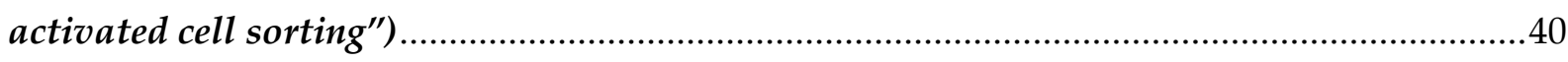

3.9 Quantificação de citocinas no extrato pancreático ….......................................................41

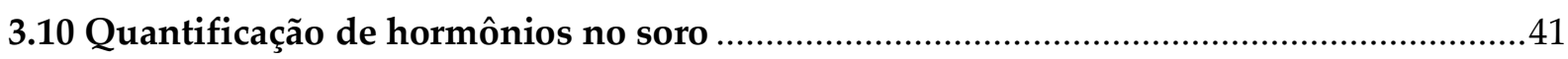

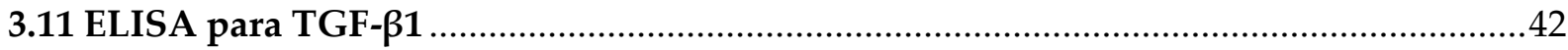

3.12 "Homing" das ADMSC após administração em camundongos NOD ...........................42

3.13 Expansão/proliferação in vitro de células CD4+CD25+Foxp3+ por ADMSC .................43 


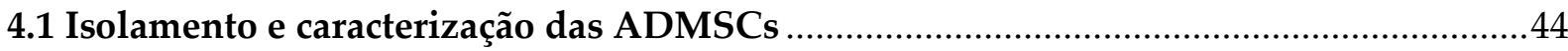

4.2 Modelo de diabetes autoimune experimental em camundongos NOD .46

4.3 Tratamento com ADMSCs reverte a hiperglicemia em camundongos NOD recémdiabéticos

4.4 Teste de tolerância a glicose e glicosúria e aumento nos níveis de insulina após o tratamento com ADMSCs

4.5 Tratamento com ADMSCs promove o aumento de diversos hormônios relacionados à melhora do diabetes autoimune em camundongos NOD 51

4.6 Tratamento com ADSMC diminui o infiltrado celular inflamatório (insulite) mantendo a expressão de insulina e PDX-1 nas ilhotas pancreáticas

4.7 Modulação da resposta imune mediada por células T CD4+ de perfil Th1 nos linfonodos pancreáticos (LPs) após o tratamento com ADMSC

4.8 Terapia com ADMSCs aumenta a freqüência de células T reguladoras nos LPs. .57

4.9 Tratamento com ADMSCs atenua a resposta imune de perfil Th1 no pâncreas combinada ao aumento da expressão de TGF- $\beta 1$ ativo

4.10 "Homing" das ADMSCs após administração em camundongos NOD diabéticos.

4.11 Expansão de células T reguladoras in vitro por ADMSCs .

4.12 Papel do contato celular na expansão de células T CD4+CD25+Foxp3+ por

ADMSCs

4.13 Expansão de células T CD4+CD25+Foxp3+ por ADMSCs em uma condição de estímulo alogênico

4.14 Expansão de células Tregs in vitro por ADMSCs é mediada pela molécula PD-L1 .....69

4.15 Conversão $x$ Expansão/manutenção de células CD4+Foxp3+ in vitro por

ADMSCs .71

4.16 ADMSCs promovem a atenuação da hiperglicemia em camundongos NOD recém-diabéticos por um longo período de tempo após o tratamento

4.17 Terapia com ADMSCs aumenta a frequência de células Tregs nos LPs 12 semanas após o tratamento

5 DISCUSSÃO

6 CONCLUSÕES

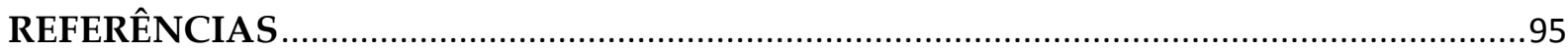

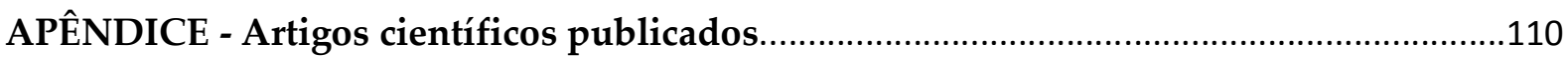




\section{INTRODUÇÃO}

\subsection{Células-tronco mesenquimais}

O termo célula-tronco (do inglês, "stem cell") foi utilizado pela primeira vez em 1868, por Ernst Haeckel em estudos botânicos. Posteriormente, na área de hematopoiese, o termo foi consolidado, visto que todas as células sanguíneas são originadas a partir de uma única célula progenitora [1,2]. Atualmente, o termo "células-tronco" é utilizado para definir uma população de células auto-renováveis e indiferenciadas capazes de se diferenciar em células especializadas/diferenciadas.

As células-tronco podem ser classificadas em células-tronco embrionárias (CTEs) ou células-tronco adultas (CTAs) de acordo com sua origem [3]. As CTEs são células pluripotentes com potencial ilimitado de auto-renovação e diferenciação, sendo obtidas a partir da massa celular interna do blastocisto [4, 5]. Por outro lado, as CTAs podem ser encontradas praticamente em todos os órgãos, sendo responsáveis pela manutenção da homeostase e integridade tecidual. Geralmente, as CTAs são multipotentes, ou seja, dão origem apenas a células do seu folheto germinativo de origem, sendo mais limitadas quando a potencialidade de diferenciação quando comparadas as CTEs. Além de serem mais facilmente cultivadas in vitro, devido à obtenção das CTAs não envolver a utilização de embriões, problemas éticos e religiosos são contornados. Dentre as CTAs, destacam-se as células-tronco mesenquimais (MSCs) ou células estromais mesenquimais multipotentes.

As MSCs foram descritas inicialmente na medula óssea por Friedenstein et al. [6-8]. Posteriormente, Owen, Caplan e colaboradores propuseram a existência de uma célula-tronco adulta de origem mesodérmica no estroma da medula óssea expressando os marcadores CD105 e CD73, denominando-a com o termo "célulatronco mesenquimal" [9-13]. Essas células representam uma fração muito pequena da população total das células nucleadas da medula óssea $(0,001 \%$ a $0,01 \%$ das células totais) podendo ser isoladas e expandidas com eficiência in vitro como células 
aderentes [14, 15]. Geralmente, as MSCs são isoladas a partir do aspirado da medula óssea por um gradiente de densidade e então separadas das células-tronco hematopoiéticas pela sua capacidade aderência a superfície plásticas em placas de cultura celular [16].

As MSCs são células clonogênicas, não hematopoiéticas e multipotentes, com capacidade de auto-renovação e diferenciação para diversas linhagens celulares como, por exemplo, osteoblastos, adipócitos e condrócitos. Nos últimos anos, mostrou-se que essas células podem ser isoladas a partir de vários tecidos, dentre eles da medula óssea, córnea, retina, polpa de dente, pele, tecido adiposo, fígado, pâncreas, sistema nervoso e rim [17, 18]. Devido à facilidade de isolamento e potencial de diferenciação, além da aceitação do ponto de vista ético, as MSCs estão entre as primeiras células-tronco a serem introduzidas na prática clínica, apresentando um grande potencial de aplicação em terapias celulares [19, 20].

Morfologicamente, as MSCs são células fusiformes, com formato semelhante a fibroblastos, e apresentam como característica, no seu período inicial de expansão in vitro, a propriedade de formação de unidades formadoras de colônias fibroblastóides (CFU-Fs). Essas células são caracterizadas pela ausência da expressão de marcadores de superfície de linhagens hematopoiéticas, tais como: CD14, CD45, CD34, CD133; e expressão das moléculas de superfície celular CD44, CD90, CD105 e CD73, dentre outras [21, 22]. A partir de 2005, de acordo com a Sociedade Internacional de Terapia Celular (do inglês, "International Society for Cellular Therapy- ISCT"), três critérios devem ser considerados e avaliados para caracterização das MSCs independentemente da sua fonte de isolamento: aderência a superfícies plásticas; potencial de diferenciação osteogênica, condrogênica e adipogênica; e expressão de moléculas específicas na superfície celular (p. ex. CD105, CD73 e CD90) [23].

As MSCs possuem um grande potencial terapêutico devido a suas habilidades de "homing" para tecidos lesados e por produzirem diversos fatores tróficos (citocinas e fatores de crescimento), os quais podem estar relacionados principalmente a mecanismos de imunorregulação, anti-fibrótico, inibição do 
estresse oxidativo, indução da proliferação de células progenitoras teciduais, antiapoptóticos, pró-angiogênicos e quimioatração [24, 25].

\subsection{Células-tronco mesenquimais do tecido adiposo (ADMSCs)}

O tecido adiposo é constituído de adipócitos, fibroblastos, células musculares e endoteliais, células do sistema imune e MSCs. No ano de 2001, Zuk et al. [26, 27] mostraram pela primeira vez a presença de MSCs presente no tecido adiposo (ADMSCs). Neste estudo, foi mostrado que as ADMSCs humanas, isoladas a partir do lipoaspirado, expressavam as moléculas CD13, CD29, CD44, CD71, CD90, CD105, SH3 e STRO-1 e eram negativas para marcadores de linhagem hematopoiética CD14, CD16, CD31, CD34, CD45, CD56, CD61, CD104 e CD106 [27]. Como a medula óssea, as ADMSCs têm origem a partir da mesoderme, possuindo várias características semelhantes, como por exemplo a capacidade de diferenciação em diferentes linhagens celulares, como neurônios, miócitos, cardiomiócitos, células endoteliais, hepatócitos, adipócitos, osteoblastos e condrócitos [12, 13].

Devido à facilidade de acesso e abundância, essas células tornaram-se muito promissoras em diversas aplicações terapêuticas para várias patologias [28]. De forma interessante, 1 grama de tecido adiposo possui um rendimento de aproximadamente 5000 células, enquanto o rendimento das MSCs obtidas de medula óssea é de 100 a 1000 células/ml de aspirado de medula [29]. O isolamento das ADMSCs geralmente é realizado por um método enzimático utilizando-se uma enzima denominada colagenase tipo I, com posterior filtração e centrifugação, sendo que as células de interesse são então selecionadas pela sua propriedade de aderência à superfície plástica [30]. Após o isolamento e expansão, as ADMSCs devem ser caracterizadas, conforme descrito anteriormente para MSCs. 


\subsection{Propriedades imunomoduladoras das MSCs}

Embora as possibilidades terapêuticas regenerativas das MSCs, levando em conta a sua capacidade de diferenciação em diversos tecidos foram as mais estudadas inicialmente, as propriedades imunomoduladoras se tornaram, recentemente, igualmente promissoras. Estas células são capazes de suprimir a resposta imune, inibindo a maturação de células dendríticas e suprimindo a função de linfócitos $\mathrm{T}$, linfócitos B e células NK [31]. Além disso, mostrou-se que estas células não expressam marcadores de superfície que permitam a ativação de uma resposta imune, sendo consideradas assim "imunoprivilegiadas" [32]. Do ponto de vista terapêutico, o baixo potencial imunogênico das MSCs tem permitido a aplicação segura dessas células de forma alogênica ou até mesmo xenogênica no tratamento experimental de diversas doenças em modelos animais. No entanto, alguns estudos mostram que as MSCs podem ser imunogênicas em alguns modelos experimentais em animais [33, 34].

Bartholomew et al. [31] foram os primeiros a mostrar que a administração endovenosa de MSCs alogênicas prolongava a sobrevida de enxerto de pele, suprimindo a resposta de células $\mathrm{T}$ in vivo. Nos anos seguintes, diversos estudos avaliaram as propriedades imunossupressoras das MSCs em diversos modelos experimentais para várias doenças autoimunes, como reação do enxerto versus hospedeiro, diabetes, artrite reumatóide, esclerose múltipla, lúpus eritematoso sistêmico, dentre outras $[35,36]$.

As propriedades imunodomuladoras das MSCs têm sido descritas ainda in vitro, em ensaios de supressão da proliferação de linfócitos $\mathrm{T}$ utilizando uma variedade de estímulos, incluindo-se: mitógenos, anticorpos agonistas (antiCD3/anti-CD28) e aloantígenos, sendo essa inibição geralmente independente do complexo principal de histocompatibilidade (MHC). Além de inibir proliferação de linfócitos T CD4+ e CD8+, as MSCs podem reduzir a expressão de certos marcadores 
de ativação, como CD25, CD38 e CD69 em linfócitos estimulados por fitohemaglutinina (PHA) [31, 37].

Diversos fatores solúveis secretados pelas MSCs, capazes de atuar sobre várias células do sistema imune, tais como TGF- $\beta 1$, fator de crescimento de hepatócitos (HGF), prostaglandina E2 (PGE2), interleucina-10 (IL-10), indoleamina 2,3dioxigenase (IDO), entre outros, tem sido apontados como os responsáveis pela propriedade imunomoduladora destas células, conforme mostrado na figura 1 [3841].

Figura 1 - Propriedades imunomoduladoras das MSCs.

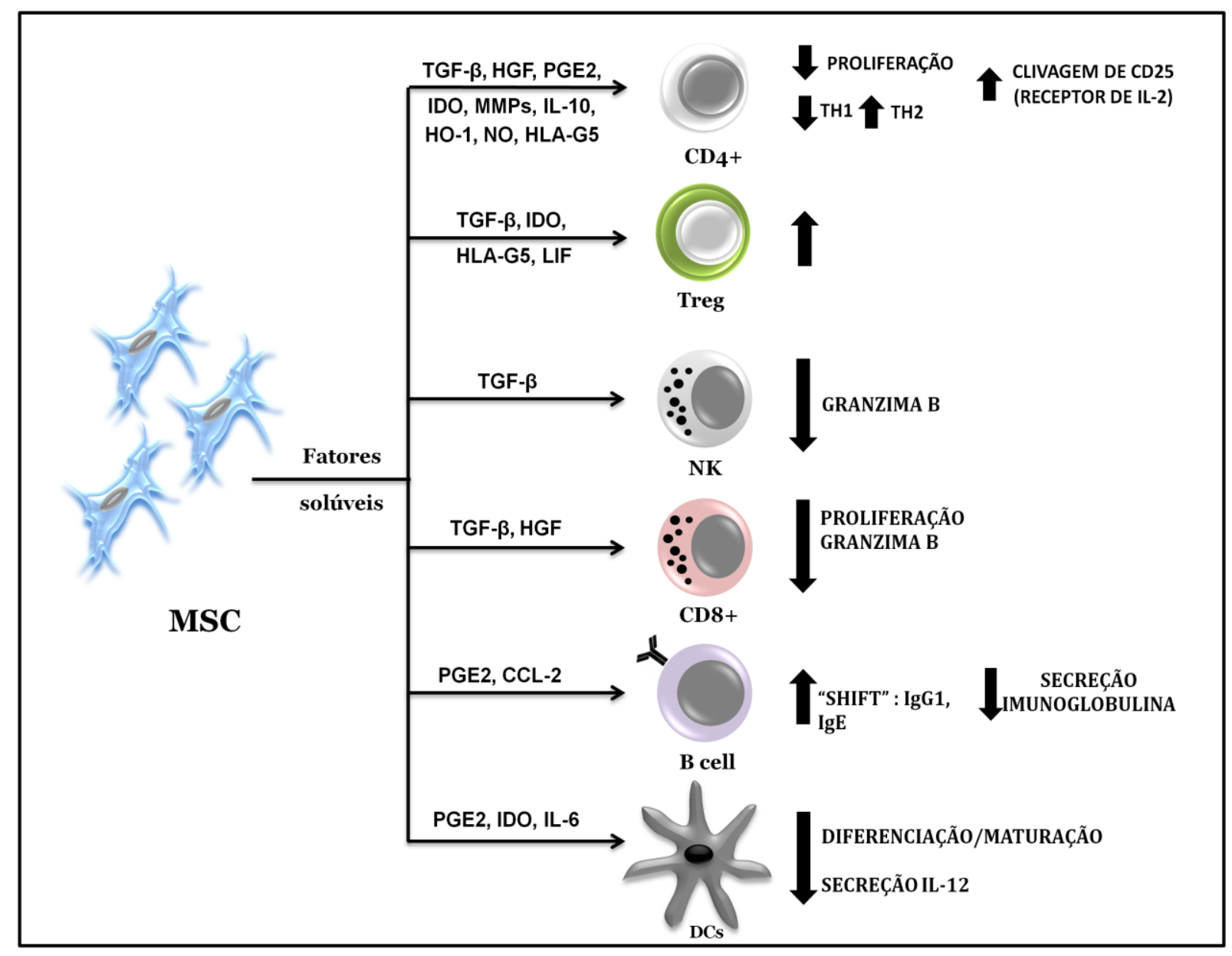

Diversos fatores solúveis secretados por MSCs estão associados a suas propriedades imunomoduladoras sobre linfócitos T CD4+ e CD8+, células T reguladoras, células "natural killer" (NK), linfócitos B e células dendríticas (DCs).

Fonte: Adaptado de Bassi et al. [42]. 
Meisel et al. [40] observaram que a indução da expressão de indoleamina 2,3dioxigenase (IDO, que catalisa a conversão de triptofano em quinurenina) em MSCs estimuladas com IFN- $\gamma$, promovia a depleção de triptofano no meio, resultando assim, na inibição da proliferação linfocitária. Outra molécula envolvida no mecanismo imunossupressor consiste na PGE2, sendo que sua inibição por indometacina pôde restaurar parcialmente a proliferação de linfócitos $\mathrm{T}$ na presença das MSCs de origem murina ou humana [43]. Em outro estudo, foi mostrado que a capacidade supressora das MSCs estava relacionada à produção da citocina IL-10 [44].

Existem outros mecanismos que poderiam contribuir para este efeito imunossupressor principalmente sobre linfócitos T CD4+, entre eles a carência de moléculas de classe II do MHC [45] e de moléculas co-estimulatórias, como CD80, CD86 e CD40 nas MSCs [32], levando a anergia de linfócitos T [46]. No entanto, a transfecção de MSCs com as moléculas CD80 e CD86 não reverteu esta capacidade de inibir a resposta imune [44], sugerindo que este não seja o principal fato envolvido na imunossupressão promovida por essas células.

As MSCs podem regular também a resposta imune por meio da interação com os linfócitos B. MSCs derivadas da medula óssea apresentaram efeitos inibitórios sobre a proliferação e secreção da imunoglobulina IgG por linfócitos B em um modelo experimental murino de lúpus eritematoso sistêmico [47]. Além disso, quando MSCs isoladas da medula óssea (BM-MSCs) e linfócitos B provenientes do sangue periférico de doadores saudáveis foram co-cultivados com diferentes estímulos para ativação dos linfócitos B, como anticorpos direcionados contra a molécula CD40, a proliferação, assim como a produção de imunoglobulinas por essas células foram inibidas [48].

As MSCs podem ainda inibir a diferenciação, maturação e ativação de células dendríticas (DCs), resultando, posteriormente, na atenuação da resposta imune mediada por células $\mathrm{T}$ [49]. Elas podem alterar o perfil secretório de citocinas das DCs, estimulando a secreção de citocinas de perfil supressor/regulador, como, por 
exemplo, a IL-10, e inibindo as citocinas pró-inflamatórias como IFN- $\gamma$, IL-12 e TNF$\alpha$ [50]. Além disso, a inibição de moléculas relacionadas à apresentação de antígenos, como CD1a, CD40, CD83, CD80, CD86 e HLA-DR foi observada durante a maturação de DCs na presença de MSC $[49,51]$.

\subsection{Células T reguladoras e MSCs}

As células com potencial regulador têm sido alvo de intensas pesquisas nos últimos anos. Logo depois da descoberta de que linfócitos T funcionam como células auxiliadoras para linfócitos B, Gershon e Kondo[52], na década de 70, propuseram que um grupo de células poderia agir suprimindo a resposta imune, sendo denominadas células T supressoras. Porém, somente a partir do final dos anos 90 que a existência dessas células passou a ter uma maior aceitação no meio científico, sendo então estudadas e amplamente caracterizadas, ressurgindo como células $\mathrm{T}$ reguladoras (Tregs) [53].

As células Tregs surgem no timo e são encontradas no sangue periférico e em órgãos linfóides secundários representando cerca de 5-15\% de todas as células T CD4+ em murinos. Essas células expressam constitutivamente a cadeia $\alpha$ do receptor de IL-2 (CD25+) exibindo uma potente atividade reguladora tanto in vivo como in vitro, inibindo células $\mathrm{T}$ auto-reativas e mantendo a homeostasia e tolerância imunológica [53]. Sakaguchi et al. [53] demonstraram que a transfusão de células T CD4+CD25- em camundongos nude atímicos pode ocasionar o desenvolvimento de doenças autoimunes, como tireoidite, gastrite, insulite e glomerulonefrite. Além disso, foi mostrado que a transferência de células T CD4+CD25+ dentro de um curto período de tempo pós-transferência de células T CD4+CD25- pode prevenir o desenvolvimento da autoimunidade de uma maneira dose-dependente.

A manutenção e sobrevivência das células Tregs é regulada pela citocina IL-2, sendo que o bloqueio desta citocina in vivo com anticorpos anti-IL-2 inibe a proliferação homeostática dessas células [54]. Apresentam ainda um fenótipo de 
células de memória, uma vez que são CD45RO+, além de expressar CTLA-4 (do inglês, "cytotoxic T-lymphocyte antigen 4") [55]. Posteriormente, uma elevada expressão do fator de transcrição Foxp3 (do inglês, "Forkhead Box P3") foi identificada como tendo um papel central no desenvolvimento e função das células Tregs CD4+CD25+, sendo o marcador mais específico disponível para essas células atualmente [56]. A importância das células Tregs na manutenção da tolerância foi evidenciada em humanos, visto que pacientes com ausência funcional dessas células, devido a uma mutação pontual no gene Foxp3, desenvolvem a síndrome conhecida como IPEX (do inglês, “immunodysregulation polyendocrinopathy enteropathy X-linked syndrome"), caracterizada por autoimunidade sistêmica [57]. Além disso, as Tregs tem um papel muito importante no controle das respostas imunes efetoras em diversas doenças autoimunes, sendo que a deleção dessas células leva a expansão clonal de células $\mathrm{T}$ autorreativas. Em diversas doenças autoimunes, foi observada uma atividade supressora reduzida dessas células isoladas a partir de PBMCs de pacientes com esclerose múltipla, diabetes tipo 1, miastenia grave, artrite reumatóide e lúpus $[58,59]$.

Atualmente, as células Tregs podem ser classificadas como células Tregs CD4+CD25+Foxp3+ naturais, geradas no timo, Tregs periféricas, induzidas na periferia a partir de células Foxp3- após estimulação antigênica na presença de TGF$\beta 1$ [60-62]. As células Tregs podem atuar suprimindo a resposta imune por diversos mecanismos envolvendo fatores solúveis, como por meio das citocinas TGF- $\beta 1$ e IL10, ou por contato célula-célula, como por exemplo a molécula CTLA-4 [63-65].Essas células podem ainda consumir os fatores de crescimento presentes no microambiente, como por exemplo, a IL-2, privando as outras células efetoras desses fatores e induzindo a apoptose nessas células [66]. O metabolismo de adenosina foi relatado como outro importante mecanismo de supressão mediado pelas Tregs, visto que essas céluas expressam as moléculas CD39 e CD73 [67]. Inicialmente, a molécula CD39 cliva o ATP em ADP e AMP. O AMP é rapidamente degradado em adenosina 
pelo CD73, gerando seus efeitos supressores ao se ligar em receptores acoplados a proteína $\mathrm{G}$, o receptor A2A, presente em células $\mathrm{T}$.

Interessantemente, as MSCs possuem a capacidade de expandir células Tregs in vitro e in vivo em diversos modelos experimentais [68]. Maccario et al. [69] descreveram que a interação de MSCs humanas com células envolvidas na resposta imune aloantígeno-específica favorecia a diferenciação de células Tregs expressando CD25 e/ou CTLA-4 com funções supressoras. Em outro estudo, o co-cultivo de MSCs com PBMCs ocasionou a geração tanto de linfócitos T CD4+, expressando elevados níveis de Foxp3, como T CD8+ reguladores capazes de inibir a proliferação linfocitária por estímulo aloantigênico, policlonal (anti-CD3) ou mitogênico (PHA) com uma eficiência supressora aproximadamente 100 vezes maior quando comparada a células Tregs CD4+CD25+ [70].

As MSCs alogênicas podem diminuir a secreção de IFN- $\gamma$ por células de perfil Th1 (do inglês "T helper 1") e aumentar a secreção de IL-4 por células Th2 (do inglês, "T helper 2"), favorecendo ainda um aumento na frequência de células Tregs na presença de IL-2, quando co-cultivadas com diferentes populações de linócitos [43]. Em outro estudo, MSCs isoladas da medula óssea de ratos co-cultivadas com células CD3+ alogênicas promoveram uma aumento na frequência de células T CD4+CD25+ assim como nos níveis de citocinas antiinflamatórias como TGF- $\beta$ e IL-10 [71].

As MSCs podem ainda recrutar e manter o fenótipo de células Tregs in vitro [72]. No estudo de Dianni et al. [72] um aumento na frequência de células CD4+CD25+Foxp3+ assim como uma diminuição na expressão de CD127 (fenótipo característico de Tregs humanas) foi observado após o co-cultivo de linfócitos CD3+ com MSCs humanas. De forma interessante, quando populações purificadas de células Tregs CD4+CD25+ foram utilizadas no co-cultivo com MSCs, observou-se uma manutenção tanto da expressão de Foxp3, assim como na capacidade supressora dessas células por um período de até 2 semanas [72].

Embora o mecanismo envolvido no processo de indução/expansão de células T CD4+CD25+Foxp3 in vitro ainda não tenha sido completamente elucidado, em MSC 
humanas derivadas de medula óssea, foi mostrado que o contato celular MSC/linfócito T CD4+ e fatores solúveis como PGE2 e TGF- $\beta$ podem estar envolvidos [73]. Além disso, em outro estudo, foi verificado que a molécula de HLA-G5 (antígeno leucocitário humano de classe I não-clássico) secretada por MSCs, na presença de IL-10, pode contribuir para a expansão de células Tregs [74].

A enzima IDO também exerce um papel importante na atividade imunomoduladora das MSCs sobre as células Tregs. Em um modelo experimental de transplante renal, observou-se que a administração de MSCs pode aumentar a sobrevida do enxerto, associado uma maior frequência de células Tregs e aumento dos níveis de quinurenina no soro, indicando assim uma maior atividade da enzima IDO [75]. Além disso, o tratamento dos animais um inibidor da IDO (1-metiltriptofano) ou a utilização de MSCs obtidas a partir de camundongos IDO $^{-/}$não promoveu a tolerância ao enxerto, confirmando assim a importância dessa enzima no mecanismo de ação terapêutico observado e na indução de células Tregs [75]. De forma importante, a IDO e a PGE2 produzidas pelas MSCs podem ainda, ao direcionar a diferenciação de células T CD4+ para um fenótipo regulador, promover a inibição da diferenciação de células Th17 (do inglês "T helper 17"), que são importantes células efetoras em diversas situações de autoimunidade [76, 77].

Recentemente, foi mostrado que a administração de MSCs alogênicas reduziu a inflamação das vias aéreas e os níveis de $\operatorname{IgE}$ no modelo experimental de asma induzida por ovoalbumina, em um mecanismo dependente da indução de células T CD4+Foxp3+, visto que o tratamento com ciclofosfamida, que promove a depleção de Tregs, pode reverter o efeito terapêutico observado [78].

Embora os mecanismos de imunossupressão das MSCs não estejam completamente elucidados, tem-se mostrado que tanto o contato MSC/células do sistema imune como a participação de fatores solúveis parecem estar envolvidos nesse processo. Além disso, é interessante ressaltar que os vários mecanismos de imunomodulação promovidos pelas MSC in vitro não são mutuamente exclusivos, e 
a contribuição relativa de cada um deles em modular a resposta imune é variável em diferentes modelos experimentais.

\subsection{MSCs, doenças autoimunes e células Tregs}

As doenças autoimunes são resultantes de defeitos nos mecanismos de tolerância imunológica, resultando na ativação de mecanismos celulares e humorais da resposta imune contra tecidos próprios. Geralmente, essas doenças são de natureza multifatorial, onde fatores genéticos e ambientais podem estar envolvidos. Nos últimos anos, a propriedade imunossupressora das MSCs tem sido explorada in vivo em modelos animais para diversas doenças de natureza autoimune.

No modelo de encefalomielite autoimune experimental (EAE), um modelo murino para esclerose múltipla humana, a administração de MSCs antes ou durante a doença diminuiu o infiltrado inflamatório no sistema nervoso central e os sinais clínicos associados com a desmielinização presentes nesta doença [46]. Em outro estudo, nesse mesmo modelo experimental, observou-se uma redução de células T produtoras de IFN- $\gamma$ e células T CD4+ de perfil Th17 pró-inflamatórias, com concomitante aumento de células de perfil Th2, produtoras de IL-4 e citocinas antiinflamatórias, contribuindo assim para a melhora clínica da doença [79]. Em pacientes com esclerose múltipla, uma maior expressão de Foxp3 nas células mononucleares, associada à estabilização clínica da doença, foi observada 6 meses após a administração de MSCs, quando comparado aos níveis de expressão antes do tratamento [80].

No tratamento da artrite induzida por colágeno em camundongos com ADMSCs humanas uma diminuição na produção de várias citocinas próinflamatórias e de células Th1/Th17 antígeno-específicas, aumento de IL-10 em linfonodos e articulações, além da expansão de células Tregs foram observadas [81, 82]. Neste mesmo modelo experimental, MSCs murinas alogênicas foram capazes de prevenir o dano tecidual em ossos e cartilagens, aumentando a frequência de Tregs 
antígeno-específicas e diminuindo a concentração de TNF- $\alpha$ no soro dos animais tratados [83]. O efeito das ADMSCs humanas sobre a proliferação e produção de citocinas por células $\mathrm{T}$ auto-reativas provenientes de pacientes com artrite reumatóide foi avaliada em experimentos de co-cultivo in vitro [84]. Neste estudo, ADMSCs humanas inibiram ainda a resposta proliferativa e a produção de citocinas inflamatórias em células T CD4 e CD8 ativadas por colágeno aumentando ainda a produção de IL-10 e a geração de células Tregs capazes de suprimir a resposta de células T específicas para este antígeno [84].

Na colite experimental e esclerose sistêmica, a infusão de MSCs isoladas da medula óssea induziu a apoptose de células $\mathrm{T}$ via um mecanismo dependente da interação FAS (receptor FAS) / FASL (Fas ligante) melhorando os sintomas clínicos de ambas as doenças [85]. As células T apoptóticas induziram então a produção de TGF- $\beta$ nos macrófagos, proporcionando assim o aumento de células Tregs e indução de tolerância imunológica [85]. O tratamento da colite experimental utilizando ADMSCs humanas ou murinas pode melhorar os parâmetros clínicos e histopatológicos da doença pela diminuição da resposta imune de perfil Th1 na mucosa intestinal e linfonodos mesentéricos, sendo esse efeito parcialmente dependente da indução de células Tregs secretoras de IL-10 [86].

No caso de lúpus eritematoso sistêmico, MSCs humanas reduziram a proliferação de linfócitos T, níveis de anticorpos anti-DNA e inibiram a progressão da doença em camundongos de uma maneira dose-dependente [87]. Em outro estudo, a administração de ADMSCs pode aumentar os níveis de GM-CSF, IL-4, e IL10 no soro e a frequência de células T CD4+Foxp3+, sem o desenvolvimento de efeitos adversos, avaliado durante um longo período de tempo pós-tratamento (60 semanas) [88].

As MSCs foram utilizadas com sucesso no tratamento de casos graves de reação do enxerto versus-hospedeiro $(\mathrm{REVH})$ tanto em modelos animais [89] como em humanos [90,91]. Em um modelo experimental de REVH em camundongos, foi observada uma diminuição no número de células T CD4+ e CD8+ e proporção 
Th1/Th2 combinado a um aumento na frequência de células Tregs após o tratamento com MSCs [92]. Além disso, um estudo clínico de fase II utilizando MSC expandidas in vitro mostrou-se como uma terapia efetiva em pacientes com REVH aguda [93].

Dessa forma, a aplicação terapêutica envolvendo a imunomodulação por MSCs é uma alternativa promissora na área de medicina regenerativa para o possível tratamento de diversas doenças autoimunes e processos inflamatórios agudos e crônicos.

\subsection{MSCs e o diabetes autoimune tipo 1 (DMT1)}

Dentre as diversas doenças autoimunes, destaca-se o diabetes mellitus autoimune do tipo 1 (DMT1), que consiste em um processo inflamatório autoimune órgão-específico que resulta na destruição seletiva das células $\beta$ pancreáticas produtoras de insulina, levando a uma hiperglicemia [94, 95]. Esta doença é o distúrbio crônico-metabólico mais frequente na infância e costuma manifestar-se geralmente abaixo dos 30 anos de idade, concentrando-se no período escolar e na adolescência em 90\% dos casos.

O DMT1 é um importante problema de saúde pública mundial, visto que o número de pacientes com diabetes (considerando o diabetes mellitus tipo 1 e tipo 2) segundo a Federação Internacional de Diabetes (FID), é estimado em aproximadamente 246 milhões de pessoas. Além disso, no ano de 2025, conforme estimativas da FID, este número aumentará para aproximadamente 380 milhões de casos. De forma importante, o número de óbitos devido a esta doença atingiu $6 \%$ do total de óbitos a nível mundial, associado principalmente a doenças cardiovasculares (50\% dos casos) [96]. Nos Estados Unidos, estima-se que 20 milhões de pessoas sejam diabéticas (7\% da população) sendo que 5-10\% dos casos correspondem ao DMT1, segundo informações do CDC ("Center for Disease Control and Prevention") [97]. A incidência mundial dessa doença é muito variável, podendo atingir valores muito elevados como 36 casos a cada 100.000 indivíduos, em países como Finlândia e 
Sardenha [98]. Além disso, estima-se um aumento anual de 3,2\% no número de casos mundiais dessa doença, principalmente entre crianças e adolescentes [99]. Dentre as complicações crônicas resultantes do DMT1 destacam-se os problemas cardiovasculares, insuficiência renal, cegueira e úlceras crônicas [100].

No Brasil, não existem dados precisos sobre a incidência desta doença, mas estima-se que corresponda a 5-10\% do número total dos casos diagnosticados de diabetes, que no ano de 2005 foi estimado em 8 milhões, existindo assim, cerca de 600 mil portadores desta doença no país [101]. A prevalência anual de DMT1 no Brasil é de aproximadamente 8 casos a cada 100 mil indivíduos [101].

Embora os eventos que controlam o início e a progressão da doença ainda não foram completamente elucidados, a combinação de predisposição genética (poligênica), fatores ambientais (p. ex. infecções virais) e imunológicos podem estar envolvidos em sua patogenia. É importante ressaltar que a maioria dos estudos genéticos, patofisiológicos e imunológicos foram realizados em modelos animais para esta doença, destacando-se o rato BB (Biobreeding) e o camundongo NOD (nonobese diabetic).

Esta doença é caracterizada por um processo autoimune mediado por células T CD4+ efetoras com um perfil do tipo Th1 [102]. Durante o seu desenvolvimento ocorre a infiltração nas ilhotas pancreáticas de células T CD4+, T CD8+, linfócitos B e macrófagos, resultando em um processo inflamatório denominado insulite [102, 103]. Os linfócitos T CD4+ e CD8+ reagem então contra os auto-antígenos expressos nas células $\beta$ pancreáticas, causando a lise destas células, ou induzindo a apoptose por meio da ação de citocinas [104, 105].

A ativação dos linfócitos $\mathrm{T}$ auto-reativos requer a apresentação de autoantígenos através de moléculas MHC (complexo principal de histocompatibilidade) de classe II [106]. Assim, auto-antígenos provenientes de células $\beta$ são apresentados por células apresentadoras de antígeno (APCs) ás células T näive auto-reativas nos linfonodos pancreáticos (LPs), ativando uma resposta imune de perfil Th1. Neste sentido, foi mostrado que a remoção de LPs de camundongos NOD pré-diabéticos 
conferiu proteção contra a formação do processo de insulite nas ilhotas pancreáticas [107]. Após a ativação, os linfócitos T CD4+ produzem citocinas pró-inflamatórias como interferon- $\gamma$ (IFN- $\gamma$ ) e fator de necrose tumoral- $\alpha$ (TNF- $\alpha$ ) que induzem a apoptose das células $\beta$ [105]. O tratamento de camundongos NOD (do inglês, "nonobese diabetic"), modelo experimental de DMT1, com anticorpo anti-IFN- $\gamma$ pôde prevenir o desenvolvimento da doença [108]. Além disso, a expressão desta citocina em linhagens de camundongos resistentes ao diabetes autoimune resultou no desenvolvimento da doença [109]. A citocina IL-1 $\beta$, produzida principalmente por macrófagos ativados, induz a expressão da enzima oxido nítrico sintase, ativando assim a síntese de oxido nítrico e radicais livres de oxigênio, levando a morte celular dessas células [110]. Além disso, foi mostrado que a combinação in vitro de IL-1 $\beta$, IFN- $\gamma$ e TNF- $\alpha$ aumenta a vulnerabilidade da célula $\beta$ a resposta autoimune [111].

Recentemente, um estudo que analisou o pâncreas de pacientes com o desenvolvimento recente de DMT1 mostrou a presença de células T CD8+ e CD68+ presentes no infiltrado mononuclear [112]. Assim, a morte celular decorrente da insulite é causada principalmente pelo contato direto das células $\beta$ com macrófagos e linfócitos $\mathrm{T}$ ativados (apoptose mediada pela interação Fas/FasL) e/ou exposição a mediadores solúveis secretados por essas células [104, 105, 113], como citocinas (IL$1 \beta$, IFN- $\gamma$ e TNF- $\alpha$ ), óxido nítrico (NO) e espécies reativas de oxigênio (ROS) [105, 114].

Além da imunidade celular, os pacientes com DMT1 podem produzir autoanticorpos considerados como específicos ou relacionados à doença, destacandose os anticorpos anti-insulina, anti-tirosina fosfatase (anti-IA2) e anti-descarboxilase ácida glutâmica (anti-GAD65), sendo que os mesmos podem ser utilizados para predição do desenvolvimento da doença $[115,116]$.

O processo autoimune no DMT1 é também composto de componentes reguladores, destacando-se as células Tregs, importantes para a supressão da ativação da resposta imune, mantendo assim a homeostase e tolerância aos antígenos próprios [117]. A redução da frequência das Tregs pela ruptura da interação das 
moléculas B7/CD28 acentuou o desenvolvimento do diabetes autoimune em camundongos NOD [118] enquanto a expansão dessas células nos linfonodos pancreáticos (LPs) foi correlacionada com a proteção ao desenvolvimento da doença [119]. De forma interessante, diversas terapias de sucesso utilizando este modelo experimental mostraram uma correlação entre a melhora do DMT1 e o aumento na frequência de Tregs [120-122].

Atualmente, as estratégias de tratamento padronizadas para o controle do DMT1 são baseadas na administração de insulina e monitoramento da glicose sanguínea. Além disso, estratégias utilizando o transplante de pâncreas ou ilhotas pancreáticas têm sido realizadas e representam uma alternativa terapêutica promissora para prevenção das complicações crônicas renais e neurológicas [123, 124]. No entanto, os custos elevados, a necessidade de terapia imunossupressora e seus eventuais efeitos adversos, assim como a quantidade limitada de doadores disponíveis, têm dificultado essa terapêutica. Dessa forma, a busca por novas terapias seguras e efetivas para a prevenção e/ou reversão do DMT1 tornou-se um desafio a ser alcançado. Entre as várias possibilidades destacam-se as MSCs, devido ao seu potencial supressor/regulador e regenerativo. Nos últimos anos, o efeito terapêutico dessas células, derivadas da medula óssea (BM-MSCs), na prevenção e reversão do DMT1 foi avaliado em diferentes modelos experimentais para esta doença [125-132].

O tratamento do diabetes experimental induzido por estreptozotocina com BM-MSCs singênicas administradas pela via endovenosa em ratos diabéticos aumentou a expressão de insulina e PDX-1 (do inglês, "pancreatic and duodenal homeobox 1"), um fator de transcrição relacionado ao desenvolvimento, diferenciação e homeostasia das células $\beta$, no pâncreas dos animais [125]. Além disso, um aumento na frequência de células CD4+Foxp3+ e nos níveis de IL-10 e IL-13 após o tratamento foram observados [125]. Em outro estudo, a administração de MSCs humanas em camundongos NOD/SCID diabéticos diminuiu a glicemia e aumentou o número de células $\beta$ produtoras de insulina após o tratamento [126]. 
Interessantemente, células mononucleares da medula óssea (BMCs) contribuíram para o efeito terapêutico das MSCs no tratamento do diabetes experimental. A combinação de $10^{6} \mathrm{BMCs}+10^{5} \mathrm{MSC}$ no tratamento de camundongos diabéticos pode restabelecer a glicemia e a concentração de insulina no soro a níveis normais, além de promover uma eficiente regeneração pancreática. Esse efeito terapêutico foi associado à supressão de linfócitos $\mathrm{T}$ específicos para antígenos presentes nas células $\beta$, garantindo assim a sobrevivência e a manutenção de ilhotas pancreáticas funcionais [133].

A administração de BM-MSCs alogênicas também pôde reverter temporariamente a hiperglicemia em camundongos NOD diabéticos, diminuindo o infiltrado celular inflamatório (insulite) de linfócitos T e B nas ilhotas pancreáticas após o tratamento [127]. Neste mesmo modelo experimental, o tratamento com BMMSCs singênicas isoladas a partir da medula óssea de camundongos NOR também reverteu a hiperglicemia, sendo este efeito mantido por até 12 semanas após o tratamento [129]. De forma interessante, uma diminuição na frequência de macrófagos (F4/80+), células T CD4+ e T CD8+ efetoras e um aumento na frequência de células dendríticas plasmocitóides no linfonodos pancreáticos foram observados após o tratamento [129].

As propriedades imunomoduladoras das MSCs na prevenção do desenvolvimento do DMT1 também foram avaliadas em camundongos NOD. A administração de MSCs alogênicas em camundongos NOD com 4 semanas de idade diminuiu a incidência do diabetes autoimune nos animais transplantados, observando-se uma redução na capacidade de células $\mathrm{T}$ diabetogênicas em infiltrar as ilhotas pancreáticas e promover o desenvolvimento da doença, assim como uma indução de células Tregs produtoras de IL-10 [128].

Nos últimos anos, as ADMSCs, que podem ser isoladas a partir do tecido adiposo e expandidas in vitro, tornaram-se uma fonte atrativa de MSCs para terapia celular. Além disso, foi mostrado que as ADMSCs podem suprimir a resposta imune de linfócitos $\mathrm{T}$ em diversos modelos experimentais de doença autoimune, como 
artrite induzida por colágeno, colite e encefalomielite autoimune experimental [81, 86, 134]. No entanto, o efeito supressor/regulador das ADMSCs na melhora do DMT1 permanece amplamente inexplorado, assim como o mecanismo de atuação dessas células no tratamento dessa doença. No presente estudo, a nossa hipótese foi que as ADMSCs poderiam melhorar o desenvolvimento recente do diabetes autoimune em camundongos NOD diabéticos promovendo seu efeito terapêutico via inibição da resposta mediada por células $\mathrm{T}$ CD4+ de perfil Th1 pró-inflamatório concomitantemente a expansão de células Tregs. 


\section{OBJETIVO GERAL}

Investigar as propriedades imunomoduladoras das ADMSCs alogênicas no tratamento do diabetes autoimune experimental em camundongos NOD.

\subsection{Objetivos específicos}

a) Isolar e caracterizar as MSCs a partir de tecido adiposo (ADMSC);

b) realizar o tratamento de camundongos NOD recém-diabéticos com ADMSC;

c) avaliar a glicemia, glicosúria, teste de tolerância à glicose e níveis de insulina após o tratamento;

d) quantificar diversos hormônios associados à melhora do diabetes autoimune no soro dos animais tratados;

e) avaliar o infiltrado celular inflamatório (insulite), a expressão de insulina e PDX-1 nas ilhotas pancreáticas;

f) analisar a frequência da população de células T CD4+ produtoras de IFN- $\gamma$ e TNF$\alpha$ e células T reguladoras (CD4+CD25+Foxp3+) nos linfonodos pancreáticos;

g) verificar a expressão do fator de transcrição Helios nas células $\mathrm{T}$ CD4+CD25+Foxp3+ para caracterização entre Treg natural ou induzida;

h) avaliar os níveis das citocinas IL-2, IFN- $\gamma$, TNF- $\alpha$ e TGF- $\beta$ no pâncreas;

i) estudar o "homing" das ADMSCs para os linfonodos pancreáticos e pâncreas $18 \mathrm{~h}$ e $72 \mathrm{~h}$ após serem administradas por via intraperitoneal em camundongos diabéticos;

j) avaliar a manutenção do efeito terapêutico por um longo período de tempo (12 semanas) após a primeira administração das ADMSCs assim como a insulite e expressão de insulina nas ilhotas pancreáticas;

k) avaliar a capacidade da expansão de células T CD4+CD25+Foxp3+ pelas ADMSC após co-cultivo in vitro, assim como os mecanismos envolvidos neste processo. 


\section{MATERIAL E MÉTODOS}

\subsection{Animais de experimentação}

Animais: Os animais NOD ( $\left.\mathrm{H}_{2}-\mathrm{A}^{\mathrm{g}}\right)$ foram gentilmente cedidos pelo Prof. Alvaro Pacheco e Silva Filho da Universidade Federal de São Paulo (UNIFESP). Os animais Balb/c (H2- $\left.\mathrm{A}^{\mathrm{d}}\right)$ foram obtidos do Biotério de Camundongos Isogênicos da Universidade de São Paulo (USP). Antes e após os procedimentos cirúrgicos, os animais foram acondicionados em microisoladores coletivos, contendo no máximo cinco animais, com ciclo artificial claro/escuro de 12 horas, a uma temperatura ambiente constante de $22{ }^{\circ} \mathrm{C}$ e com suprimentos de água e alimento autoclavados disponíveis todo o tempo. Os animais C57BL/6 Foxp3-GFP "knock in" (KI) foram gentilmente cedidos pelo Prof. Alexandre Salgado Basso da Universidade Federal de São Paulo (UNIFESP). O projeto foi submetido e aprovado pelo comitê de ética em experimental animal do Instituto de Ciências Biomédicas da USP.

\subsection{Isolamento e caracterização das ADMSC}

\subsubsection{Isolamento das ADMSC a partir de tecido adiposo murino}

As ADMSC foram obtidas do tecido adiposo supra-epididimal (região abdominal) de camundongos Balb/c machos $(\mathrm{n}=10)$ conforme o método descrito por Cho [135]. O tecido adiposo foi extensivamente lavado com PBS pH 7,4 (2,7 mM $\mathrm{NaCl}, 8 \mathrm{mM} \mathrm{KCl}, \mathrm{Na}_{2} \mathrm{HPO}_{4}$ and $1,4 \mathrm{mM} \mathrm{KH}_{2} \mathrm{PO}_{4}$ ) e posteriormente submetido à digestão com colagenase tipo IA $(1 \mathrm{mg} / \mathrm{ml})$ (Sigma-Aldrich, St Louis, EUA) a $37{ }^{\circ} \mathrm{C}$ por 30 min. A atividade enzimática foi neutralizada pela adição de meio DMEM lowglucose (DMEM; Gibco, Grand Island, EUA) contendo 10\% de soro bovino fetal (Hyclone, Logan, EUA) e a amostra foi centrifugada por $300 \mathrm{~g}$ por $10 \mathrm{~min}$ seguido da lise de eritrócitos utilizando-se um tampão de lise $\left(55 \mathrm{mM} \mathrm{NH}_{4} \mathrm{Cl}, 10 \mathrm{mM} \mathrm{KHCO}\right.$, 1 
mM EDTA - pH 7,4). O precipitado foi filtrado em membrana de nylon de $70 \mu \mathrm{m}$ para remoção de debris celulares e as células obtidas então incubadas a $3^{\circ}{ }^{\circ} \mathrm{C}$ em uma atmosfera úmida com 5\% de $\mathrm{CO}_{2}$ em meio de cultivo (DMEM low-glucose, $10 \% \mathrm{SBF}$, $100 \mathrm{U} / \mathrm{ml}$ penicilina, $100 \mu \mathrm{g} / \mathrm{ml}$ estreptomicina, Sigma-Aldrich) em garrafas de 75 $\mathrm{cm}^{3}$. Após $72 \mathrm{~h}$, as células foram então lavadas utilizando-se PBS para remoção de células residuais não aderentes. A população celular resultante foi cultivada por uma semana e quando a monocamada celular atingiu a confluência de $80 \%$, um subcultivo foi realizado por tratamento com 0,05\% tripsina - 0,53 mM EDTA (Gibco). A cada passagem 1/2 das células foi transferida para uma nova garrafa. As células foram usadas até a passagem 12.

\subsubsection{Caracterização fenotípica}

A caracterização imunofenotípica foi realizada por citometria de fluxo nas células na quinta passagem (P5) sendo estudadas as moléculas CD105, CD90, CD44, CD73, CD45, CD11c, CD11b e CD34 em citômetro de fluxo BD FACSCanto II (BD, San Jose, Estados Unidos). Os dados foram representados como histograma utilizando o software FlowJO 7.5 (Tree Star, Ashland, EUA) sendo a população celular positiva compensada pelos controles isotípicos para os anticorpos monoclonais ligados aos determinados fluorocromos.

\subsubsection{Diferenciação adipogênica, osteogênica e condrogênica}

Para a caracterização funcional das ADMSCs foram empregados três testes de plasticidade: diferenciação osteogênica, condrogênica e adipogênica baseando-se em protocolos previamente descritos $[15,135,136]$.

Diferenciação adipogênica - As ADMSCs foram cultivadas em placas de 24 poços na densidade de $6 \times 10^{4}$ células/poço até atingirem confluência em 100\%. Neste ponto, foi adicionado o meio de indução adipogênica que consiste em meio DMEM 
low-glucose suplementado com $1 \mu \mathrm{M}$ de dexametasona, 0,5 mM de indometacina, 10 $\mu \mathrm{g} / \mathrm{ml}$ de insulina, $100 \mathrm{mM}$ de 3-isobutil-1-metilxantina (IBMX) (Sigma-Aldrich) e 10\% SBF por 3 dias. Como controle negativo, as células foram cultivadas somente em meio DMEM low-glucose 10\% SBF. O meio de indução foi trocado a cada 3 dias e após 10 dias de cultivo as células foram fixadas com paraformaldeído $4 \%$ por 30 minutos e submetidas à coloração de Oil Red $O$ para evidenciar vacúolos lipídicos em vermelho.

Diferenciação osteogênica - Para a diferenciação osteogênica das ADMSC o kit de diferenciação osteogênica para células mesenquimais (Mesenchymal Stem Cell Osteogenesis kit, Millipore, Billerica, EUA) foi utilizado, conforme recomendações do fabricante. Resumidamente, as células foram cultivadas em placas de 24 poços revestidas com vitronectina e colágeno tipo I na concentração de $12 \mu \mathrm{g} / \mathrm{ml}$ em meio contendo $100 \mathrm{nM}$ dexametosona, $10 \mathrm{mM}$ de glicerol-2-fosfato e 0,05 $\mathrm{mM}$ de ácido ascórbico 2-fosfato por 21 dias, sendo o meio de cultura trocado a cada 3-4 dias. No $21^{\circ}$ dia de indução, as células foram fixadas por $1 \mathrm{~h}$ com etanol $70 \%$ gelado seguido da coloração de Alizarin Red $S$ para evidenciar a presença de cálcio na matriz óssea em vermelho.

Diferenciação condrogênica - as ADMSC foram diferenciadas em meio específico para diferenciação em condrócitos contendo $6,5 \mu \mathrm{g} / \mathrm{ml}$ de insulina (SigmaAldrich), 10 ng/ml de TGF- $\beta 1$ (R\&D Systems, Minneapolis, EUA) e $50 \mathrm{nM}$ de ácido ascórbico 2-fosfato (Sigma-Aldrich) durante 21 dias sendo o meio trocado a cada 3-4 dias. Após esse período, foi realizada a coloração de Safranina O (Sigma-Aldrich) para evidenciar a matriz extracelular rica em glicosaminoglicanos em vermelho.

\subsubsection{Inibição da proliferação de células T CD4+ por ADMSC}

A propriedade de inibição da proliferação de linfócitos T CD4+ pelas ADMSC foi avaliada co-cultivando essas células com linfócitos T CD4+ isolados por seleção positiva do baço de camundongos C57BL/6 utilizando-se microesferas magnéticas (L3T4, Miltenyi Biotech, Auburn, EUA) estimulados com anti-CD3 (1 $\mu \mathrm{g} / \mathrm{ml})$ e anti- 
CD28 $(2 \mu \mathrm{g} / \mathrm{ml})$ (ambos da Biolegend, San Diego, EUA) por 4 dias. A proliferação dos linfócitos T CD4+ foi verificada por citometria de fluxo utilizando-se o kit de proliferação CellTrace ${ }^{\mathrm{TM}}$ Violet (Molecular Probes, Eugene, EUA) conforme recomendações do fabricante.

\subsection{Citometria de fluxo}

\subsubsection{Detecção da produção intracelular de citocinas}

As células foram obtidas do baço ou linfonodos pancreáticos (LPs) para análise por citometria de fluxo. Para isso, o baço ou LPs dos animais foram macerados com o êmbolo de uma seringa em uma placa de petri e a suspensão celular obtida foi então centrifugada a $300 \mathrm{~g}$ por 5 minutos para obtenção de um pellet celular. As hemácias foram então lisadas e seguido da contagem das células vivas pelo método de azul de Tripan 0.4\% em PBS em câmara de Neubauer. Para a análise da produção intracelular de citocinas, $1 \times 10^{6}$ células foram estimuladas in vitro por 5 h a $37{ }^{\circ} \mathrm{C}$ em atmosfera de $\mathrm{CO}_{2}(5 \%)$ pela adição de phorbol-12-miristato-13-acetato (PMA, $100 \mathrm{ng} / \mathrm{ml})$ e ionomicina $(1 \mu \mathrm{g} / \mathrm{ml})$ na presença de brefeldina A $(1 \mu \mathrm{g} / \mathrm{ml})$ (todos adquiridos da Sigma-Aldrich) em meio RPMI 10\% SBF. Após esse período, as células foram centrifugadas a $300 \mathrm{~g}$ por 5 min e lavadas pela adição de $500 \mu \mathrm{l}$ de tampão FACS (2\% de soro bovino fetal e 0,02\% azida sódica em PBS) seguido de uma nova centrifugação. As células foram então incubadas por 30 minutos a $4{ }^{\circ} \mathrm{C}$ na presença do anticorpo anti-CD4 PerCP (1:100) (eBioscience, San Diego, EUA) seguido da permeabilização utilizando-se o kit BD Cytofix/Cytoperm Fixation/Permeabilization (BD Biosciences). A marcação intracelular de TNF- $\alpha$ e IFN- $\gamma$ foi realizada utilizandose os anticorpos anti-TNF- $\alpha$ APC (1:100) (Biolegend) e anti-IFN- $\gamma$ FITC (1:100) (Biolegend), respectivamente. 


\subsubsection{Imunofenotipagem de células T reguladoras}

As células foram obtidas do baço ou LPs conforme descrito previamente. Para a determinação da freqüência de células $\mathrm{T}$ reguladoras, inicialmente a marcação das moléculas de superfície foi realizada incubando 1 × $10^{6}$ células por 30 minutos a $4^{\circ} \mathrm{C}$ na presença dos anticorpos CD4 (PerCP) e CD25 (FITC). Após a incubação, $500 \mu$ l de tampão FACS foram adicionados as amostras e as mesmas centrifugadas a $300 \mathrm{~g}$ por 5 minutos. O sobrenadante foi desprezado, e os tubos foram agitados no vórtex por 5 segundos para o desprendimento das células. A marcação do fator de transcrição intracelular Foxp3 foi então realizada utilizando-se o kit APC anti-mouse/rat Foxp3 staining (eBioscience), conforme recomendações do fabricante. Após a marcação, as células foram suspendidas em $300 \mu$ de tampão FACS e 80.000 eventos foram adquiridos em citômetro de fluxo (FACSCanto II).

\subsection{Modelo de diabetes autoimune experimental em camundongos NOD e protocolo de tratamento com ADMSC}

Para o estudo das propriedades imunomoduladoras das ADMSC in vivo foi utilizado o modelo experimental de diabetes autoimune experimental em camundongos NOD (non-obese diabetic) [137]. A glicemia foi verificada no sangue obtido da extremidade da cauda em fêmeas a partir da $12^{\text {a }}$ semana de idade, semanalmente, até a $30^{\mathrm{a}}$ semana de idade utilizando-se o glicosímetro Accu-Chek Advantage (Roche, Mannheim, Alemanha). Os animais foram considerados diabéticos quando o valor da glicemia foi maior que $240 \mathrm{mg} / \mathrm{dl}$ por duas vezes consecutivas [130]. Para o tratamento dos animais, 1 × $10^{6}$ ADMSC foram suspendidas em $200 \mu \mathrm{l}$ de PBS e administradas pela via intraperitoneal (i.p.) em fêmeas NOD diabéticas ( $n=9)$ nos dias 0, 7 e 14. Além disso, um grupo controle de camundongos diabéticos ( $\mathrm{n}=7$ ) foi injetado com PBS (controle negativo). Além disso, as fêmeas que não desenvolveram diabetes (hiperglicemia) foram utilizadas como controles normoglicêmicos $(n=5)$. Os valores de glicemia foram determinados 
semanalmente após o tratamento por 28 dias, sendo a eutanásia dos animais realizada no dia 35. Em outro grupo experimental, para avaliar a manutenção do efeito terapêutico por um longo período de tempo, a eutanásia dos animais foi realizada 12 semanas após a primeira administração das ADMSCs ( $n=9$ grupo tratado; $\mathrm{n}=15$ grupo controle diabético).

\subsection{Teste de tolerância a glicose}

Após $12 \mathrm{~h}$ de jejum foi realizado o teste de tolerância a glicose nos animais tratados ou não com ADMSC, assim como nos animais normoglicêmicos, 32 dias após o tratamento. A solução de glicose foi administrada na cavidade intraperitoneal na concentração de 1,5 mg por grama de animal (em PBS) e a glicemia monitorada antes da injeção de glicose, 15, 30, 60, 90 e 120 minutos após a administração. O sangue foi coletado a partir da extremidade da cauda de cada animal nos determinados períodos de tempo e os níveis de glicose determinados utilizando-se o glicosímetro Accu-Check Advantage (Roche).

\subsection{Análise histológica e imunohistoquímica}

Cortes histológicos do pâncreas embebido em parafina de $5 \mu \mathrm{m}$ foram realizados utilizando-se um micrótomo, seguido da coloração de hematoxilina e eosina (HE). A quantificação do infiltrado celular inflamatório (escore de insulite) nas ilhotas pancreáticas foi determinando pela contagem de aproximadamente 60 ilhotas/grupo experimental provenientes de 5 animais/grupo utilizando-se a seguinte classificação: $0 \%$ (ausência de infiltrado celular), 0-25\%, 25-50\%, > 50\% e 100\% de insulite em cada ilhota, conforme descrito previamente [138, 139].

A expressão de insulina e do fator de transcrição PDX-1 (pancreatic and duodenal homeobox 1) foi verificada pela técnica de imunohistoquímica utilizando-se os anticorpos anti-insulina (anti-mouse insulin, diluição 1:400; C27C9, Cell 
Signalling, Danvers, EUA) e anti-PDX-1 (anti-mouse PDX-1, diluição 1:500, ab47267, Abcam, Cambridge, EUA), respectivamente, conforme recomendações do fabricante. Para o desenvolvimento da reação foi utilizado o kit Envision Dual Link System-HRP (Dako, Glostrup, Dinamarca), de acordo com recomendações do fabricante. Após a reação, foi realizada a contra coloração das lâminas pela coloração HE.

\subsection{Separação de células T CD4+}

As células T CD4+ foram isoladas do baço de animais C57BL/6 Foxp3 GFP knock in (KI) utilizando-se microesferas magnéticas que se ligam a molécula de CD4 (L3T4, Miltenyi) nos linfócitos T. O baço foi macerado utilizando-se o êmbolo de uma seringa de $1 \mathrm{ml}$ e a suspensão celular obtida foi então centrifugada a $1500 \mathrm{rpm}$ por 5 minutos para obtenção do pellet celular. As células foram suspendidas em um tampão de separação (PBS, 0,5 \% de soro-albumina bovina - BSA e 2 mM EDTA seguido do procedimento de separação em coluna LS (Miltenyi), conforme recomendações do fabricante. Ao final do processo, a pureza das células foi verificada por citometria de fluxo, sendo $\geq 90 \%$.

\subsection{Separação de células T CD4+62L+Foxp3- e CD4+Foxp3+ por FACS ("fluorescence activated cell sorting")}

O processo de separação de células T CD4+ näive (CD4+62L+Foxp3-) e células T CD4+Foxp3+ a partir do baço e linfonodos de camundongos C57BL/6 Foxp3-GFP KI foi realizado por FACS. Inicialmente, um enriquecimento da população de células T CD4+ foi realizada utilizando-se de microesferas magnéticas. Após esse procedimento, as células foram marcadas para as moléculas CD4 e CD62L e submetidas ao processo de separação celular no equipamento BD FACS Aria II da Universidade Federal de São Paulo (UNIFESP) para separação de células CD4+CD62L+GFP- (Foxp3-) e CD4+GFP+ (Foxp3+). As células obtidas no final do processo de separação apresentaram uma pureza $\geq 99 \%$. 


\subsection{Quantificação de citocinas no extrato pancreático}

Os níveis das citocinas IL-2, IFN- $\gamma$ e TNF- $\alpha$ foram quantificados no lisado pancreático por meio da metodologia de Bio-Plex (Bio-Plex Cytokine assay kit, Bio-Rad Laboratories, Hercules, EUA). Para obtenção do lisado de proteínas do pâncreas, uma parte do órgão foi homogeneizada em $1 \mathrm{ml}$ de tampão RIPA (Sigma-Aldrich) contendo inibidores de proteases (Complete Mini EDTA-free cocktail, Roche), utilizando-se um homogeneizador de amostras (Polytron, Littau-Lucerne, Suíça). As amostras foram então centrifugadas a $600 \mathrm{~g}$ por $10 \mathrm{~min}$ a $4{ }^{\circ} \mathrm{C}$, sendo as citocinas quantificadas nos sobrenadantes obtidos após a centrifugação. A normalização entre as amostras foi realizada utilizando-se a quantidade de proteína total tecidual, determinada pela metologia de Bradford (DC protein assay, Bio-Rad). Os resultados foram expressos como níveis de determinada citocina (pg)/100 mg de proteína total. Para análise dos dados foi utilizado o software Bio-Plex Manager versão 4.0 (Bio-Rad).

\subsection{Quantificação de hormônios no soro}

Os hormônios GLP-1 (peptídeo-1 semelhante ao glucagon), GIP (polipeptídeo inibitório gástrico), PYY (polipetídeo Y), amilina, leptina e insulina foram quantificados no soro dos animais utilizando-se o kit Mouse Gut Multiplex Assay (Millipore, Billerica, EUA). O sangue foi obtido a partir de punção cardíaca dos animais anestesiados no dia da eutanásia (35 dias após o tratamento). A curva de detecção do método foi de $3.0 \mathrm{pg} / \mathrm{ml}$ a $50.000 \mathrm{pg} / \mathrm{ml}$ para insulina e leptina, 41.0 a $30.000 \mathrm{pg} / \mathrm{ml}$ para GLP-1 e amilina, 3.0 a $2.000 \mathrm{pg} / \mathrm{ml}$ para GIP e 7.0 a $5.000 \mathrm{pg} / \mathrm{ml}$ para PYY. 


\subsection{ELISA para TGF- $\beta 1$}

Os níveis de TGF- $\beta 1$ no lisado pancreático e meios condicionados obtidos dos ensaios in vitro foram quantificados pela metodologia de ELISA (TGF- $\beta 1 \mathrm{E}_{\max }{ }^{\circledR}$, Promega, Madison, EUA) de acordo com recomendações do fabricante. Por meio desta técnica, a quantidade de TGF- $\beta 1$ total e biologicamente ativo pôde ser detectada em uma faixa de 15.6 a $1.000 \mathrm{pg} / \mathrm{ml}$ sendo os resultados expressos como: quantidade de TGF- $\beta 1$ (pg)/100 mg de proteína total quantificada nos lisados pancreáticos.

\subsection{2 "Homing" das ADMSC após administração em camundongos NOD}

A detecção in vivo do "homing" das ADMSC administradas pela via intraperitoneal (i.p.) para outros tecidos foi realizada utilizando-se as técnicas de citometria de fluxo (para o baço, linfonodo pancreático e lavado peritoneal) e imunofluorescência (para o pâncreas), baseando-se nos estudos de Fiorina et al. (2009) [127] e Madec et al. (2009) [128]. Para isso, 2 x 106 ADMSC foram marcadas por 10 min a $37^{\circ} \mathrm{C}$ com CFSE $5 \mu \mathrm{M}(5,6$-carboxylfuorescein diacetate succinimidyl ester, Molecular Probes) e injetadas i.p. em camundongos NOD diabéticos. A presença de células CFSE+ foi então pesquisada 18 h e 72 h após a administração das ADMSC CFSE+ no baço, lavado peritoneal e linfonodos pancreáticos, por citometria de fluxo e no pâncreas, por imunofluorescência. Fêmeas NOD diabéticas não tratadas com ADMSC foram utilizadas para verificar e considerar a autofluorescência basal de cada tipo tecidual. Um total de 500.000 eventos foi adquirido para cada amostra utilizando-se o citômetro FACS Canto II. Além disso, cortes congelados do pâncreas de $6 \mu \mathrm{m}$ de diâmetro foram realizados no criostato para análise por imunofluorescência. 


\subsection{Expansão/proliferação in vitro de células CD4+CD25+Foxp3+ por ADMSC}

Para determinar a capacidade das ADMSCs em expandir células Treg CD4+CD25+Foxp3+ in vitro, linfócitos T CD4+ foram isolados a partir do baço de camundongos C57BL/6 Foxp3-GFP KI por meio de microesferas magnéticas (CD4 microbeads, L3T4, Miltenyi Biotec). As células T CD4+ totais $\left(1 \times 10^{6}\right)$ foram cocultivadas com ADMSCs $\left(1 \times 10^{5}\right)$ em placas de 6 poços na proporção de 10:1 na presença de IL-2 (50 U/ml). Para estudar a necessidade de contato celular entre os linfócitos T CD4+ e as ADMSCs, as células foram co-cultivadas em um sistema de transwell (Millipore), sendo separadas por uma membrana de $3 \mu \mathrm{m}$ de diâmetro. A proliferação dos linfócitos T CD4+ foi verificada utilizando-se o kit de proliferação celular Cell Trace ${ }^{\mathrm{TM}}$ Violet (Molecular Probes). A frequência e a proliferação de células CD25+Foxp3+, no gate de linfócitos T CD4+, na presença ou ausência de ADMSCs, foi analisada após 4 dias por citometria de fluxo. Para bloqueio do receptor PD-L1 foi utilizado o anticorpo neutralizante anti-PD-L1 (Biolegend, clone 10F.9G2) na concentração de 0,2 a $5 \mu \mathrm{g} / \mathrm{ml}$ [140].

\subsection{Análise estatística}

Os resultados obtidos foram expressos como média \pm erro padrão (SEM). A diferença entre os grupos experimentais foi determinada utilizando-se os testes $t$ de Student, para comparação entre dois grupos experimentais, ou ANOVA (seguido pelo pós-teste de Tukey-Kramer), para comparação entre vários grupos experimentais. Todas as análises foram realizadas utilizando-se o software GraphPad PRISM $^{\circledR} 4.0$ (GraphPad Software, San Diego, EUA) e as diferenças foram consideradas estatisticamente significativas para um valor de $\mathrm{p}<0,05$. 


\section{RESULTADOS}

\subsection{Isolamento e caracterização das ADMSCs}

As ADMSCs foram isoladas a partir do tecido adiposo de camundongos Balb/c machos conforme protocolos previamente descritos [135, 141]. As células aderentes apresentaram uma morfologia fusiforme (Figura 2A) sendo possível observar a formação de unidades formadoras de colônia de fibroblastos (CFUs), propriedade característica de células-tronco mesenquimais (Figura 2B) [21, 142]. De acordo com a "International Society for Cellular Therapy"- ISCT, para uma célula ser caracterizada MSC, três características devem ser avaliadas: expansão in vitro como células aderentes, imunofenotipagem e potencial de diferenciação osteogênica, condrogênica e adipogênica [143]. Assim, a multipotencialidade das ADMSCs foi verificada pela capacidade de diferenciação em linhagens celulares de origem mesodérmica: osteogênica, adipogênica e condrogênica, utilizando-se métodos preconizados para diferenciação in vitro MSCs [23]. As ADMSCs puderam ser diferenciadas in vitro para as linhagens de origem mesodérmica: adipócitos (Figura 2C), condrócitos (Figura 2D) e osteócitos (Figura 2E).

A expressão de moléculas de superfície características de MSCs foi verificada por meio de citometria de fluxo. Na imunofenotipagem, as células mostraram-se positivas para as moléculas CD105, CD90, CD44 e CD73, características de MSCs, e negativas para marcadores característicos de células hematopoiéticas e endoteliais (CD45 e CD34, respectivamente) conforme mostrado na figura 2F. De forma importante, as células não apresentaram positividade para as moléculas CD11b (macrófagos) e CD11c (células dendríticas). Além disso, as ADMSCs inibiram a proliferação de linfócitos T CD4+ estimulados com anti-CD3 e anti-CD28, demonstrando um potencial imunossupressor, característico das MSCs (Figura 2G). 
Figura 2 - Isolamento e caracterização das ADMSCs.

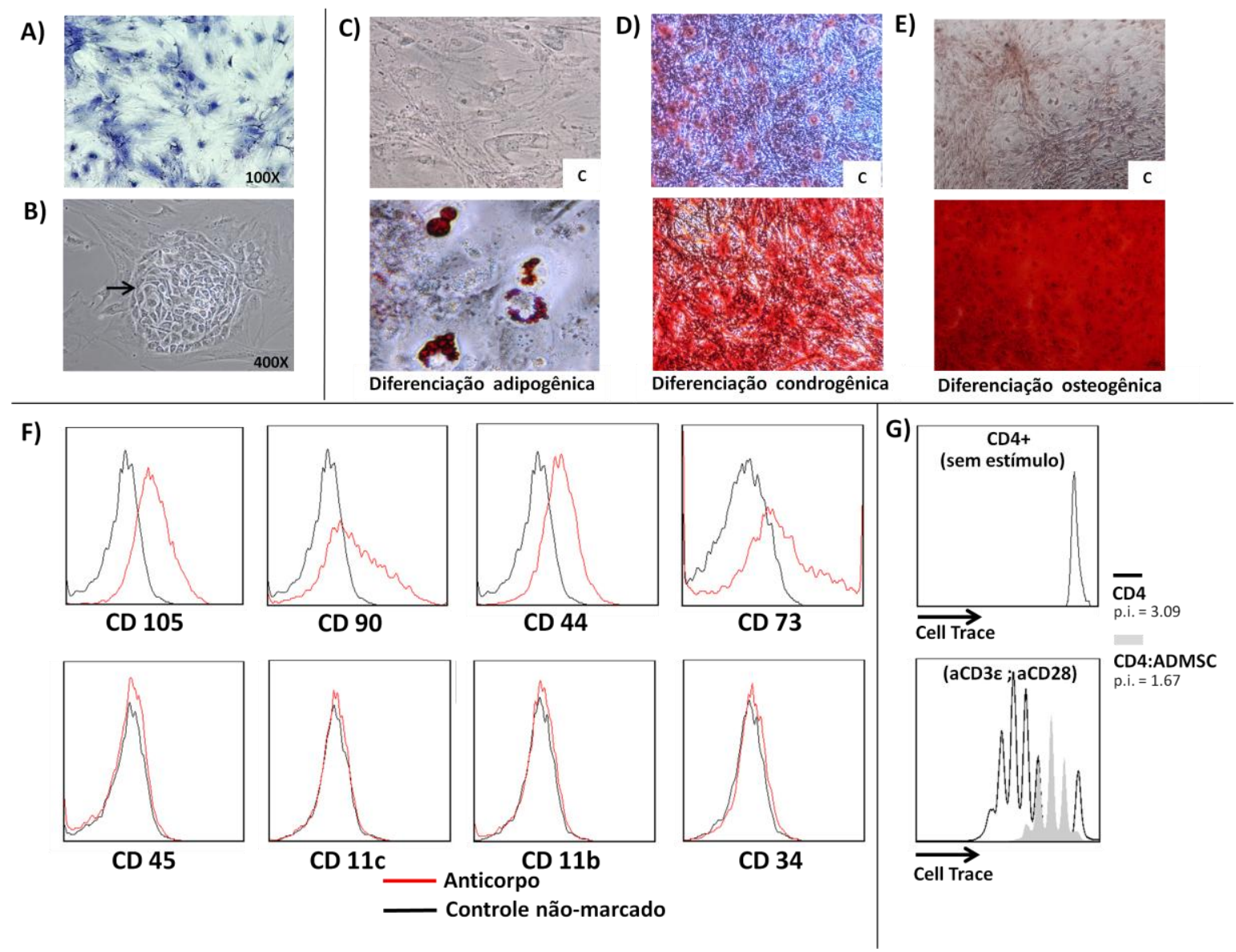

A) Coloração de hematoxilina evidenciando células aderentes com formato fusiforme ou fibroblastóide obtidas durante a primeira semana de cultivo in vitro após o isolamento. Aumento de 100X. B) Microscopia de contraste de fase mostrando na ponta da seta uma unidade formadora de colônia de fibroblastos (CFU) característica de MSCs. Aumento de 200X. C) Diferenciação adipogênica: coloração de Oil Red O realizada após 10 dias de cultivo em meio de diferenciação adipogênica. c: controle negativo. Em vermelho, verifica-se a presença de gotículas de gordura presente em adipócitos. Aumento de 400X. D) Diferenciação condrogênica: coloração de Safranina O realizada após 21 dias de cultivo em meio de indução condrogência. $O$ acúmulo de matriz extracelular rica em glicosaminoglicanos foi verificado pela forte coloração em vermelho. c: controle negativo. Aumento de 200X. E) Diferenciação osteogênica: coloração de vermelho de alizarina (Alizarin Red S) para depósitos de cálcio após 21 dias de cultivo das ADMSCs em meio de diferenciação osteogênica. $c=$ controle negativo. Aumento de 200X. F) Caracterização imunofenotípica para deteç̧ão de moléculas de superfície características de células-tronco mesenquimais (CD105, CD90, CD44 e CD73) e ausência da expressão de marcadores hematopoiéticos e endoteliais (CD45, CD11c, CD11b, CD34). G) Histograma representativo da inibição da proliferação de linfócitos T CD4+ ativados por anti-CD3 e anti-CD28 na presença de ADMSCs. p.i.= índice de proliferação.

Fonte: Bassi [144]. 


\subsection{Modelo de diabetes autoimune experimental em camundongos NOD}

Para estudar as propriedades imunomoduladoras das ADMSCs em condições patológicas em um processo de autoimunidade, o modelo de diabetes autoimune experimental em camundongos NOD foi implantado em nosso laboratório. Essa linhagem de camundongos é o modelo experimental mais ideal para o estudo do DMT1 humano, sendo que os animais desenvolvem uma autoimunidade espontânea, resultando na destruição das células $\beta$ pancreáticas [137]. Inicialmente, a glicemia foi monitorada semanalmente em camundongos NOD fêmeas da $10^{\underline{a}}$ a $30^{\underline{a}}$ semana de idade e os animais foram considerados diabéticos quando os valores de glicemia foram maiores que $240 \mathrm{mg} / \mathrm{dl}$ por duas vezes consecutivas. A incidência de diabetes em fêmeas em nossa colônia até a $30^{\underline{a}}$ semana foi de $75 \%$, sendo que a maioria dos casos de hiperglicemia foi detectada entre 18 a 22 semanas de idade (Figura 3A). A análise histológica do pâncreas revelou um intenso infiltrado celular inflamatório nas ilhotas pancreáticas, processo denominado de insulite, a partir da $12^{\underline{a}}$ semana de idade (Figura 3B). Nos animais hiperglicêmicos também foi possível observar a presença de lesão renal, evidenciada por um aumento nos espaços da região glomerular e túbulos disformes (Figura 3F).

Além disso, a frequência de células T CD4+ produtoras de TNF- $\alpha$ e IFN- $\gamma$ nos linfonodos pancreáticos (LPs) foram determinadas em diferentes estágios de desenvolvimento da doença. Para isso, um grupo de camundongos pré-diabéticos (6 semanas de idade), normoglicêmicos (12-14 semanas de idade) e diabéticos foram comparados ( $n=4-6 /$ grupo experimental). A frequência de células CD4+TNF- $\alpha+$ (Figura 3C e 3E) e CD4+IFN- $\gamma+$ (Figura 3D e 3E) foi maior no LP do grupo diabético quando comparado ao grupo normoglicêmico e pré-diabético, confirmando assim o perfil Th1 pró-inflamatório das células $\mathrm{T}$ CD4+ neste modelo experimental, observado em outros estudos $[145,146]$. 
Figura 3 - Modelo experimental de diabetes autoimune experimental em camundongos NOD.

A)
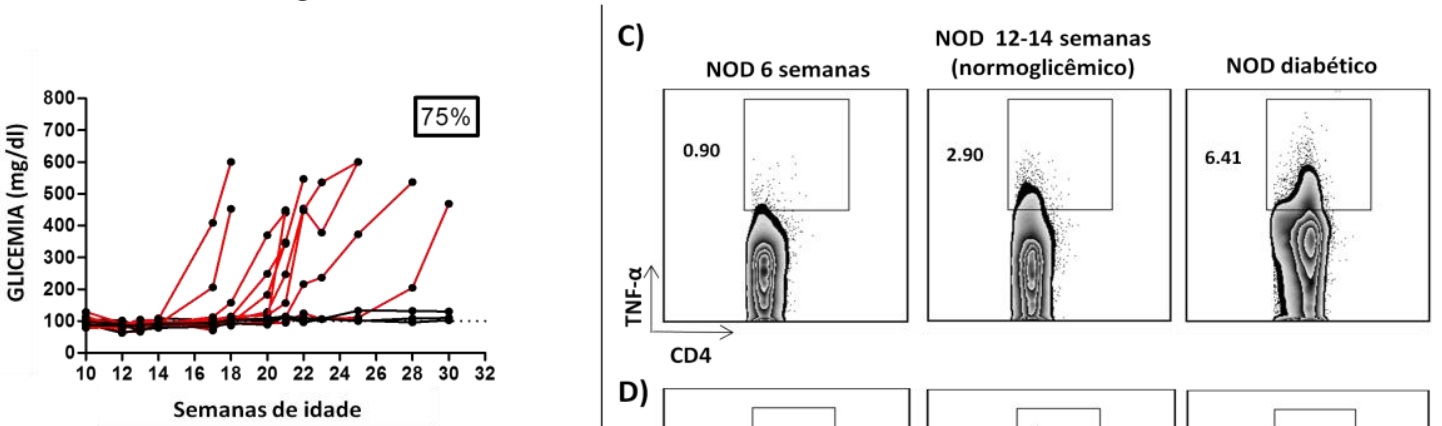

B)

Semanas de idade

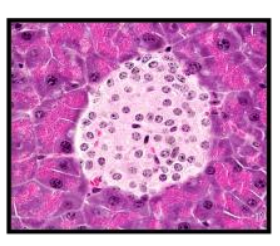

Controle (Balb/c)

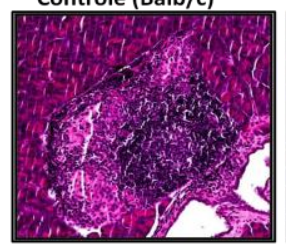

NOD 12 semanas (normoglicêmico)

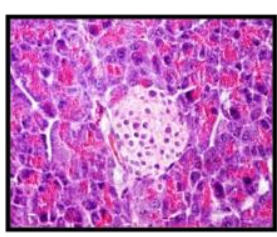

NOD 6 semanas

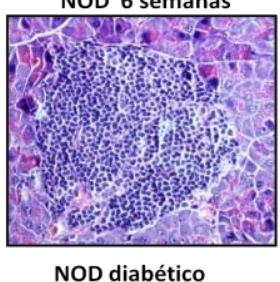

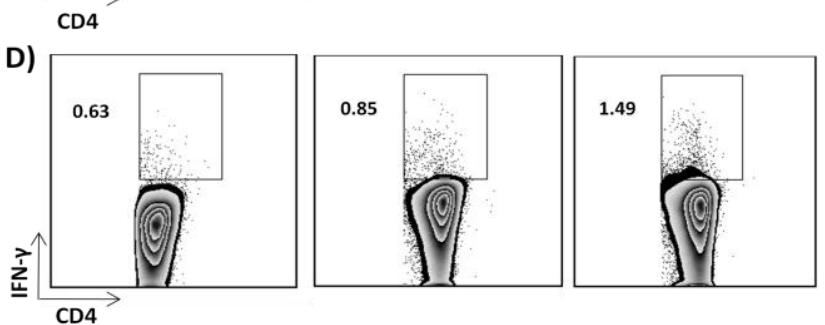

E)

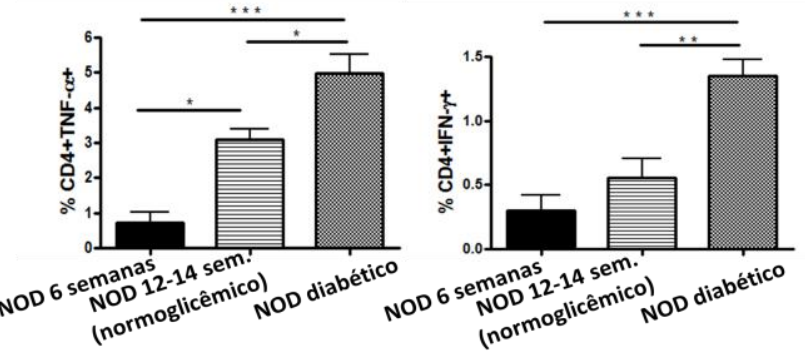

F)
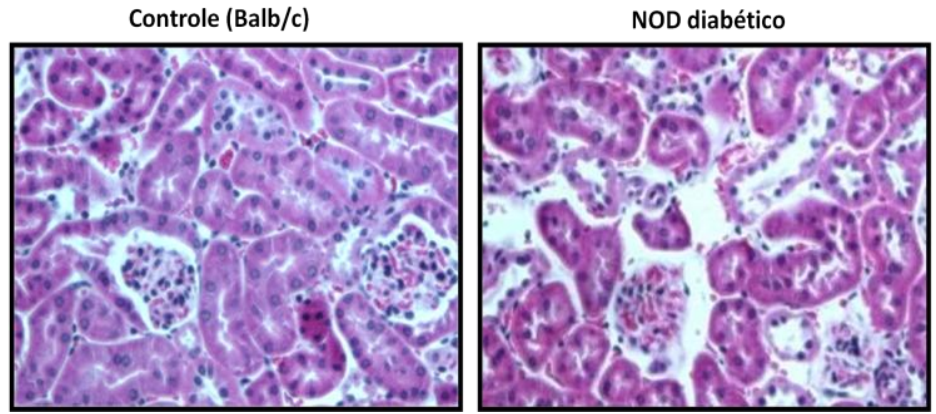

A) A glicemia foi determinada uma vez por semana em animais NOD fêmeas $(n=12)$ da $10^{\underline{a}}$ a $30^{\mathrm{a}}$ semana de idade. A incidência da doença até 30 semanas de idade foi de $75 \%$. Em vermelho são mostrados os animais hiperglicêmicos que desenvolveram hiperglicemia no período estudado e em preto os animais que permaneceram normoglicêmicos até a $30^{\mathrm{a}}$ semana de idade. B) Coloração de hematoxilina-eosina (HE) no pâncreas em diferentes estágios do desenvolvimento da diabetes autoimune mostrando um intenso infiltrado celular inflamatório nas ilhotas pancreáticas conforme o decorrer do desenvolvimento da doença. $\mathrm{C}$ e D) Produção de citocinas de perfil Th1 pró-inflamatório por linfócitos T CD4+ obtidos a partir do linfonodo pancreático (LP) de fêmeas NOD em diferentes estágios da doença. Density-plots representativos das frequências (\%) de células T CD4+TNF- $\alpha+(\mathrm{C})$ e CD4+IFN$\gamma^{+}$(D) mostrada em E. F) Coloração de HE em rins provenientes de animais Balb/c (controle) e NOD diabéticos hiperglicêmicos. Aumento de 400X.

Fonte: Bassi [144]. 


\subsection{Tratamento com ADMSCs reverte a hiperglicemia em camundongos NOD recém-diabéticos}

Para avaliar a capacidade das ADMSCs em reverter a hiperglicemia em camundongos recém-diabéticos, 1 × $10^{6}$ ADMSCs (grupo tratado) ou PBS (grupo não tratado) foram administradas nos dias 0,7 e 14 pela via intraperitoneal em camundongos NOD diabéticos. A média dos valores de glicemia no início do tratamento foi semelhante entre os grupos $(\mathrm{p}=\mathrm{ns})$.

O tratamento com ADMSCs reverteu a hiperglicemia em 80\% dos animais tratados 28 dias após o tratamento (7 de 9 animais) conforme mostrado na figura 4A. Os valores de glicemia dos animais na ausência de jejum foram mais baixos no grupo tratado (Figura 4A) quando comparados ao grupo não tratado (Figura 4B), que permaneceram hiperglicêmicos durante todo o período analisado. Além disso, a área sobre a curva correspondente ao período de 28 dias foi menor para os animais tratados (Figura 4C). Para obter uma melhor avaliação da atenuação da hiperglicemia obtida pelo tratamento com ADMSCs, os níveis de glicemia após $12 \mathrm{~h}$ de jejum foram determinados 32 dias após o tratamento. Interessantemente, no grupo tratado, os níveis de glicemia após o jejum foram menores, próximos a normoglicemia, quando comparados ao grupo não tratado $(147.8 \mathrm{mg} / \mathrm{dl} \pm 25.0$ grupo tratado vs $487.3 \mathrm{mg} / \mathrm{dl} \pm$ 8.5 grupo não tratado, $\mathrm{p}<0,001$ ) conforme mostrado na figura 4D. 
Figura 4 - Tratamento com ADMSC reverte a hiperglicemia de camundongos NOD recém-diabéticos.

A)

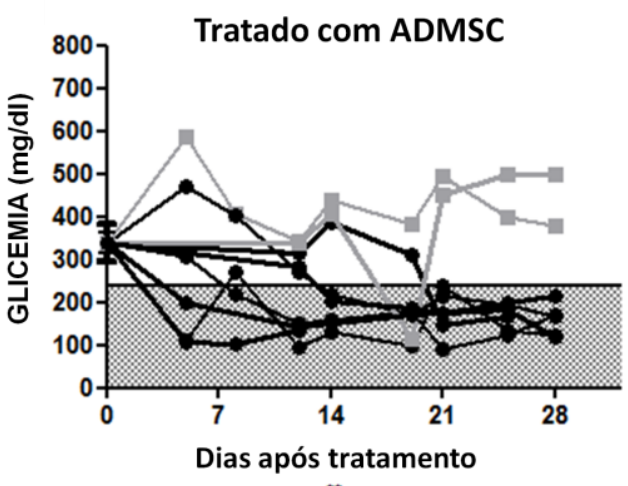

C)

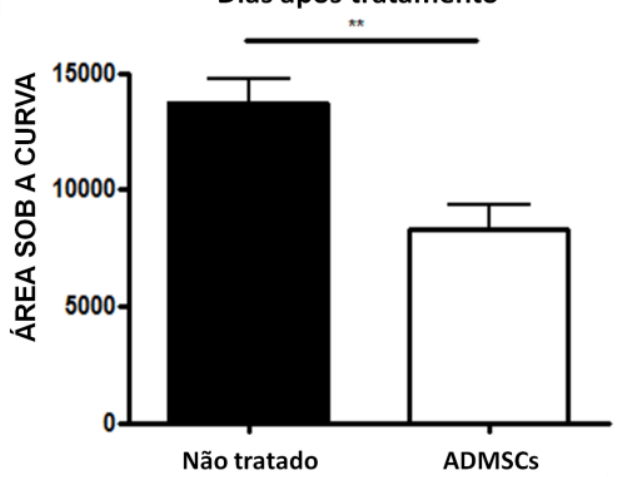

B)

D)
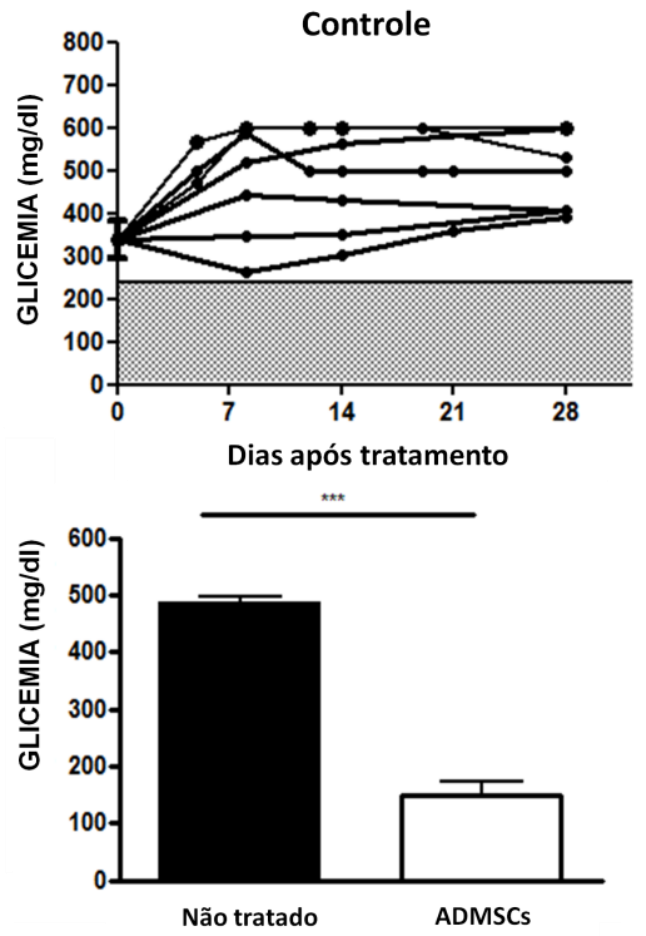

A) Curva glicêmica na ausência de jejum dos animais tratados com ADMSC. Linhas em preto: animais que apresentaram uma redução nos valores de glicemia após o tratamento $(n=7 / 9)$. Uma redução da glicemia foi observada principalmente 21 dias após o tratamento com ADMSC. Linhas em cinza: animais que não apresentaram uma redução da glicemia após o tratamento $(n=2 / 9)$. B) Curva glicêmica do grupo não tratado: um grupo de camundongos diabéticos foi tratado com PBS $(n=7)$ nos mesmos dias da administração de ADMSC no grupo tratado. Região pontilhada e preenchida: denota valores de glicemia abaixo de $240 \mathrm{mg} / \mathrm{dl}$. A média \pm s.e.m. dos valores de glicemia no início do tratamento é mostrada e não diferiu entre os grupos $(p=n s)$. C) Área sob a curva dos níveis de glicemia compreendidos do dia 1 ao 28 após o tratamento. A área sob a curva foi determinada para cada animal e a média \pm s.e.m. para cada grupo é mostrada. D) Glicemia após $12 \mathrm{~h}$ jejum 32 dias após o tratamento. Níveis mais baixos de glicemia foram detectados em camundongos tratados quando comparado ao grupo não tratado. E) Peso (g) dos animais tratados e não tratados no período de 28 dias após o tratamento. Os resultados são expressos como média \pm s.e.m. ${ }^{* *} \mathrm{p}<0.01,{ }^{* * *} \mathrm{p}<0.0001$.

Fonte: Bassi [144].

\subsection{Teste de tolerância a glicose e glicosúria e aumento nos níveis de insulina após o tratamento com ADMSCs}

A avaliação da resposta periférica a glicose foi realizada por meio do teste de tolerância a glicose intraperitoneal (IGTT) no grupo tratado e não tratado. A 
tolerância à glicose de um grupo de animais NOD normoglicêmicos também foi adicionada e analisada no teste, para comparar com os animais tratados ou não com ADMSCs.

Conforme mostrado na figura 5A e 5B, os animais que receberam o tratamento com ADMSCs apresentaram uma melhora significativa na resposta à administração de glicose. A glicemia de jejum apresentou valores normoglicêmicos e 60 min após a administração da glicose a mesma retornou aos valore iniciais nos animais tratados, sendo o mesmo não observado para o grupo não tratado. Após $120 \mathrm{~min}$ da administração de glicose os valores de glicemia observados foram: 71,7 $\pm 23,7 \mathrm{mg} / \mathrm{dl}$ para o grupo tratado com ADMSC, $69,0 \pm 8,2 \mathrm{mg} / \mathrm{dl}$ para o grupo de animais NOD normoglicêmicos e 355,0 $\pm 84,2 \mathrm{mg} / \mathrm{dl}$ para o grupo não tratado. Além disso, ao calcular a área sob a curva para o período analisado, uma diferença estatisticamente significante $(\mathrm{p}<0,01)$ foi observada ao comparar o grupo tratado e não tratado $(15.388$ \pm 5.042 vs. $52.135 \pm 5.351, \mathrm{p}<0,01$ ) (Figura 5B). Uma melhora significativa na glicosúria também foi observada nos animais após o tratamento (Figura 5C).

Devido ao tratamento promover uma melhora significativa na resposta periférica à glicose, verificado pelo teste de IGTT, foi interessante avaliar os níveis de insulina no soro dos animais. Conforme mostrado na figura 5D, níveis maiores de insulina foram detectados no grupo tratado quando comparados ao grupo não tratado diabético $(552,2 \pm 186,0 \mathrm{pg} / \mathrm{ml}$ vs. $198,5 \pm 38,14 \mathrm{pg} / \mathrm{ml}$, respectivamente, $\mathrm{p}<0,05)$, sendo similares ao do grupo controle normoglicêmico $(462,6 \pm 85,85 \mathrm{pg} / \mathrm{ml})$. 
Figura 5 - Teste de tolerância a glicose administrada por via intraperitoneal e níveis de insulina no soro de animais após tratamento com ADMSCs.

A)

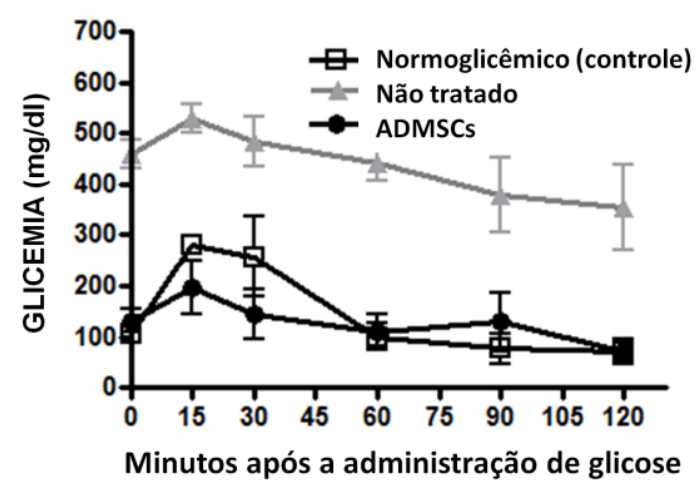

C)

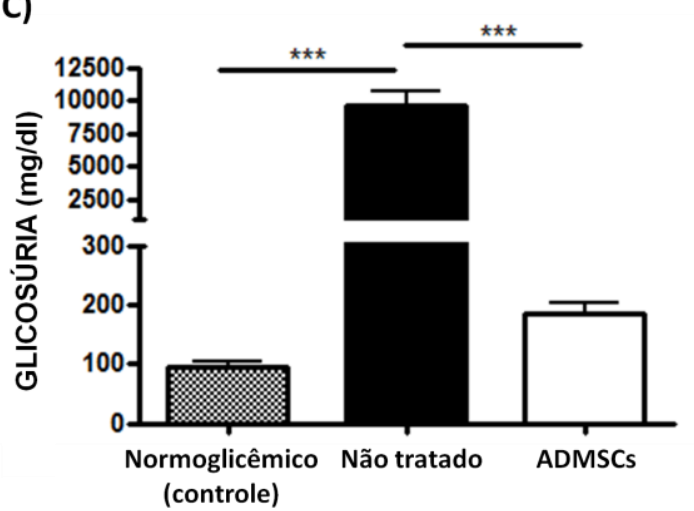

B)
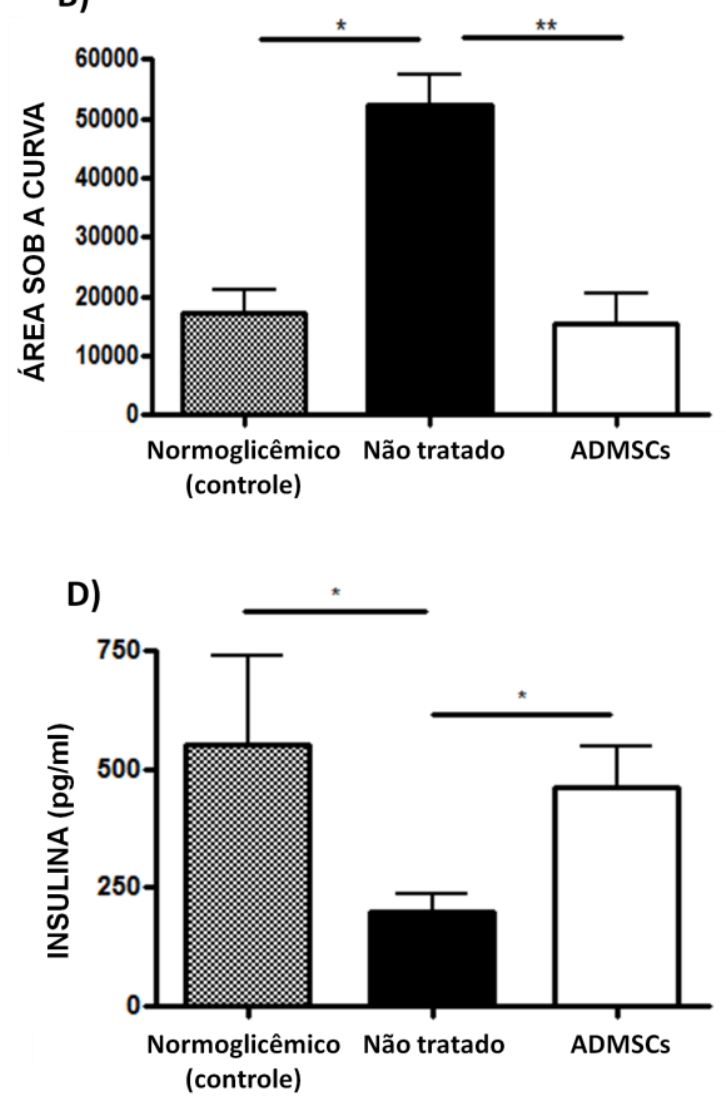

A) Curva glicêmica do teste de tolerância a glicose intraperitoneal realizado 32 dias após o tratamento com ADMSC. Uma dose de $1.5 \mathrm{mg} / \mathrm{kg}$ foi administrada por via intraperitoneal e a glicemia determinada $0,15,30,60,90$ e 120 minutos após a administração ( $\mathrm{n}=5$ animais/grupo). B) A área sob a curva correspondente ao tempo de 0 a 120 minutos foi determinada para cada animal e a média \pm s.e.m. de cada grupo é mostrada. C) Níveis de glicose na urina (glicosúria) foram quantificados 28 dias após o tratamento. As amostras de urina foram diluídas em solução fisiológica para que as amostras ficassem dentro dos limites de detecção do glicosímetro. D) Detecção de insulina (pg/ml) por ELISA no soro dos animais eutanizados no dia 35 conforme descrito na Metodologia. Resultados expressos como média \pm s.e.m. ${ }^{*} \mathrm{p}<0.05,{ }^{* *} \mathrm{p}<0.01,{ }^{* * *} \mathrm{p}<0.001$.

Fonte: Bassi [144].

\subsection{Tratamento com ADMSCs promove o aumento de diversos hormônios relacionados à melhora do diabetes autoimune em camundongos NOD}

Diversos hormônios, como amilina, GIP e GLP-1 foram descritos como tendo um efeito benéfico para a melhora do quadro clínico de DMT1; assim, os níveis destes hormônios foram quantificados no soro dos animais (Figura 6). Os níveis de amilina, um hormônio peptídico secretado simultaneamente com a insulina pelas 
células $\beta$, foram mais elevados no grupo tratado comparando-se ao grupo não tratado $(65,33 \pm 8,27 \mathrm{pg} / \mathrm{ml}$ grupo tratado vs. $29,43 \pm 7,54 \mathrm{pg} / \mathrm{ml}$ grupo não tratado, $\mathrm{p}<0,05)$ conforme mostrado na figura 6A. De forma interessante, o tratamento com ADMSCs também promoveu um aumento significante nos níveis de GLP-1 conforme mostrado na figura $6 \mathrm{E}(104,5 \pm 25,98 \mathrm{pg} / \mathrm{ml}$ grupo tratado vs. $38.82 \pm 7.55 \mathrm{pg} / \mathrm{ml}$ grupo não tratado, $\mathrm{p}<0,05)$.

Figura 6 - Administração de ADMSCs promove aumento de hormônios que contribuem para a melhora do diabetes autoimune.

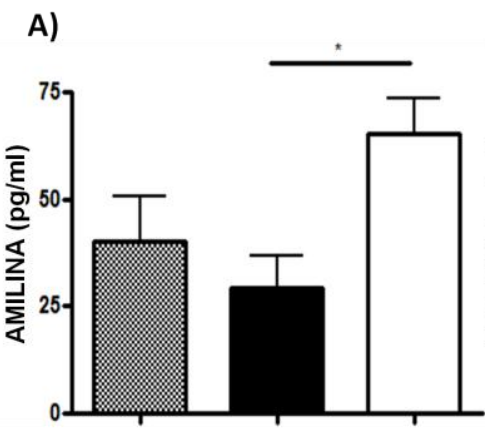

D)

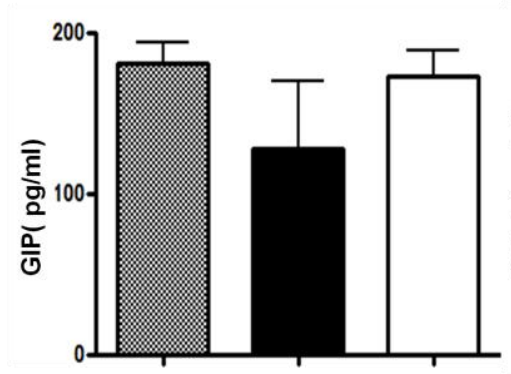

B)

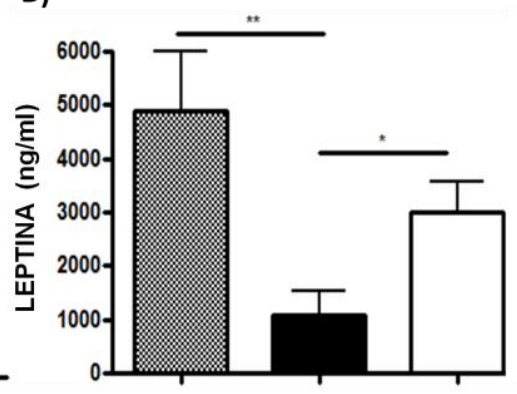

E)
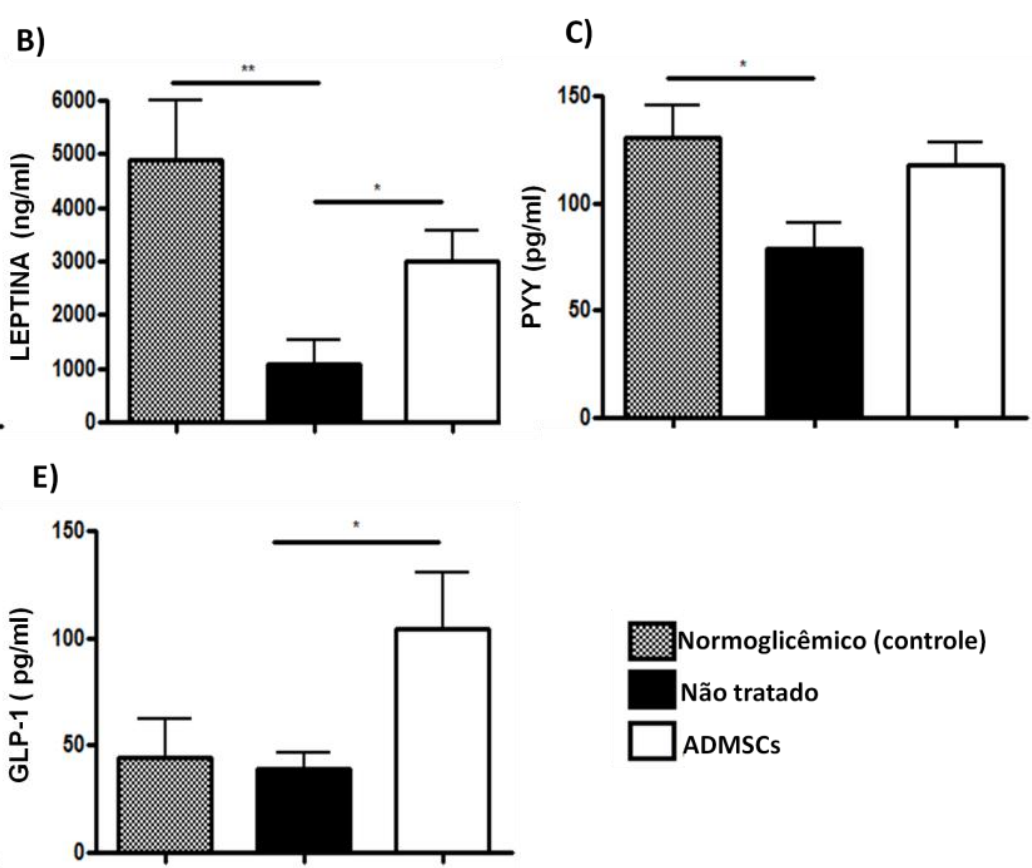

Normoglicêmico (controle)

Não tratado

ADMSCs

Os níveis de (A) amilina (pg/ml), (B) leptina (ng/ml), (C) PYY (pg/ml), (D) GIP (pg/ml) e (E) GLP-1 (pg/ml) foram quantificados no soro dos animais 35 dias após o tratamento pela metodologia de Milliplex. Os resultados foram expressos como média \pm s.e.m. ${ }^{*} \mathrm{p}<0.05$, ** $\mathrm{p}<0.01 . \mathrm{n}=5$ /grupo experimental.

Fonte: Bassi [144].

\subsection{Tratamento com ADSMC diminui o infiltrado celular inflamatório (insulite) mantendo a expressão de insulina e PDX-1 nas ilhotas pancreáticas}

O pâncreas dos animais foi coletado e processado para análise histológica para avaliação da presença de infiltrado celular nas ilhotas pancreáticas. Para isso, foram analisados os seguintes grupos experimentais: 1 - grupo de camundongos NOD com 
6 semanas de idade (onde há um elevado número de ilhotas ainda sem infiltrado celular); 2 - grupo de camundongos NOD normoglicêmicos com idade superior a 12 semanas (considerado pré-diabético); 3 - grupo não tratado com ADMSC e 4 - grupo tratado com ADMSC. Com o objetivo de analisar quantitativamente o resultado obtido, aproximadamente 60 ilhotas de cada grupo experimental foram analisadas individualmente, sendo realizada uma classificação (escore) para cada ilhota, conforme a intensidade de insulite observada: $0 \%, 0-25 \%, 25-50 \%,>50 \%$ e $100 \%$. Conforme mostrado na figura 7G nos animais com 6 semanas de idade há ausência de insulite em $85 \%$ das ilhotas analisadas. Por outro lado, nos camundongos com idade superior a 12 semanas (pré-diabéticos) esse número cai para 30\%. A análise dos grupos 1, 2 e 3 demonstrou um aumento da severidade da insulite conforme o desenvolvimento da doença neste modelo experimental (Figura 7G).

Nas ilhotas pancreáticas dos animais não tratados um escore mais severo de insulite pôde ser observado, sendo que em $45 \%$ das ilhotas analisadas, o infiltrado celular recobriu totalmente a área da ilhota (escore de 100\% de insulite) (Figuras 7C, 7D e 7G). Por outro lado, o tratamento com ADMSCs spromoveu uma redução significativa na insulite quando comparado ao grupo não tratado $(\mathrm{p}<0,0001)$, sendo que a maioria das ilhotas analisadas apresentaram ausência de infiltração ou somente peri-insulite (Figuras 7E, 7F e 7G). 
Figura 7 - Diminuição do infiltrado celular inflamatório (insulite) nas ilhotas pancreáticas após o tratamento com ADMSCs.
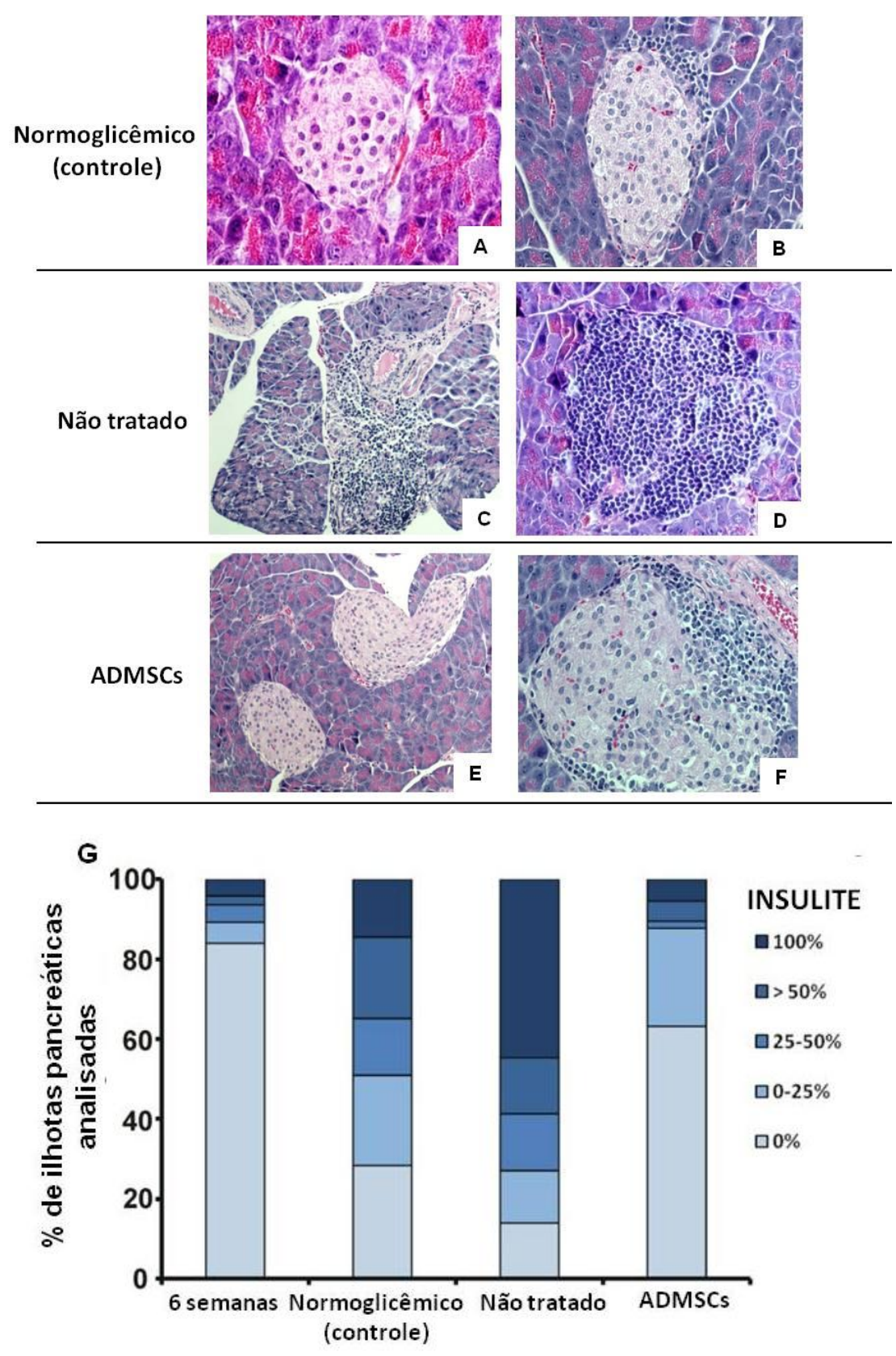

A-F) Análise histológica do pâncreas pela coloração de HE para verificação de insulite nas ilhotas pancreáticas. A) Grupo de camundongos NOD fêmeas normoglicêmicas com 6 semanas de idade. B) Grupo controle normoglicêmico com idade superior a 12 semanas. C e D) Grupo não tratado. E e F) Grupo tratado com ADMSCs. Aumento de 400X. F) Análise quantitativa da insulite nas ilhotas pancreáticas. Foram analisadas aproximadamente 60 ilhotas individualmente para cada grupo experimental sendo realizado um escore conforme a intensidade do infiltrado celular observado: $0 \%$ - ausência de infiltrado; 0-25\% - periinsulite ou infiltrado presente em até $25 \%$ da área da ilhota pancreática; $25-50 \%$ - infiltrado presente entre 25 a $50 \%$ da ilhota; $>50 \%$ - infiltrado que abrange mais de $50 \%$ da área da ilhota; $100 \%$ - infiltrado celular recobrindo toda a área da ilhota pancreática.

Fonte: Bassi [144]. 
Devido ao tratamento com ADMSCs reduzir o infiltrado celular nas ilhotas pancreáticas foi interessante analisar a expressão de insulina e do fator de transcrição PDX-1 (do inglês "pancreatic and duodenal homeobox 1"), os quais podem indicar a manutenção/sobrevivência de células $\beta$ funcionais nos animais após o tratamento. Interessantemente, as ilhotas do grupo de animais tratados com ADMSCs apresentaram uma elevada expressão de insulina quando comparadas ao grupo não tratado diabético (Figura 8A e Figura 9; $\mathrm{p}<0,05$ ). Além disso, as ilhotas do grupo tratado apresentaram uma expressão de PDX-1 similar ao grupo controle normoglicêmico, enquanto no grupo não tratado, a expressão deste fator de transcrição foi pouco detectada (Figura 8B).

Figura 8 - Expressão de insulina e PDX-1 nas ilhotas pancreáticas após o tratamento com ADMSCs.

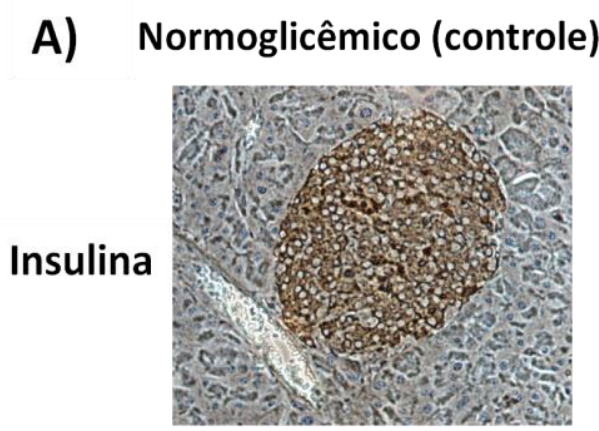

Não tratado

ADMSCs
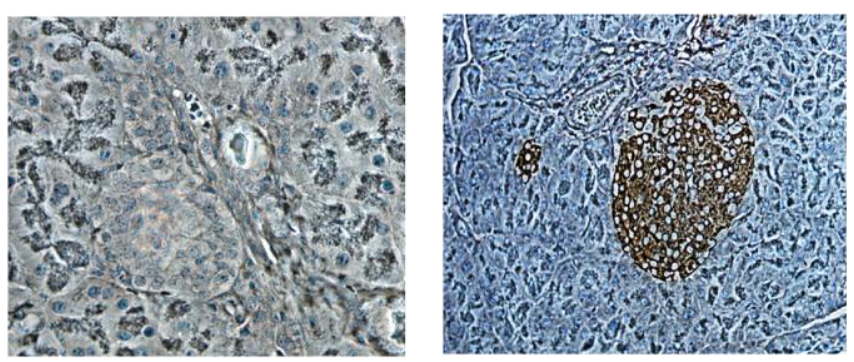

B)

PDX-1
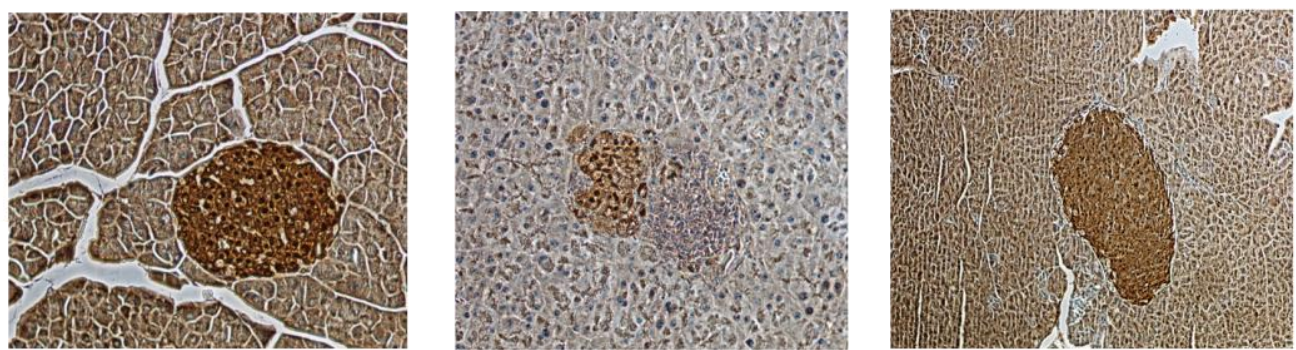

Análise imunohistoquímica para insulina (A) e PDX-1 (B) realizada no pâncreas de animais tratados com ADMSCs, não tratados e normoglicêmicos (controle). Fotomicrografia representativa de ilhota pancreática após a imunohistoquímica utilizando o kit Envision (DAKO), conforme descrito na metodologia. Aumento de 400X.

Fonte: Bassi [144]. 
Figura 9 - Quantificação da área positiva para insulina nas ilhotas pancreáticas após o tratamento com ADMSC.

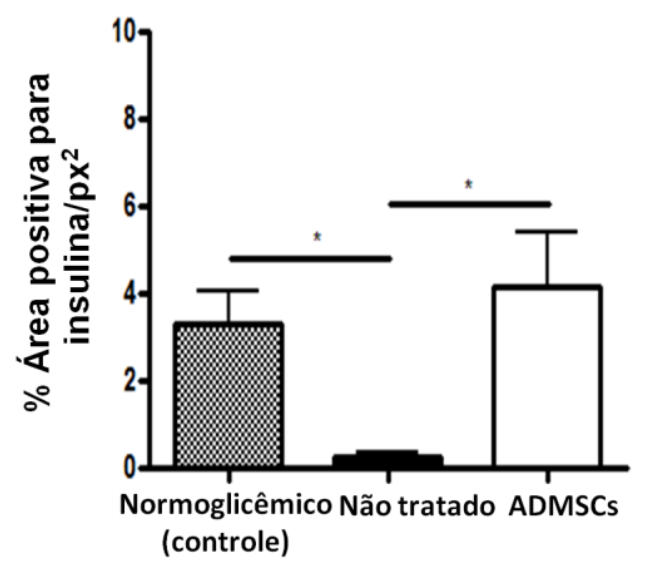

Após realizar a imunohistoquímica, a área positiva para insulina nas ilhotas pancreáticas foi determinada utilizando o software NIS-Elements AR 3.2 (Nikon). Gráfico da análise quantitativa da expressão de insulina nas ilhotas pancreáticas do grupo tratado, não tratado e normoglicêmico (controle). Resultado expresso como média \pm s.e.m da percentagem da área positiva para insulina/pixel ${ }^{2} .{ }^{*} \mathrm{p}<0,05$.

Fonte: Bassi [144].

\subsection{Modulação da resposta imune mediada por células T CD4+ de perfil Th1 nos linfonodos pancreáticos (LPs) após o tratamento com ADMSC}

Devido ao fato do diabetes autoimune ser uma doença caracterizada por uma resposta imune de perfil Th1 foi interessante avaliar se o tratamento com ADMSCs pôde atenuar os elevados níveis IFN- $\gamma$ e TNF- $\alpha$ produzidos por células T CD4+ nos LPs dos animais após o tratamento. Conforme mostrado na figura $10 \mathrm{~A}$ e 10B, a frequência e o número absoluto de células T CD4+IFN- $\gamma+$ e CD4+TNF- $\alpha+$ foi menor nos LPs dos animais tratados quando comparada ao grupo não tratado. Embora o baço dos animais também tenha sido analisado, não verificamos diferença estatisticamente significante na freqüência destas células neste órgão, indicando que o efeito imunossupressor provavelmente tenha ocorrido somente no sítio regulador da resposta autoimune desenvolvida. 
Figura 10 - Tratamento com ADMSCs modula a resposta imune Th1 diminuindo a freqüência de células T CD4+IFN- $\gamma+$ e CD4+TNF- $\alpha+$ no LP de camundongos recém-diabéticos.
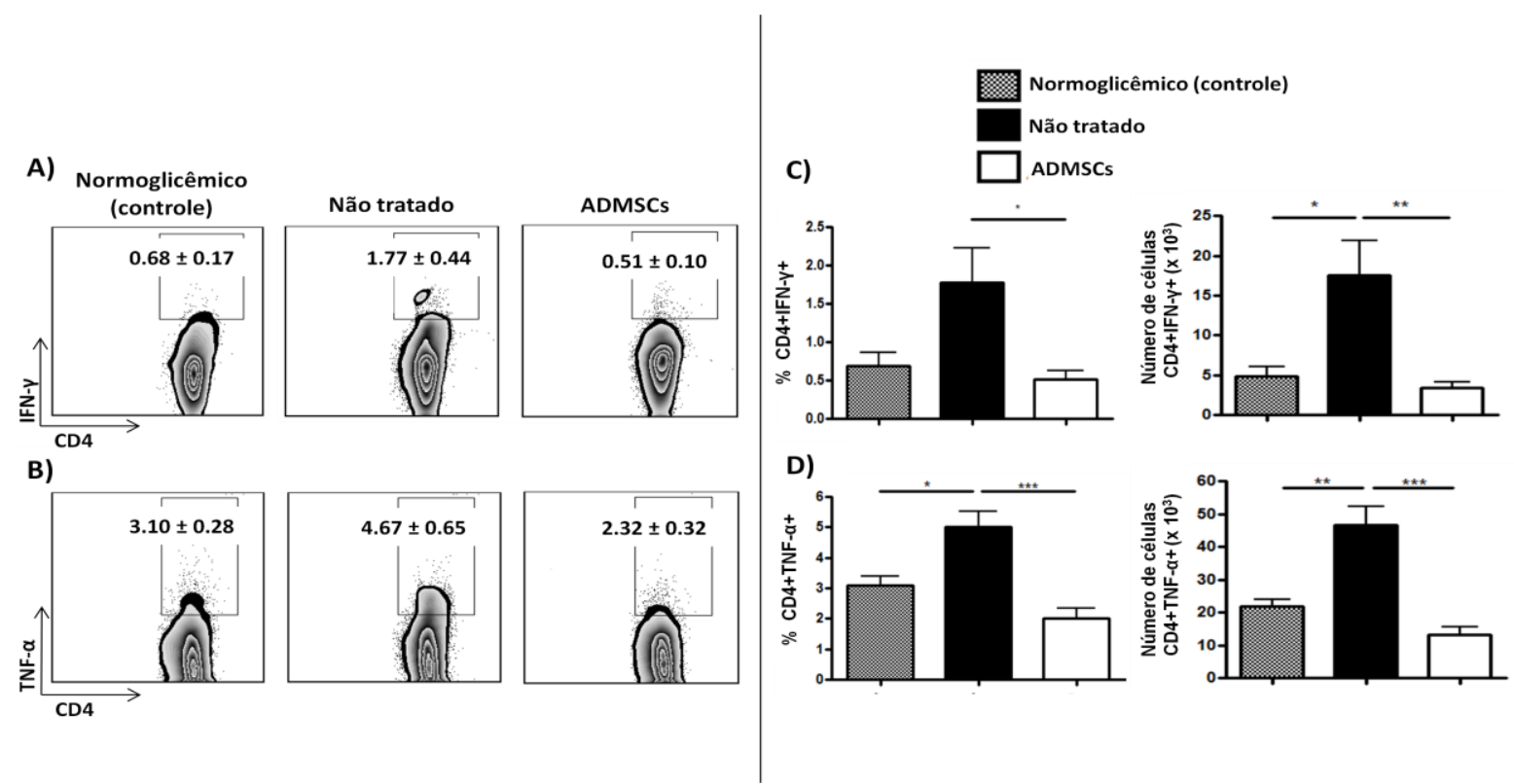

As células foram obtidas a partir do LP e estimuladas in vitro com PMA + ionomicina na presença de brefeldina A por $5 \mathrm{~h}$ para posterior análise da produção de citocina intracelular por citometria de fluxo. Dot-plots representativos da freqüência de células (A) CD4+IFN- $\gamma+e$ (B) CD4+TNF- $\alpha+$ no gate de células CD4+ no grupo de animais normoglicêmicos (controle), não tratado e tratado, respectivamente. A média \pm s.e.m. é mostrada no interior do gate para cada grupo experimental. C e D) Gráfico representativo da frequência (\%) e número absoluto de células CD4+IFN- $\gamma+$ e CD4+TNF- $\alpha+$, respectivamente. $n=5-8 /$ grupo experimental. Os resultados foram expressos como média \pm s.e.m. ${ }^{*} \mathrm{p}<0,05,{ }^{* *} \mathrm{p}<0,01,{ }^{* * *} \mathrm{p}<0,001$.

Fonte: Bassi [144].

\subsection{Terapia com ADMSCs aumenta a freqüência de células T reguladoras nos LPs}

As células Tregs são encontradas em órgãos linfóides secundários exibindo uma potente atividade supressora tanto in vitro como in vivo, inibindo células $\mathrm{T}$ autoreativas e mantendo a tolerância imunológica. Essas células suprimem a proliferação de células T CD4+CD25- e células T CD8+, assim como a secreção de IFN- $\gamma$ [147]. Recentemente, foi mostrado que as células-tronco mesenquimais possuem a capacidade de expandir células T reguladoras [73]. Assim, para avaliar a hipótese de que o efeito terapêutico do tratamento com ADMSCs poderia estar associado com a expansão de células $\mathrm{T}$ reguladoras, a freqüência de células $\mathrm{T}$ 
CD4+CD25+Foxp3+ nos LPs foi analisada nos animais tratados comparando-se com o grupo não tratado e normoglicêmico (controle).

A frequência de células T CD4+CD25+ (Figura 11B) e T CD4+Foxp3+ (Figura 11A e 11C) foi maior no grupo tratado comparada ao grupo não tratado. Além disso, a freqüência de células T CD4+CD25+Foxp3+ foi maior no LP dos animais tratados quando comparado ao grupo não tratado $(12,55 \pm 1,22 \%$ grupo tratado vs. $5,96 \pm$ $1,12 \%, p<0,01$ grupo não tratado) conforme mostrado na figura 11D.

Figura 11 - Frequência de células Tregs nos LPs de camundongos NOD diabéticos após o tratamento com ADMSC.

A)
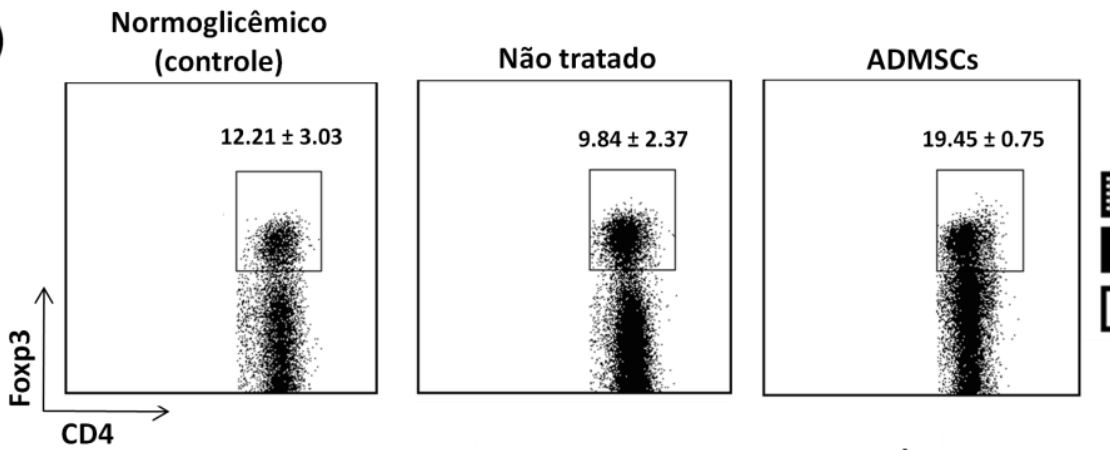

Normoglicêmico (controle)

B)

C)
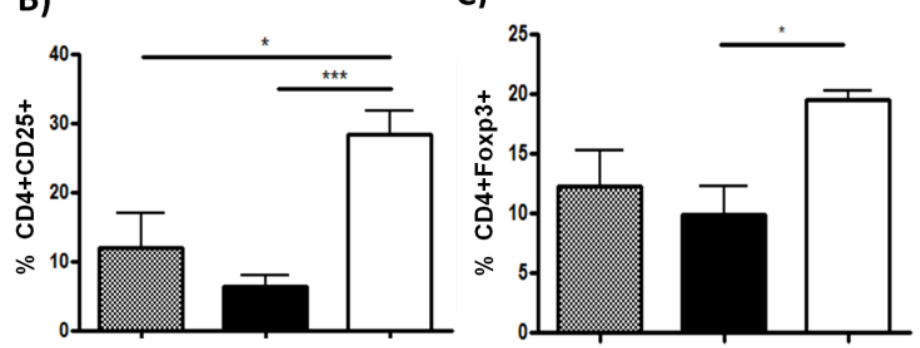

D)

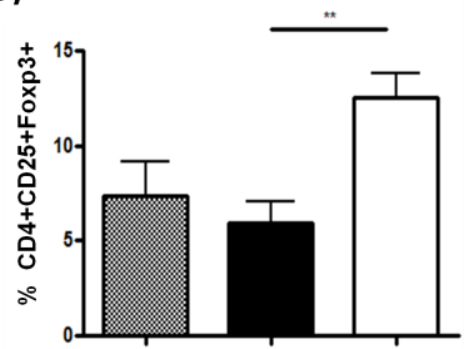

A frequência de células T CD4+CD25+Foxp3+ foi analisada por citometria de fluxo em células obtidas a partir dos LPs. A) Dot-plots representativos da freqüência de células CD4+Foxp3+ no gate de células T CD4+. B, C e D) Gráficos representativos da frequência de células T CD4+CD25+, CD4+Foxp3+ e CD4+CD25+Foxp3+ no gate de células T CD4+, respectivamente, para cada grupo experimental. $n=5 /$ grupo. Os resultados são mostrados como média \pm s.e.m. ${ }^{*} \mathrm{p}<0,05,{ }^{* *} \mathrm{p}<0,01,{ }^{* * *} \mathrm{p}<0,001$.

Fonte: Bassi [144]. 


\subsection{Tratamento com ADMSCs atenua a resposta imune de perfil Th1 no pâncreas combinada ao aumento da expressão de TGF- $\beta 1$ ativo}

Após avaliar o efeito imunomodulador das ADMSCs no LP, foi interessante verificar se o tratamento com essas células poderia ocasionar um efeito supressor na resposta autoimune Th1 no pâncreas. Assim, os níveis de citocinas Th1 próinflamatórias IL-2, IFN- $\gamma$ e TNF- $\alpha$ foram quantificadas no lisado pancreático. De forma interessante, uma significante redução nos níveis de IFN- $\gamma$ pôde ser observada nos animais após o tratamento comparado ao grupo não tratado $(3,2 \pm 0,89$ pg/100 mg de proteína total no grupo tratado vs. 21,33 $\pm 6,38$ pg/100mg de proteína total no grupo não tratado, $\mathrm{p}<0,05$ ) (Figura 12B). Embora valores menores de IL-2 e TNF- $\alpha$ puderam ser detectados no grupo tratado quando comparado ao grupo não tratado, essa diferença não foi estatisticamente significante (Figura 12A e 12C).

O TGF- $\beta 1$ é uma citocina supressora associada a melhora da resposta autoimune desenvolvida no DMT1. De forma interessante, níveis aumentados de TGF- $\beta 1$ biologicamente ativo puderam ser detectados no pâncreas de animais do grupo tratado comparando-se ao grupo não tratado $(6.183 \pm 184$ vs. $3.590 \pm 217$ pg/100mg de proteína total, $\mathrm{p}<0.001)$ e ao grupo normoglicêmico $(3.956 \pm 232 \mathrm{pg} / 100 \mathrm{mg}$ de proteína total, p<0.001) (Figure 12D). 
Figura 12 - Supressão da resposta imune Th1 e aumento da expressão de TGF- $\beta 1$ ativo no pâncreas após tratamento com ADMSC.

A)

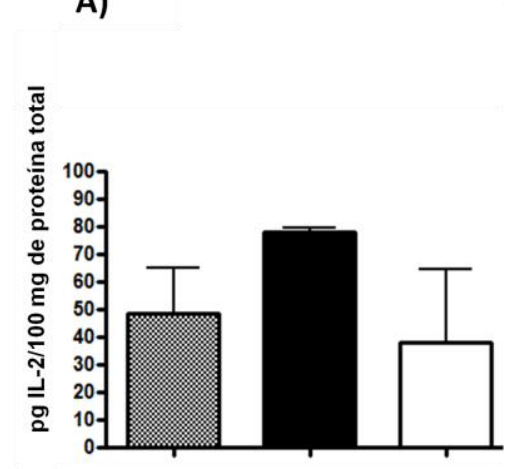

B)

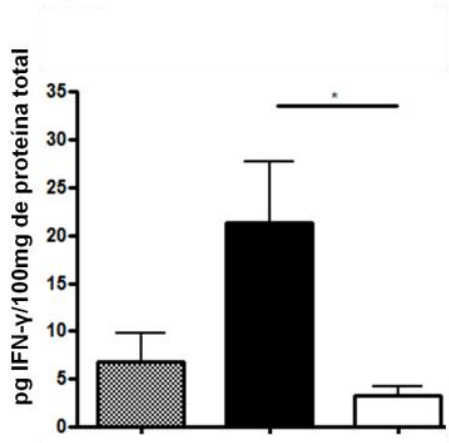

C)

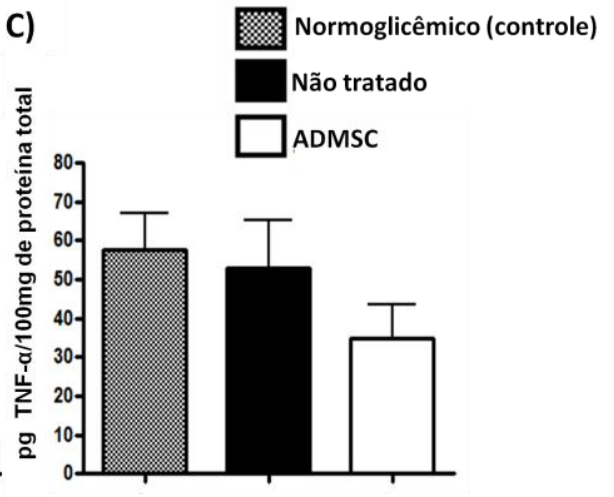

D)

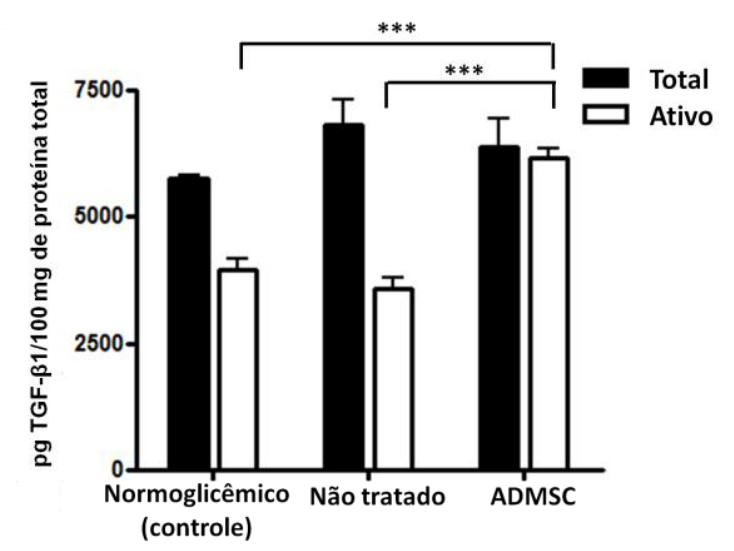

Os níveis de IL-2 (A), IFN- $\gamma$ (B) e TNF- $\alpha$ (C) foram quantificados no lisado pancreático tecidual. A normalização entre as amostras foi realizada pela quantificação de proteína total e os resultados foram expressos como nível de citocina (pg)/100 mg de proteína total. (D) TGF- $\beta 1$ total e biologicamente ativo no lisado pancreático tecidual quantificado pela metodologia de ELISA. Os resultados foram expressos como pg TGF- $\beta 1 / 100 \mathrm{mg}$ de proteína total (média \pm s.e.m.). ${ }^{*} \mathrm{p}<0.05,{ }^{* *} \mathrm{p}<0.01,{ }^{* * *} \mathrm{p}<0.001$.

Fonte: Bassi [144].

\subsection{0 "Homing" das ADMSCs após administração em camundongos NOD diabéticos}

Para o estudo do "homing" in vivo das ADMSCs, as células foram previamente marcadas com CFSE (Figura 13B) e administradas por via intraperitoneal em camundongos NOD fêmeas diabéticas. Após um período de 18 h e 72 h, a presença das células CFSE+ foi avaliada no baço, LPs e lavado peritoneal por citometria de fluxo, e no pâncreas, por imunofluorescência. 
Conforme mostrado na figura 13C, a presença das ADMSC (CFSE+) foi detectada somente no lavado peritoneal $18 \mathrm{~h}$ após a administração. No entanto, $72 \mathrm{~h}$ após a administração, as células puderam ser detectadas tanto no lavado peritoneal quanto nos LPs (Figura 13C). De forma interessante, as ADMSCs expressam os receptores de quimicionas CCR4 e CRR7, conforme mostrado na figura 13A, envolvidos com o homing para sítios inflamatórios e linfonodos, respectivamente.

Figura 13 - Expressão de CCR4 e CCR7 e "homing" das ADMSCs in vivo 18h e 72h após administração em camundongos NOD diabéticos.

A)
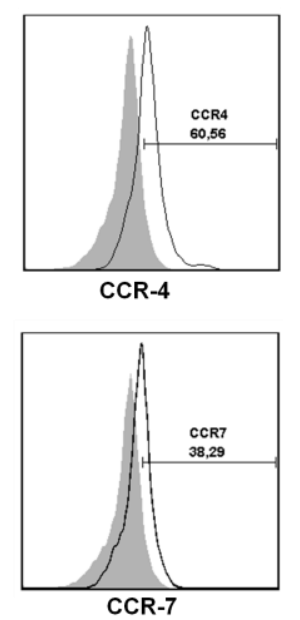

B)
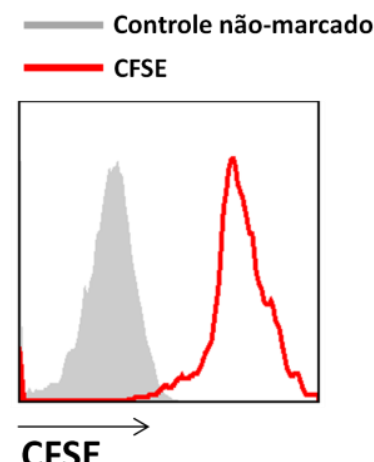

c)
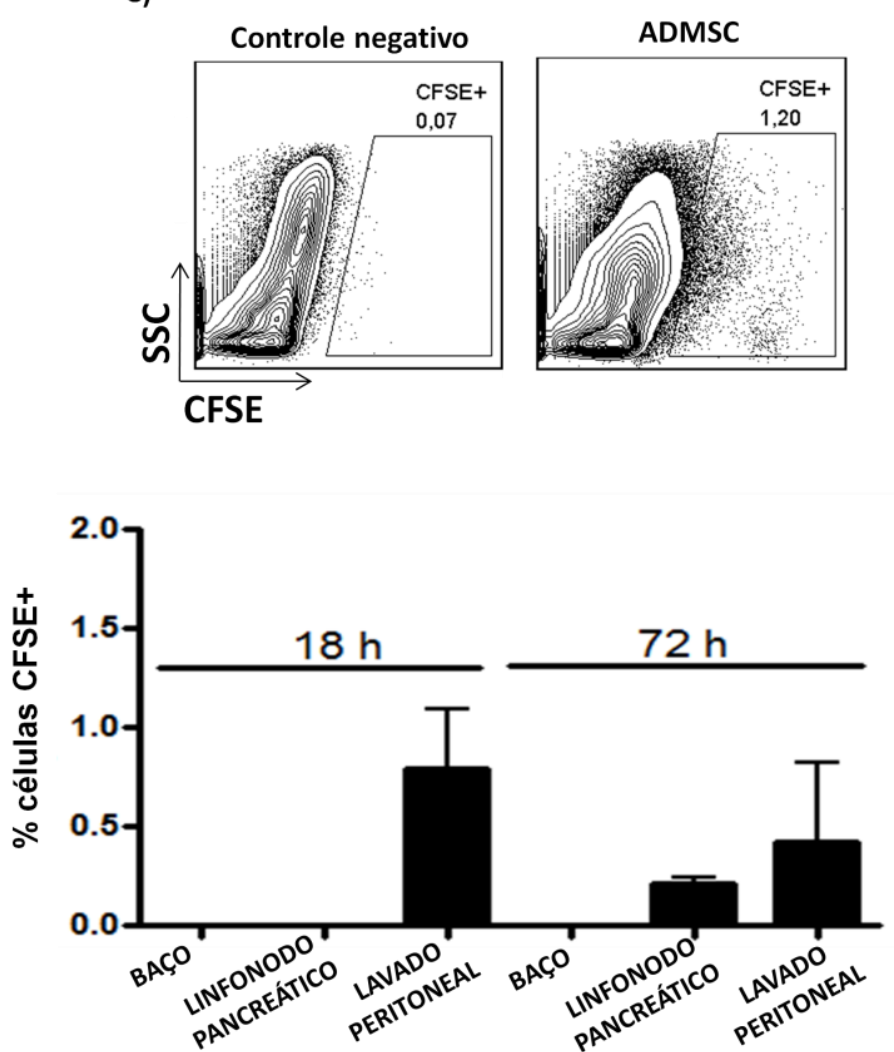

A) Expressão dos receptores de quimiocinas CCR4 e CCR7 nas ADMSCs verificado por citometria de fuxo. B) As ADMSC foram marcadas com CFSE e administradas i.p. em fêmeas NOD diabéticas. A frequência de células CFSE+ foi analisada no baço, linfonodos pancreáticos e lavado peritoneal $18 \mathrm{~h}$ e $72 \mathrm{~h}$ após a administração por citometria de fluxo. Foram adquiridos 500.000 eventos para cada amostra por meio do citômetro FACS Canto II. O baço, linfonodos e lavado peritoneal de camundongos NOD fêmeas não tratadas (PBS) foram utilizados como controle negativo.

Fonte: Bassi [144]. 
O pâncreas foi coletado e processado para confecção de cortes congelados (6 $\mu \mathrm{m}$ de espessura) em criostato para análise de imunofluorescência. Conforme mostrado na figura 14, a presença das ADMSCs (CFSE+) pode ser visualizada no pâncreas dos animais tratados $72 \mathrm{~h}$ após a administração. Assim, constatou-se que as ADMSCs puderam migrar para os LPs e pâncreas de animais diabéticos após a administração sistêmica por via intreaperitoneal.

Figura 14 - "Homing" das ADMSCs in vivo para o pâncreas 72h após administração em camundongos NOD diabéticos.

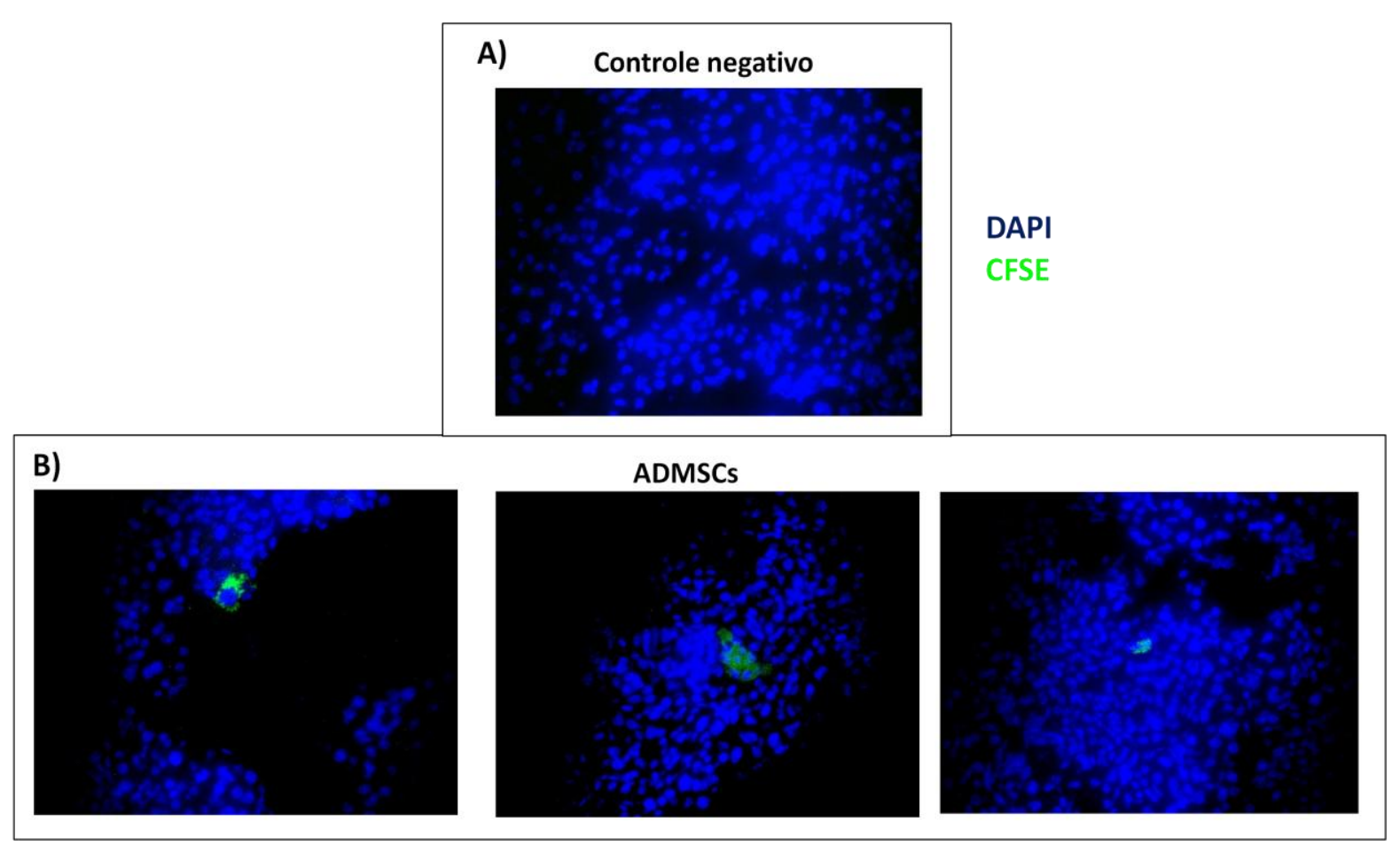

As ADMSC foram coradas com CFSE e administradas i.p. em fêmeas NOD diabéticas. A presença de células CFSE+ foi analisada no pâncreas dos animais $72 \mathrm{~h}$ após a administração pelo método de imunofluorescência. Amostras de pâncreas de camundongos NOD fêmeas não tratadas foram utilizadas como controle negativo. A coloração de DAPI (do inglês " 4 '-6diamidino-2-phenylindole") foi utilizada como contra-coloração para visualização do núcleo celular. A sobreposição de imagens (merge) foi realizada utilizando-se o software ImageJ versão 1.44. A) Controle negativo. B) Representação de diversos cortes histológicos de pâncreas obtidos do grupo de animais tratados com ADMSCs CFSE+. Aumento de 200 X. n= 3 animais/grupo experimental.

Fonte: Bassi [144]. 


\subsection{Expansão de células T reguladoras in vitro por ADMSCs}

Para o estudo das propriedades imunomoduladoras de expansão de células Tregs por ADMSCs in vitro, inicialmente a separação de linfócitos T CD4+ foi realizada a partir do baço e linfonodos de animais C57BL/6 Foxp3 GFP KI por meio de microesferas magnéticas. Além disso, para estudos de proliferação celular, as células foram marcadas com o Cell Trace Violet (Molecular Probes).

As células T CD4+ totais foram então co-cultivadas por 4 dias na presença ou ausência de ADMSCs. Conforme mostrado na figura 15, uma maior frequência de células T CD4+Foxp3+ e CD4+CD25+Foxp3+ foi observada após cultivo na presença das ADMSCs em uma maneira dose-dependente.

Figura 15 - Expansão de células T reguladoras in vitro por ADMSCs.

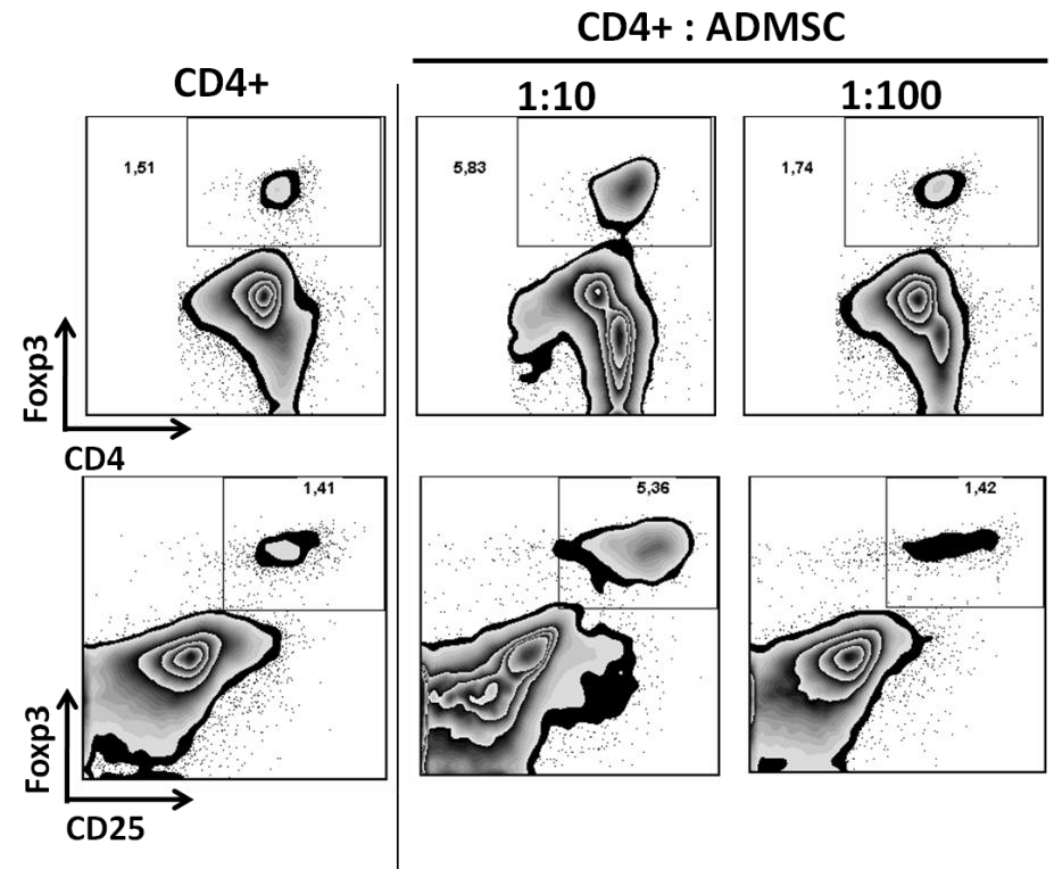

Co-cultivo de linfócitos T CD4+ com ADMSCs. As células T CD4+ foram cultivadas com diferentes quantidades de ADMSC na presença de IL-2 (50U/ml). Após um período de 4 dias, as células foram coletadas e analisadas por citometria de fluxo para determinação da frequência de células T CD4+Foxp3+ e CD4+CD25+Foxp3+. Density-plot representativo da frequência de células CD4+Foxp3+ e CD25+Foxp3+ no gate de linfócitos CD4+ de 1 de 3 experimentos independentes.

Fonte: Bassi [144]. 
Para avaliar se as células T CD4+Foxp3+ sofreram uma expansão/proliferação na presença de ADMSCs, a proliferação celular foi estudada utilizando-se o kit Cell Trace Violet. Assim, na presença das ADMSCs pôde-se verificar uma proliferação no gate de células T CD4+Foxp3+ e não de células T CD4+Foxp3- (Figura 16A e B), o que provavelmente tenha resultado no aumento da frequência dessas células, observada anteriormente.

Figura 16 - Proliferação de células T CD4+Foxp3+ in vitro na presença de ADMSCs.
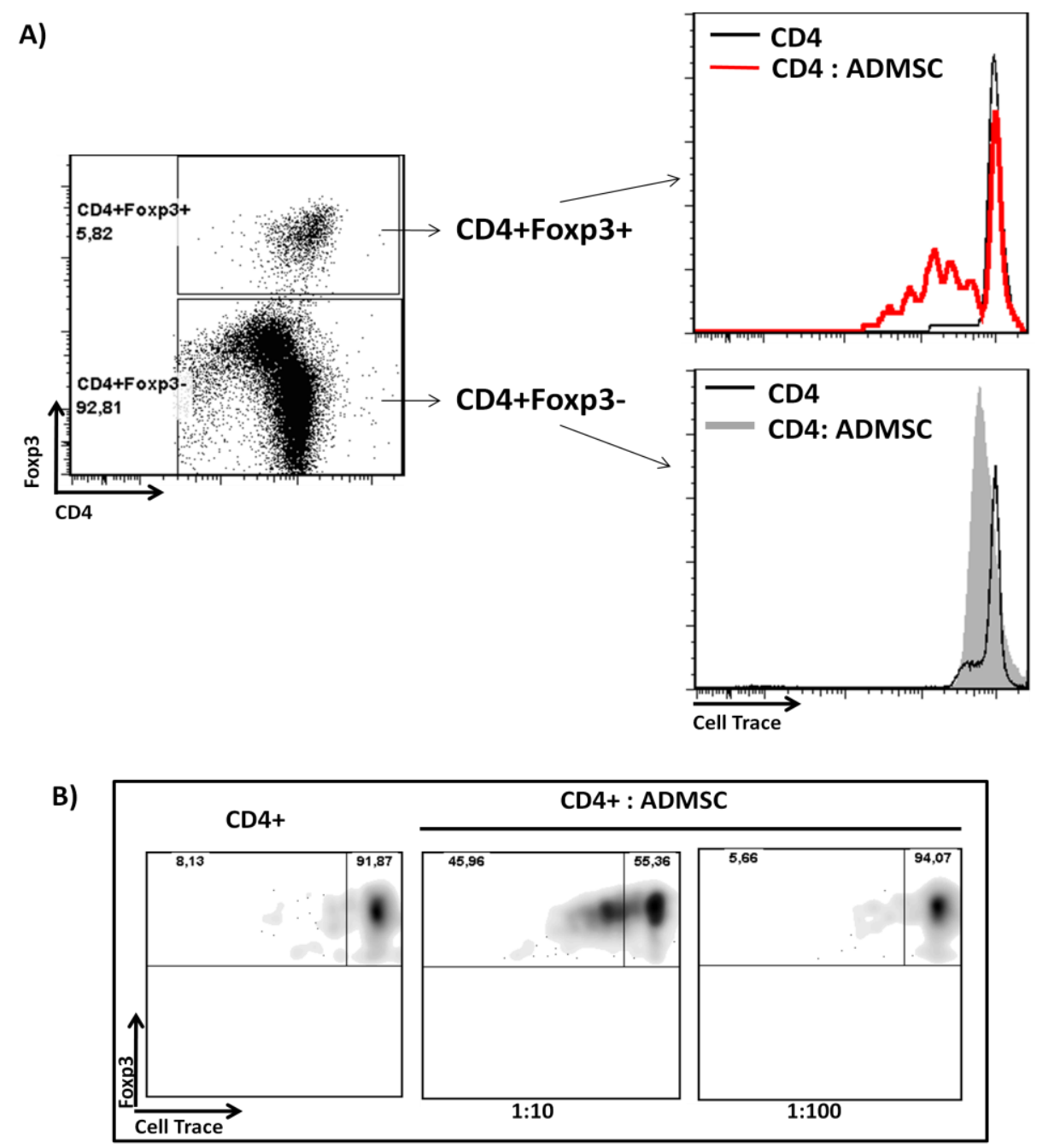

As células T CD4+ foram marcadas com o Cell Trace Violet para análise da proliferação celular e co-cultivadas com ADMSCs na proporção de 10 linfócitos : 1 ADMSCs na presença de IL-2, conforme descrito na metodologia. A) Na presença de ADMSCs, a proliferação/expansão de células T CD4+Foxp3+ e não de células T CD4+Foxp3- pode ser verificada por citometria de fluxo. B) Density-plot representativo da proliferação de células CD4+Foxp3+ no gate de células CD4+ de maneira dose-dependente.

Fonte: Bassi [144]. 
Devido a frequência de células T CD4+CD25+Foxp3+ ter sido aumentada na presença das ADMSCs, foi interessante avaliar a expansão/proliferação dessa população celular in vitro na presença das ADMSCs. Conforme mostrado na figura 17, uma maior frequência (Figura 17A) e proliferação (Figura 17B e 17C) de células T CD4+CD25+Foxp3+ pôde ser observada na condição em que as células T CD4+ foram co-cultivadas por 4 dias na presença de ADMSCs, de uma maneira dose-dependente.

Figura 17 - Expansão e proliferação de células T CD4+CD25+Foxp3+ após co-cultura com ADMSCs.
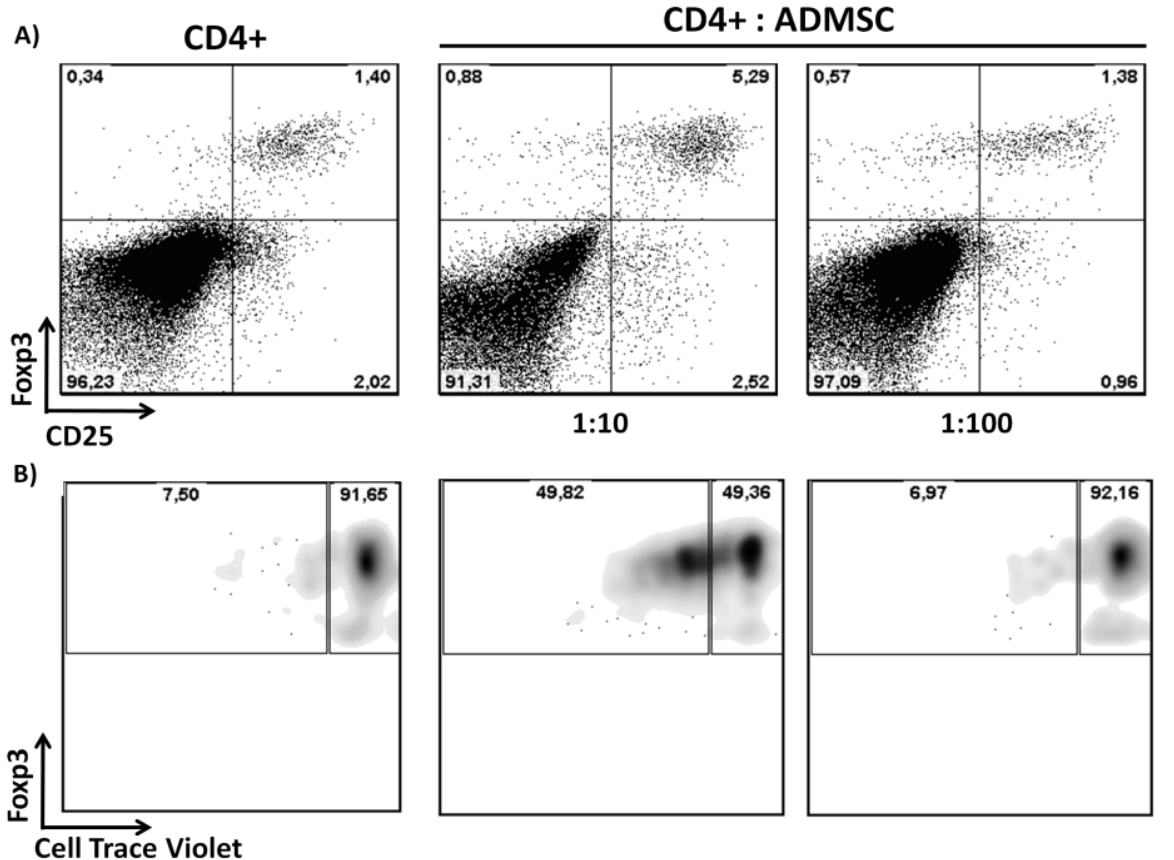

c)

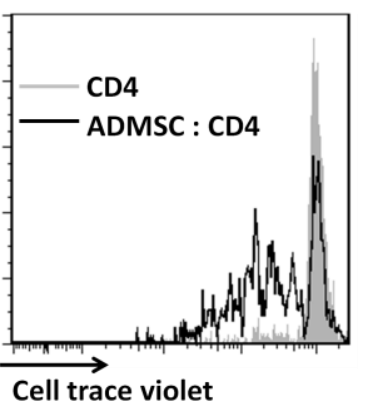

Cell trace violet

Células T CD4+ marcadas com Cell Trace Violet (Molecular Probes) foram co-cultivadas com diferentes quantidades de ADMSCs. A) Dot-plots representativos da freqüência de células CD4+CD25+Foxp3+ obtida após 4 dias de co-cultivo na presença ou ausência de ADMSCs. B) Análise da proliferação celular de células CD4+CD25+Foxp3+. Density-plot representativo da freqüência de células $\mathrm{CD} 4+\mathrm{CD} 25+$ Foxp3+ que proliferaram após 4 dias de co-cultivo com ADMSC. C) Histograma representativo da proliferação de células CD4+CD25+Foxp3+ cocultivadas por 4 dias na presença ou ausência de ADMSCs.

Fonte: Bassi [144]. 


\subsection{Papel do contato celular na expansão de células T CD4+CD25+Foxp3+ por ADMSCs}

Para investigar a importância do contato celular entre os linfócitos T CD4+e as ADMSCs no mecanismo de expansão/proliferação de células Tregs, as células foram separadas por uma membrana com microporos, evitando assim o contato entre as células (transwell). Assim, após 4 dias, uma maior frequência e proliferação de células T CD4+CD25+Foxp3+ foi verificada na condição em que as células foram mantidas em contato (Figura 18A, B e C). Por outro lado, quando as ADMSCs foram separadas dos linfócitos T CD4+ pelo sistema de transwell, uma menor frequência de células T CD4+CD25+Foxp3+ pode ser observada (Figura 18C), mostrando a importância do contato celular no mecanismo de expansão de Tregs in vitro. Além disso, os níveis de TGF- $\beta 1$ ativo foram significativamente maiores na condição em que as células foram co-cultivadas em contato, quando comparados tanto as condições de ausência das ADMSCs, como ao co-cultivo em transwell (Figura 18D). 
Figura 18 - Papel do contato celular e níveis de TGF- $\beta 1$ no mecanismo de expansão de células T CD4+CD25+Foxp3+ por ADMSC.
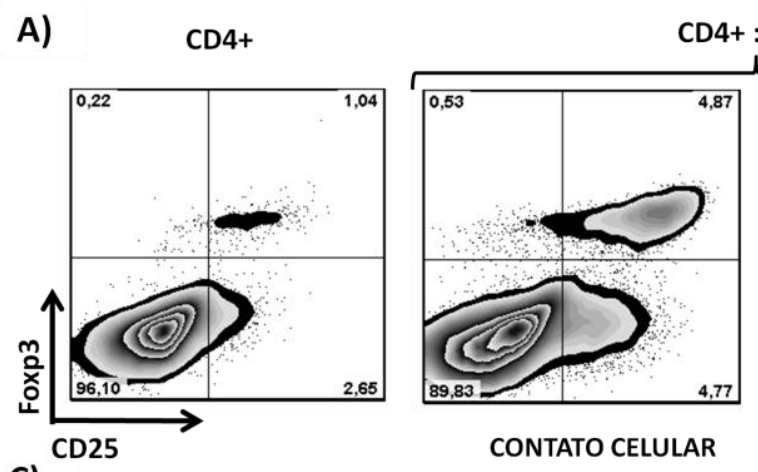

CONTATO CELULAR

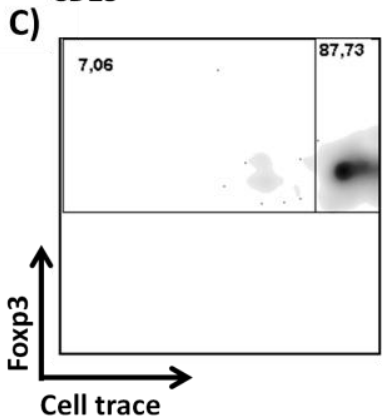

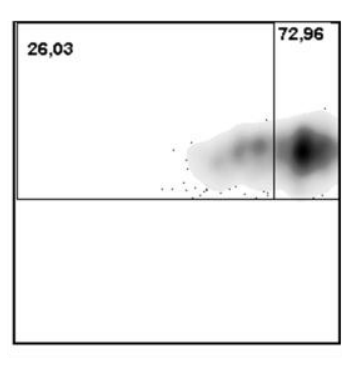

B)
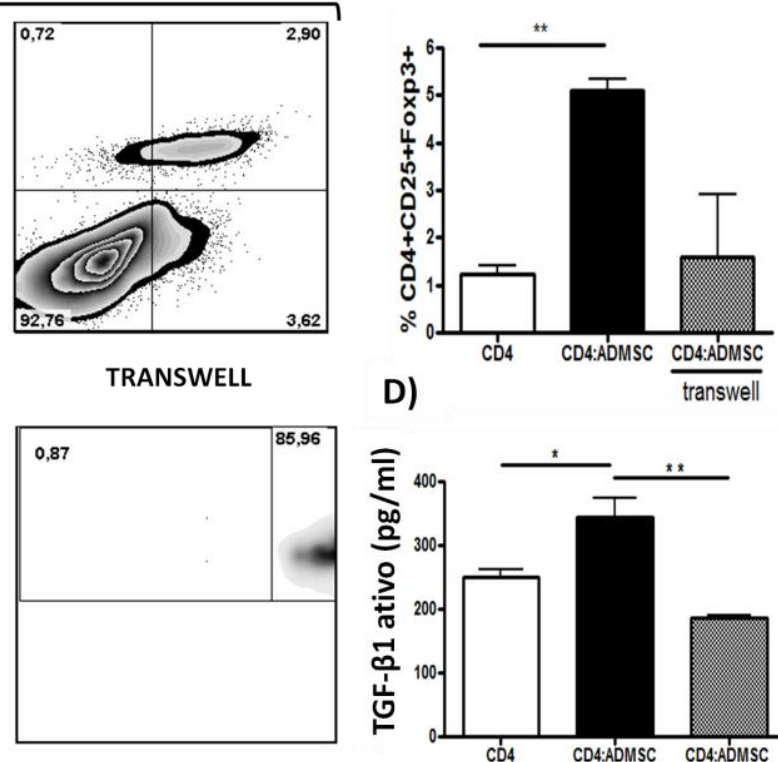

D)

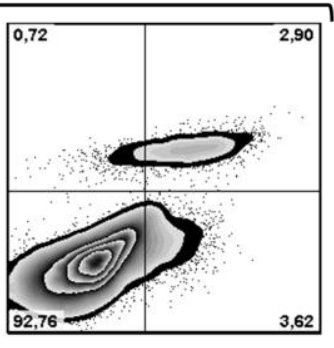

TRANSWELL

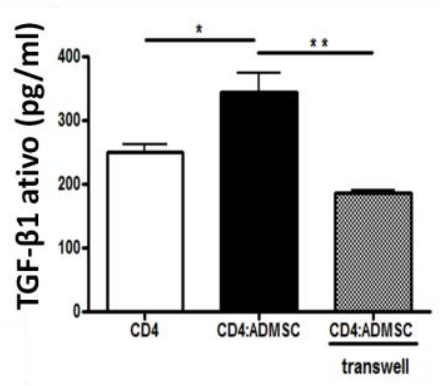

Células T CD4+ foram co-cultivadas com ADMSC por 4 dias na condição em contato célulacélula ou separadas por uma membrana de $3 \mu \mathrm{m}$ de diâmetro para evitar o contato entre linfócitos T CD4+ e ADMSC. A) Dot-plot representativo da frequência de células CD25+Foxp3+ no gate de células T CD4+. B) Gráfico representativo da frequência de células T CD4+CD25+Foxp3+ (média \pm s.e.m). C) Proliferação de células T CD4+CD25+Foxp3+ verificada por citometria de fluxo utilizando o kit Cell Trace Violet. D) Níveis de TGF- $\beta 1$ ativo quantificados por ELISA nos meios condicionados obtidos a partir das condições mostradas em A.

Fonte: Bassi [144].

\subsection{Expansão de células T CD4+CD25+Foxp3+ por ADMSCs em uma condição de estímulo alogênico}

A capacidade das ADMSCs expandirem células Tregs frente a um estímulo alogênico também foi investigada. Para isso, células apresentadoras de antígeno (APCs) (1,5 x $10^{5}$ células) foram isoladas a partir do baço de camundongos Balb/c SCID (do inglês "severe combined immune deficiency mutation") e co-cultivadas por 4 dias com linfócitos T CD4+ isolados de camundongos C57BL/6 Foxp3 GFP KI (1,5 x $10^{5}$ células) na presença ou ausência de ADMSCs (1,5 x $10^{4}$ células). Conforme 
mostrado na figura 19, a frequência de células CD4+CD25+ e CD4+CD25+Foxp3+ foi maior na presença de ADMSCs.

Figura 19 - Expansão de células T reguladoras por ADMSCs na condição de um estímulo alogênico.

APC Balb/SCID
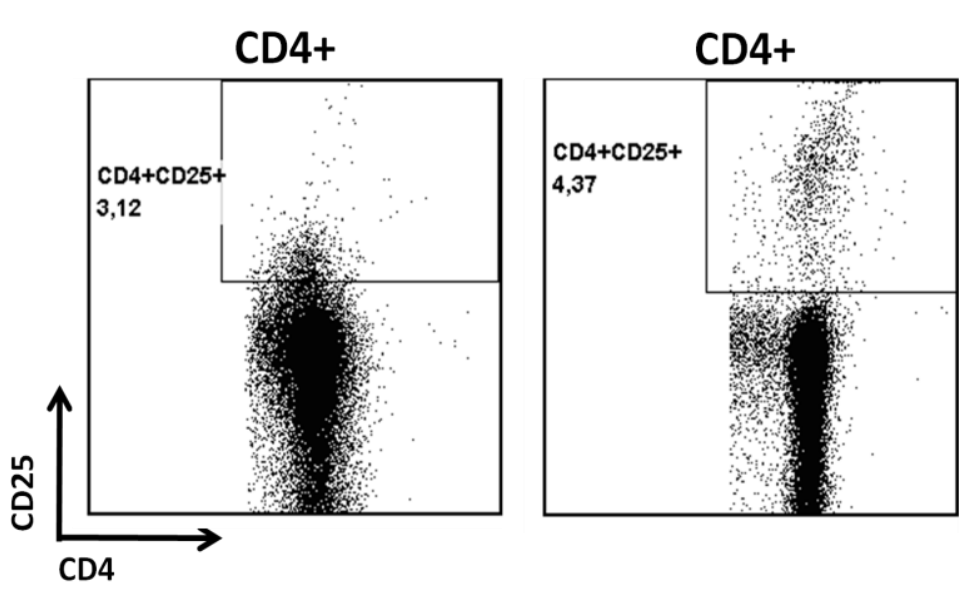

CD4+ : ADMSC (10:1)
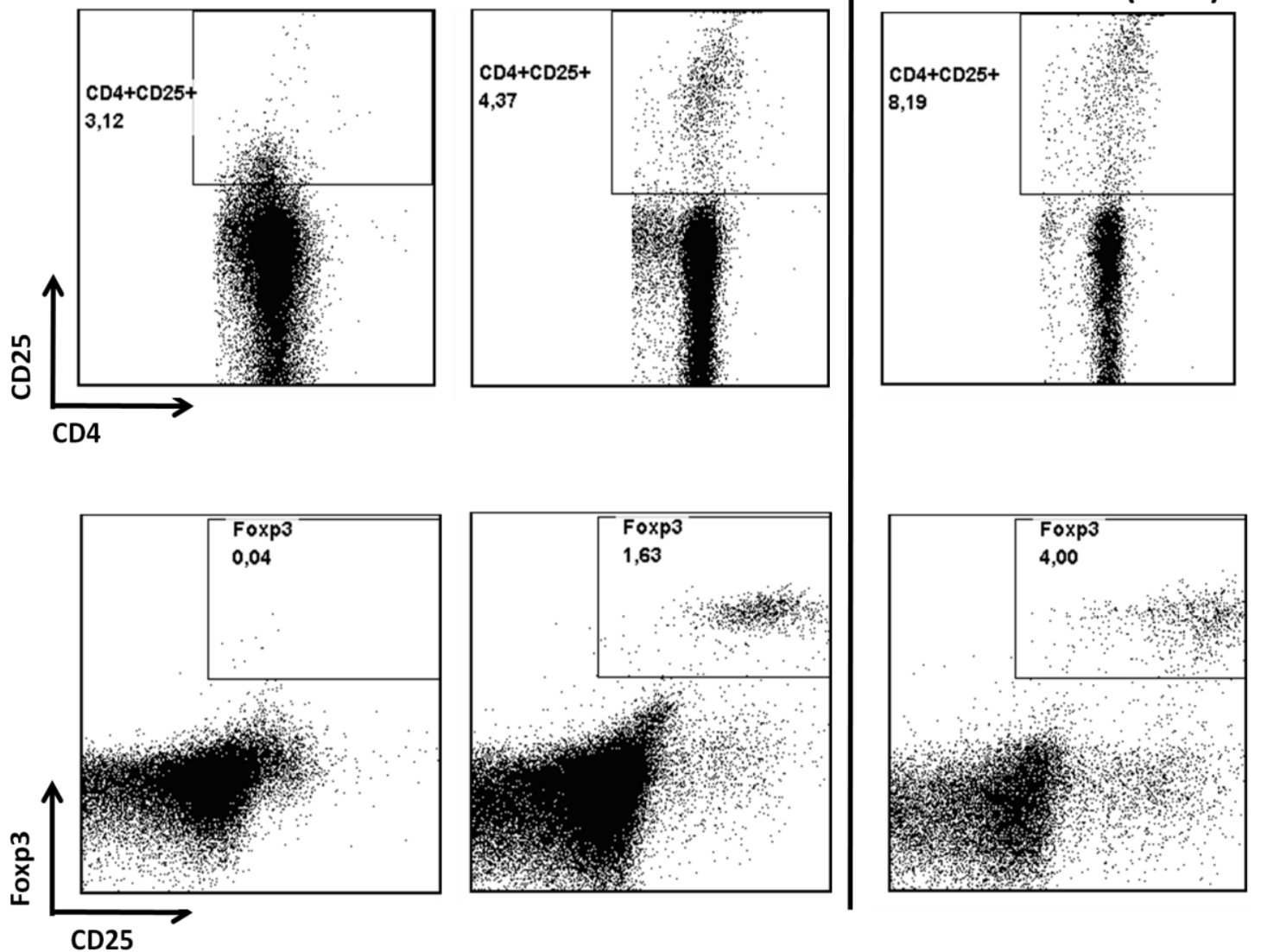

APCs de camundongos Balb/c SCID foram utilizadas como estímulo alogênico para linfócitos T CD4+ isolados de camundongos C57BL/6 Foxp3 GFP KI e co-cultivadas na presença ou ausência de ADMSC por 4 dias. Dot-plots representativos da frequência de células CD4+CD25+ e CD25+Foxp3+ no gate de células CD4+.

Fonte: Bassi [144].

Além disso, uma maior proliferação de célula T CD4+CD25+Foxp3+ na presença das ADMSCs frente a um estímulo alogênico (APC Balb/SCID) também foi observada (Figura 20) e níveis maiores de TGF- $\beta 1$ foram detectados, conforme mostrado na figura 20. 
Figura 20 - Análise da proliferação de células T CD4+CD25+Foxp3+ no co-cultivo de células T CD4+ e APCs alogênicas na presença ou ausência de ADMSCs.

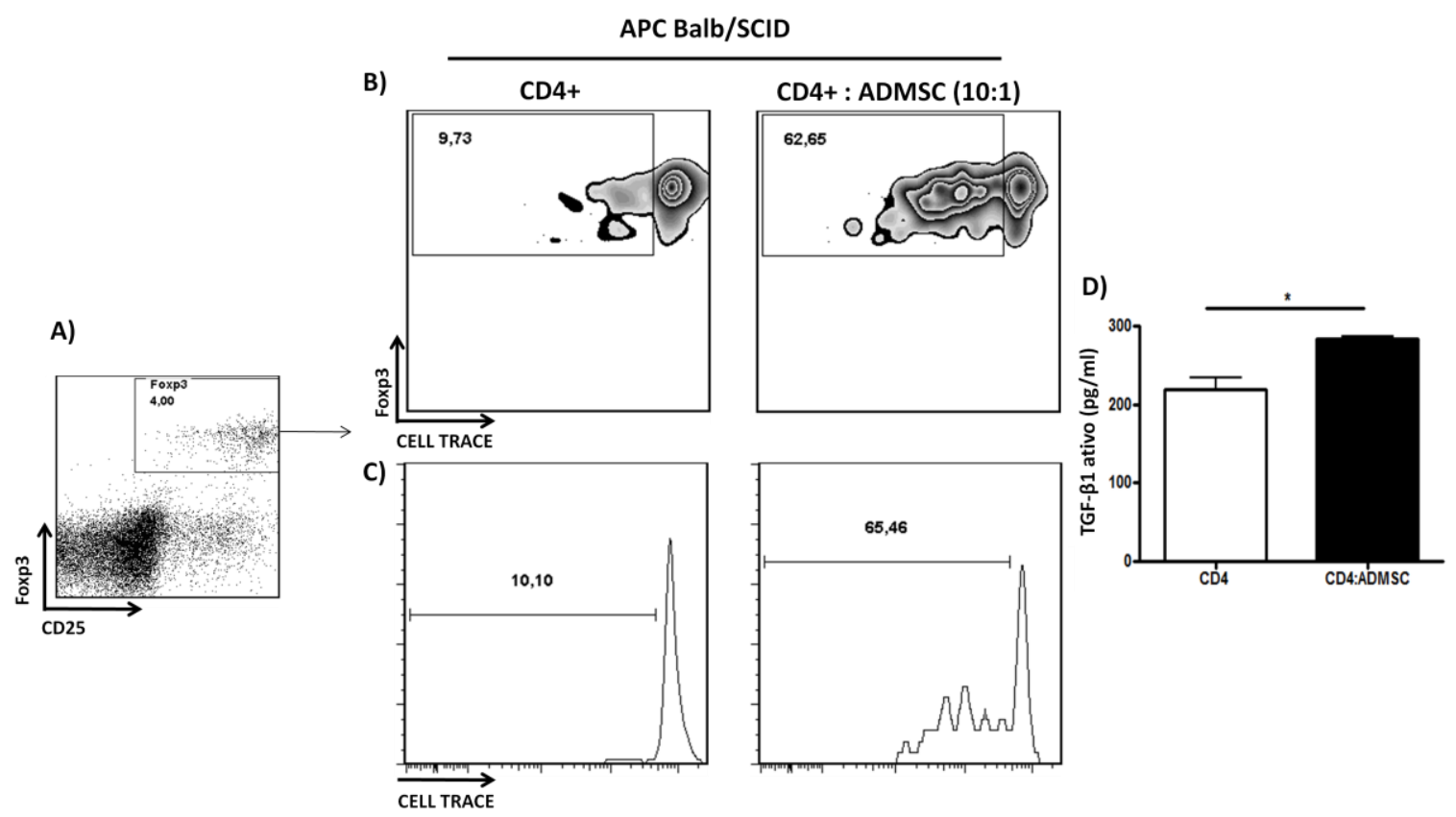

Células T CD4+ foram marcadas com Cell Trace Violet e co-cultivadas com APCs alogênicas por 4 dias na presença ou ausência de ADMSC. A) A proliferação de células CD25+Foxp3+ no gate de células CD4+ foi analisada por citometria de fluxo. B) Density-plot representativo da frequência (\%) de células CD4+CD25+Foxp3+ que proliferaram após 4 dias de cultivo. C) Histograma representativo da frequência de proliferação de células CD4+CD25+Foxp3+ na presença ou ausência de ADMSCs após 4 dias de cultivo frente a um estímulo alogênico. D) Detecção de TGF- $\beta 1$ ativo (pg/ml) por ELISA nos meios de cultura. Resultado expresso como média \pm s.e.m. $* \mathrm{p}<0,05$.

Fonte: Bassi [144].

\subsection{Expansão de células Tregs in vitro por ADMSCs é mediada pela molécula PD- L1}

Conforme mostrado previamente na figura 18, a expansão de células Tregs por ADMSCs in vitro foi parcialmente dependente do contato celular entre os linfócitos T CD4+ e as ADMSCs, sugerindo o papel de uma molécula de superfície envolvida neste mecanismo. Estudos recentes mostraram o papel da molécula coestimuladora PD-L1 no desenvolvimento, manutenção e função de células Tregs ao interagir com o receptor PD-1 presente nos linfócitos, principalmente em Tregs [148, 149]. Inicialmente, verificamos que as ADMSCs expressam PD-L1 em sua superfície (Figura 21A). Assim, a nossa hipótese foi que essa molécula poderia estar envolvida no mecanismo de expansão de células Tregs pelas ADMSCs in vitro. De forma 
interessante, o bloqueio dessa molécula, utilizando um anticorpo neutralizante para PD-L1 [140], pode inibir a expansão de células T CD4+Foxp3+ pelas ADMSCs (figura 21B e 21C) de uma maneira dose-dependente (Figura 22).

Figura 21 - ADMSCs promovem a expansão de células Tregs em um mecanismo dependente de PD-L1.

A)

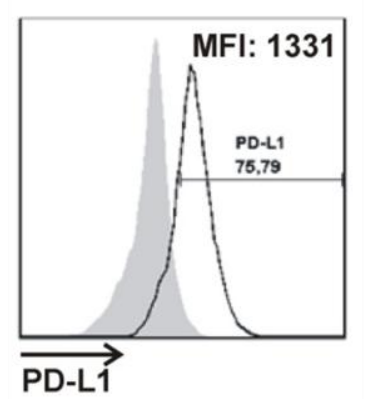

B)

CD4 : ADMSC
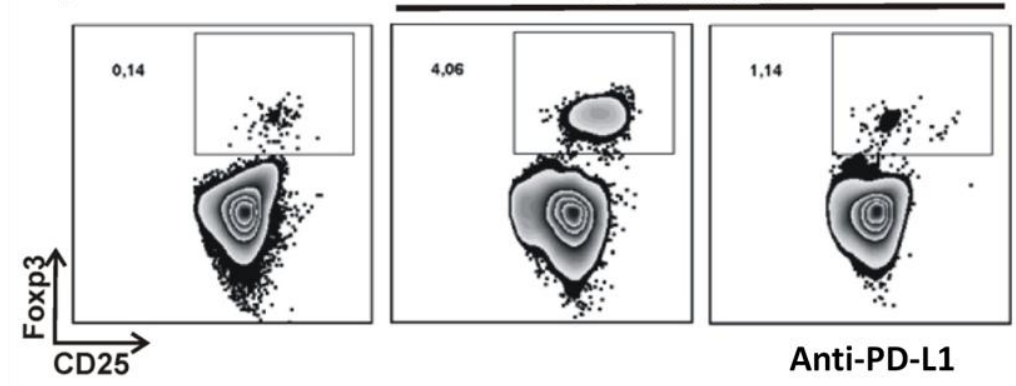

C)

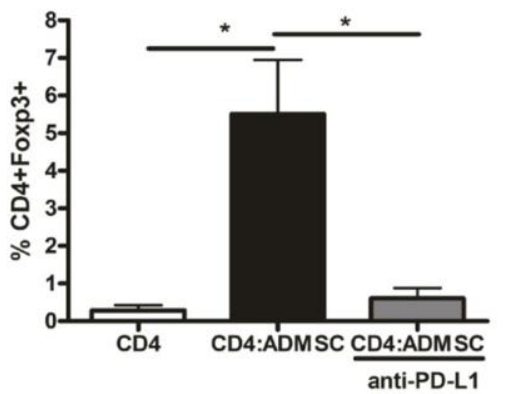

A) Expressão de PD-L1 por ADMSC. Histograma representativo da frequência de células positivas (\%) e da mediana da intensidade de fluorescência da molécula PD-L1 em ADMSCs. B) ADMSCs foram co-cultivadas com linfócitos $\mathrm{T}$ CD4+ na presença de anticorpos neutralizantes para PD-L1 (clone 10F.9G2) ou isotipo controle. Density-plot representativo da frequência de células CD4+Foxp3+ no gate de células CD4+ após 4 dias de co-cultivo. C) Gráfico da frequência de células CD4+Foxp3+ correspondente a 3 experimentos independentes (média \pm s.e.m.). ${ }^{*} \mathrm{p}<0,05$.

Fonte: Bassi [144]. 
Figura 22 - Bloqueio de PD-L1 reverte parcialmente a expansão de células Tregs por ADMSCs de uma maneira dose-dependente.
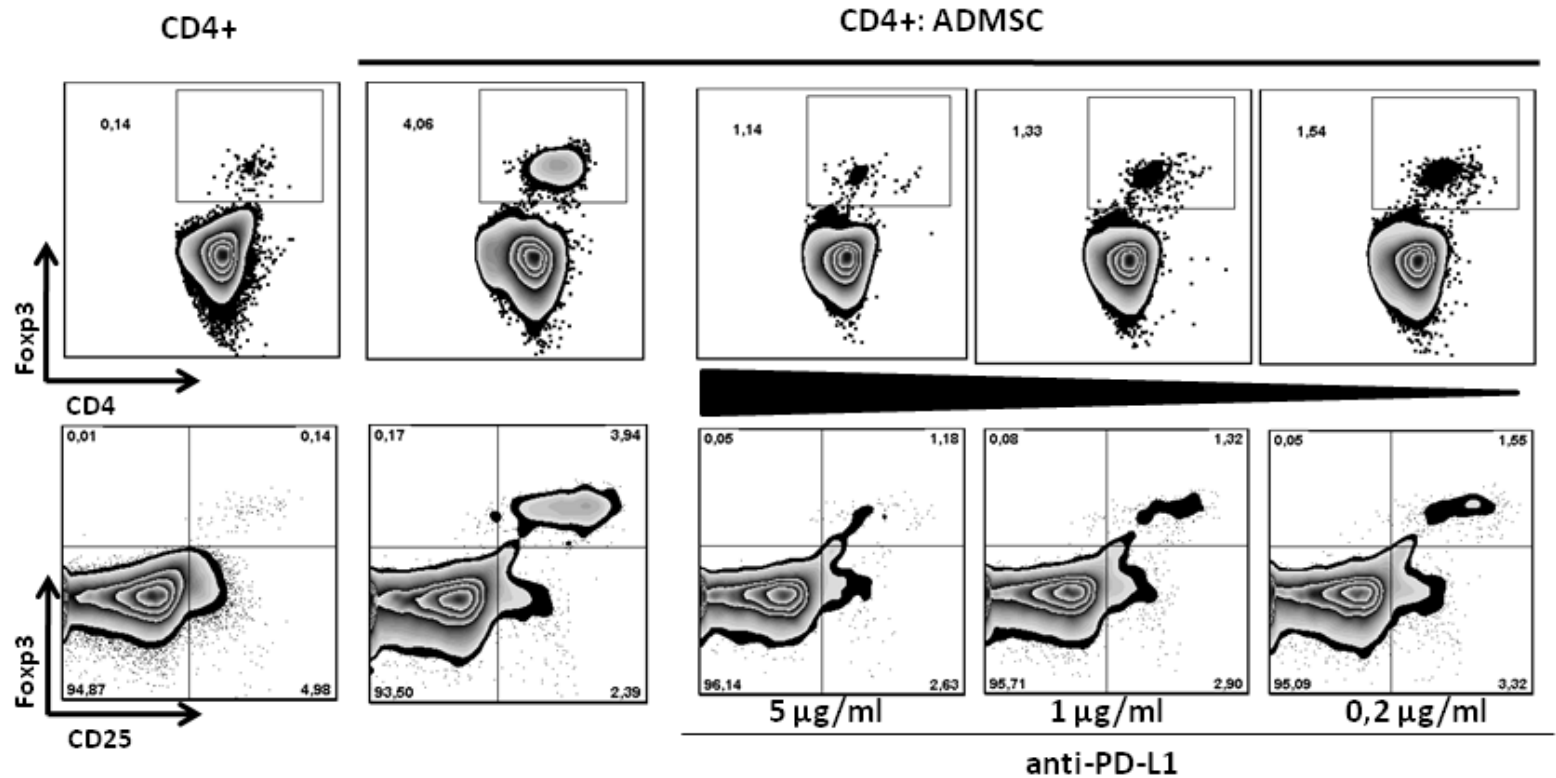

Células T CD4+ foram co-cultivadas com ADMSCs (10:1) na presença de diferentes concentrações (de 0,2 a $5 \mu \mathrm{g} / \mathrm{ml}$ ) do anticorpo anti-PD-L1 (clone 10F.9G2) ou isotipo controle. Density-plots representativos da frequência de células CD4+Foxp3+ e CD4+CD25+Foxp3+, respectivamente, analisados por citometria de fluxo após 4 dias de cultura celular in vitro. Fonte: Bassi [144].

\subsection{Conversão $x$ Expansão/manutenção de células CD4+Foxp3+ in vitro por ADMSCs}

Após verificar a expansão/proliferação de células T CD4+CD25+Foxp3+ a partir de linfócitos T CD4+ totais promovida por ADMSCs, foi interessante avaliar a possibilidade da geração/conversão de células Tregs a partir de células naïve (CD4+CD62L+Foxp3-) ou somente a expansão/manutenção dessas células por ADMSCs in vitro. A separação de células CD4+CD62L+Foxp3- e células $\mathrm{T}$ CD4+Foxp3+ de camundongos C56BL/6 Foxp3 GFP KI foi então realizada por "cell sorting" no equipamento FACS Aria II. A utilização dos linfócitos T CD4+ desse camundongo possibilitou a separação de células CD4+ GFP+ (ou Foxp3+) das células GFP- (ou Foxp3-). As células T CD4+62L+Foxp3- e CD4+Foxp3+ foram então cocultivadas com ADMSCs na proporção de 10:1, conforme mostrado na figura 23. 
Figura 23 - Co-cultivo de linfócitos T CD4+ com ADMSC.

A)

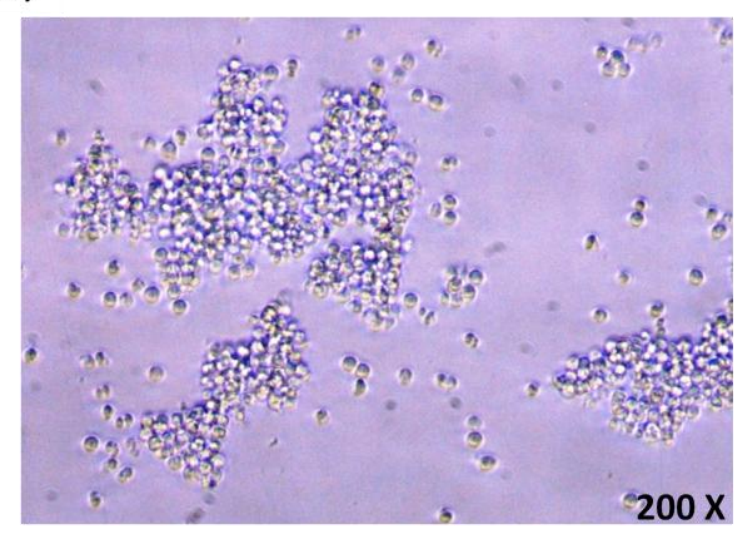

B)

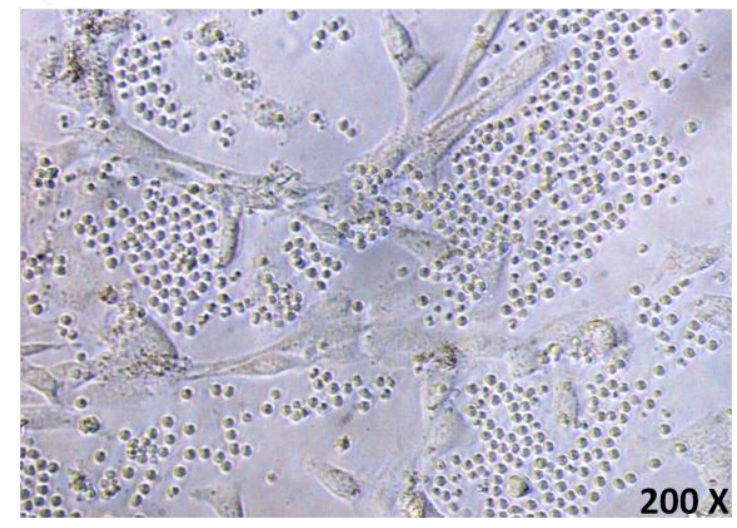

Microscopia óptica da co-cultura de linfócitos CD4+ com ADMSCs. A) Linfócitos T CD4+CD62L+Foxp3- 24h após separação celular em cultura. B) Linfócitos $\mathrm{T}$ CD4+CD62L+Foxp3- e ADMSCs após 24h de co-cultivo. Aumento de 200X.

Fonte: Bassi [144].

A capacidade das ADMSCs promoverem a conversão de células $\mathrm{T}$ CD4+CD62L+Foxp3- para células CD4+CD25+Foxp3+ foi então investigada. Para isso, células T CD4+CD62L+Foxp3- foram co-cultivadas com ADMSCs em diferentes condições: na presença de IL-2 (50 U/ml), frente a um estímulo alogenêico (APCs de Balb/SCID) ou estimuladas com anti-CD3 (1 $\mu \mathrm{g} / \mathrm{ml})$ (Figura 24). Após 4 dias de cocultivo, as células foram coletadas e analisadas por citometria de fluxo para determinar a frequência de células T CD4+CD25+Foxp3+ na presença ou ausência de ADMSCs. Conforme mostrado na figura 24, as ADMSCs não promoveram a conversão de células Foxp3- para células T CD4+CD25+Foxp3+ em nenhuma das condições avaliadas. Na presença do estímulo com anti-CD3, uma maior frequência de células T CD4+CD25+ foi observada (Figura 24), no entanto, essa população celular foi negativa para Foxp3. Assim, pôde-se concluir que as ADMSCs, nas condições estudadas, não promoveram a conversão de células CD4+CD62L+Foxp3para células CD4+CD25+Foxp3+. 
Figura 24 - Análise da conversão de células CD4+62L+Foxp3- em células CD4+CD25+Foxp3+ após o co-cultivo com ADMSCs.
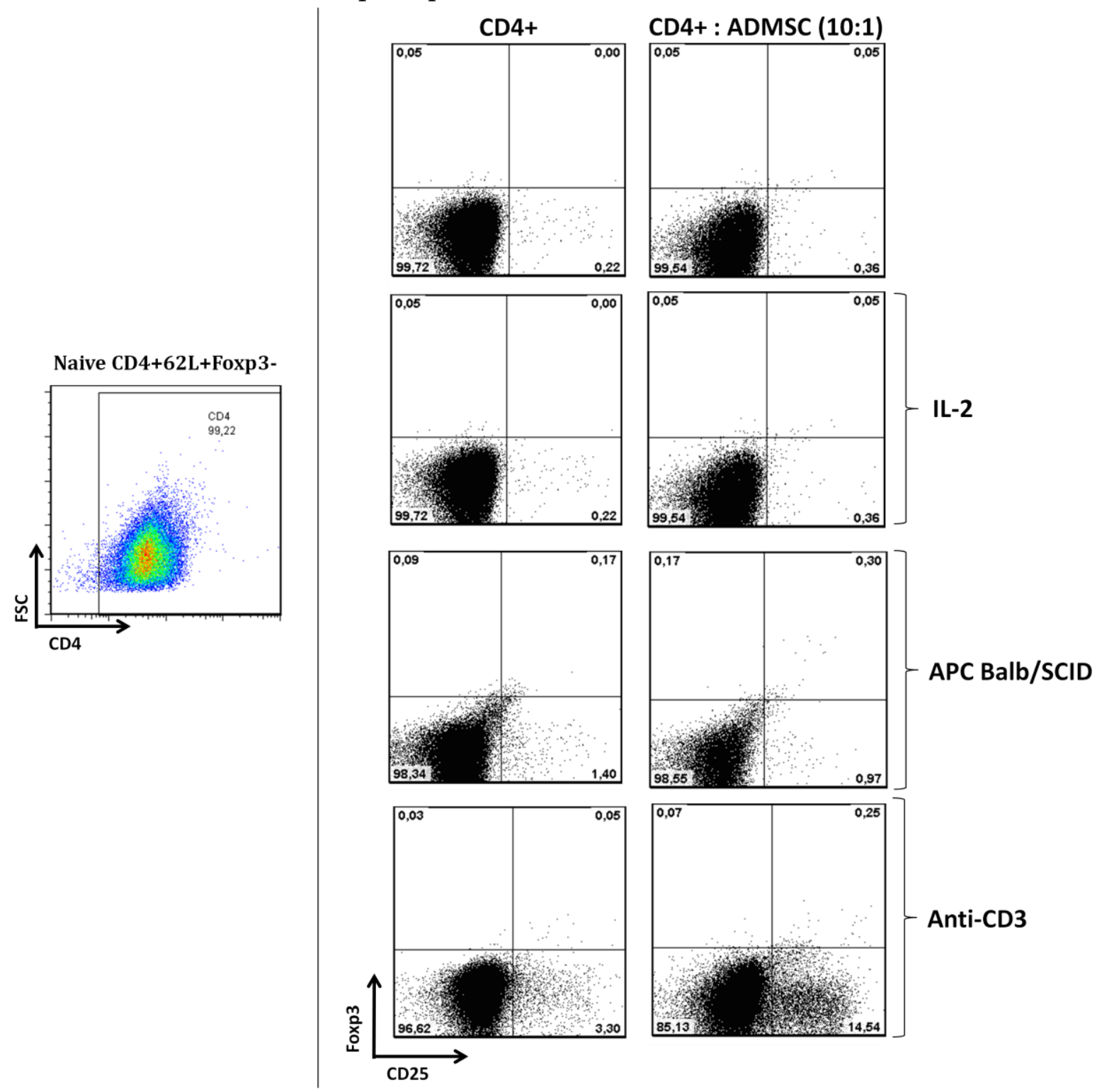

Células T naive CD4+CD62L+Foxp3- foram separadas a partir de linfócitos T CD4+ totais obtidos de camundongos C57BL/6 Foxp3 GFP KI por meio de FACS. As células foram então co-cultivadas com ADMSC na proporção de 10 linfócitos: 1 ADMSC por 4 dias na presença de IL-2 (50U/ml), estímulo alogênico (APC Balb/SCID) ou anti-CD3 por 4 dias. Esquerda: Dot-plot representativo da freqüência das células $\mathrm{CD} 4+$ após o processo de separação celular. Direita: co-cultivo de linfócitos T CD4+62L+Foxp3- e ADMSCs. Dot-plots representativos da freqüência de células T CD25+Foxp3+ no gate de células T CD4+ após 4 dias de co-cultivo com ADMSC. Resultado representativo de 1 experimento.

Fonte: Bassi [144]. 
A possibilidade de expansão/manutenção de células Tregs putativas a partir de uma população celular T CD4+Foxp3+ por ADMSCs, foi então investigada. Para isso, células T CD4+Foxp3+ foram separadas a partir de linfócitos T CD4+ totais pela metodologia de FACS utilizando o equipamento FACS Aria II. Após o processo de separação celular uma pureza maior que 99\% de células T CD4+Foxp3+ foi obtida. Como a IL-2 é uma citocina importante para sobrevivência e manutenção de células Tregs in vitro, avaliamos a expansão/manutenção de células T CD4+Foxp3+ a partir de uma população celular T CD4+Foxp3+ promovida pelas ADMSCs na presença desta citocina $(50 \mathrm{U} / \mathrm{ml})$. As células foram então co-cultivadas com ADMSCs na presença de IL-2, sendo a frequência de células $T$ CD4+Foxp3+ e $T$ CD4+CD25+Foxp3+ analisada após 4 dias, por citometria de fluxo. Conforme mostrado na figura 25A, as ADMSCs promoveram uma maior manutenção/expansão de células T CD4+Foxp3+e T CD4+CD25+Foxp3+. Além disso, níveis menores de IL-2 foram detectados na presença das ADMSCs (figura 25B), devido, provavelmente, ao maior consumo desta citocina pela maior frequência de células T CD4+CD25+Foxp3+ presentes (Figura 25A). Um aumento de IL-6 também foi observado na presença das ADMSCs (Figura 25B). 
Figura 25 - Análise da expansão/manutenção de células T CD4+CD25+Foxp3+ a partir de células Foxp3+ após co-cultivo com ADMSCs na presença de IL-2 (50U/ml).

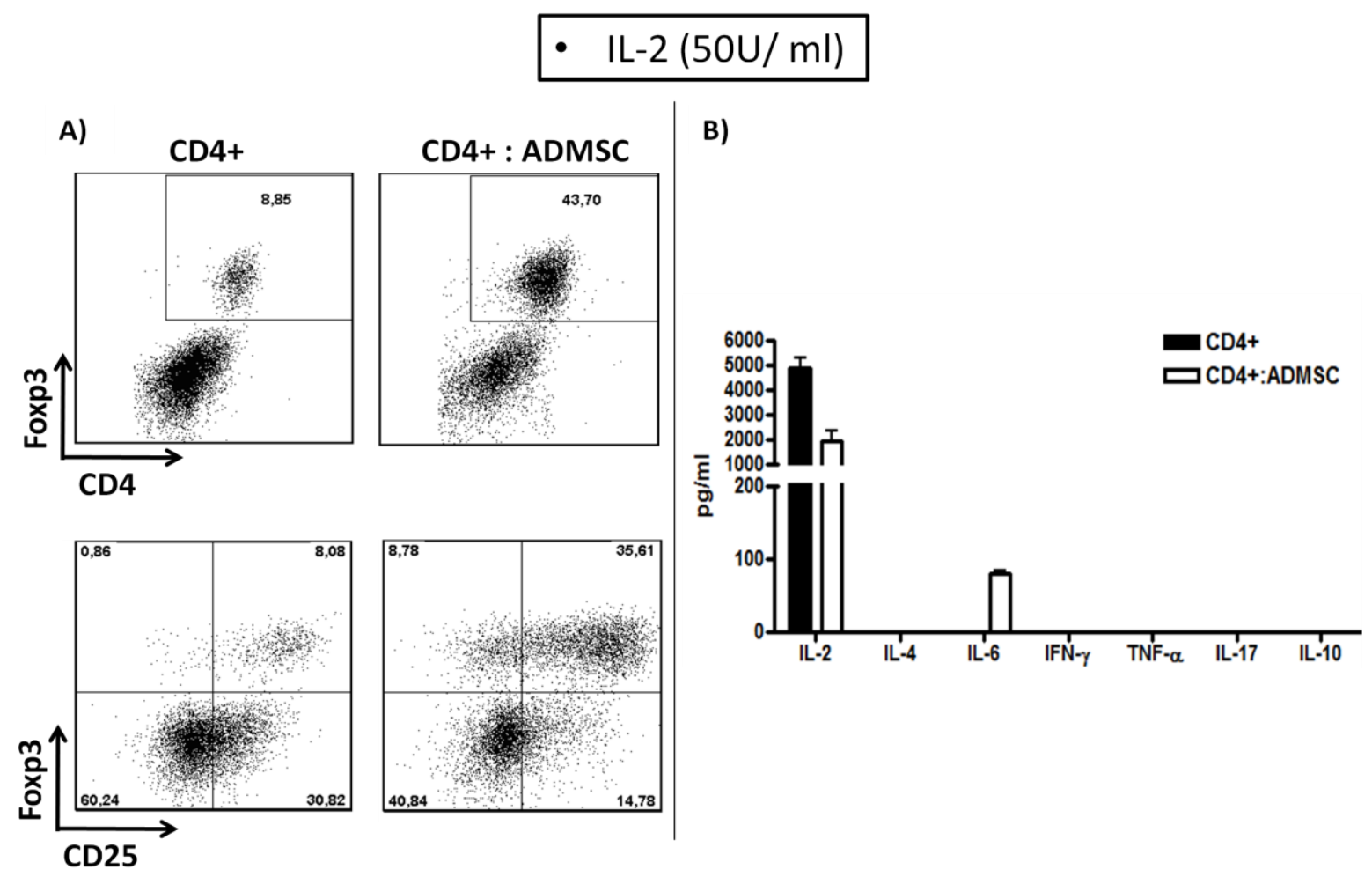

Células T CD4+Foxp3+ foram separadas a partir de linfócitos T CD4+ totais obtidos de camundongos C57BL/6 Foxp3 GFP KI. A) As células foram co-cultivadas com ADMSC e IL-2 $(50 \mathrm{U} / \mathrm{ml})$ por 4 dias sendo a freqüência de células T CD4+CD25+Foxp3+ analisada por citometria de fluxo. Resultado representativo de 2 experimentos independentes. B) Detecção de citocinas Th1/Th2/Th17 no meio de cultura pela metodologia de CBA (Cytometric bead array, BD Biosciences).

Fonte: Bassi [144].

Por meio desse experimento foi possível concluir que as ADMSCs puderam atuar na manutenção/expansão de células T CD4+Foxp3+, contribuindo para elucidar o mecanismo de ação dessas células sobre células Tregs in vitro. No entanto, as ADMSCs não promoveram a conversão de células T CD4+Foxp3+ a partir de células CD4+CD62L+Foxp3- nas condições e períodos de co-cultivo estudados.

Para avaliar o papel de PD-L1 no efeito das ADMSCs sobre a subpopulação de células T CD4+Foxp3+, realizamos um co-cultivo dessas células com ADMSCs por 4 dias na presença ou ausência de um anticorpo neutralizante para PD-L1. Conforme 
mostrado na figura 26, o bloqueio de PD-L1 reverteu parcialmente a manutenção/expansão de células T CD4+Foxp3+ e CD4+CD25+Foxp3+ promovido pelas ADMSCs.

Figura 26 - Papel da molécula PD-L1 no mecanismo de manutenção/expansão da subpopulação de células CD4+Foxp3+ por ADMSCs.
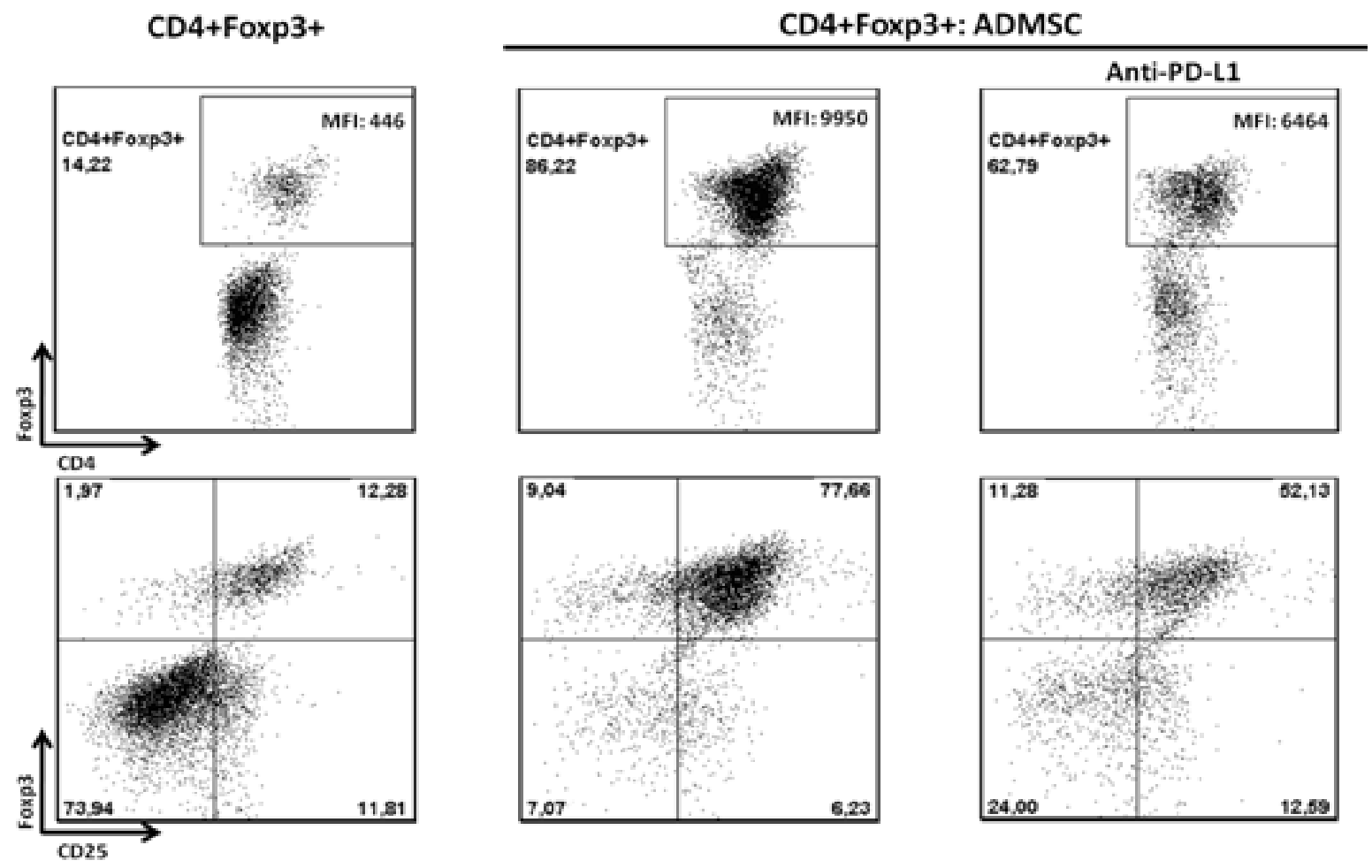

Células T CD4+Foxp3+ foram separadas a partir de linfócitos T CD4+ totais obtidos de camundongos C57BL/6 Foxp3 GFP KI. A) As células foram co-cultivadas com ADMSC e IL-2 $(50 \mathrm{U} / \mathrm{ml})$ na presença do anticorpo anti-PD-L1 sendo a freqüência de células T CD4+Foxp3+e CD4+CD25+Foxp3+ analisada por citometria de fluxo após 4 dias. Dot-plots representativos da frequência de células CD4+Foxp3+ e CD4+CD25+Foxp3+ no gate de linfócitos CD4+. MFI: mediana da intensidade de fluorescência de Foxp3 (GFP+).

Fonte: Bassi [144].

\subsection{ADMSCs promovem a atenuação da hiperglicemia em camundongos NOD recém-diabéticos por um longo período de tempo após o tratamento}

Para avaliar a manutenção do efeito terapêutico da reversão da hiperglicemia após o desenvolvimento recente do diabetes autoimune experimental, camundongos NOD recém-diabéticos foram tratados com ADMSCs e avaliados por um período de 
12 semanas após o tratamento. Conforme mostrado na figura 27, todos os camundongos do grupo controle permaneceram hiperglicêmicos durante todo o período analisado. Por outro lado, no grupo tratado, a reversão da hiperglicemia pode ser mantida por até 8 semanas em $78 \%$ dos animais tratados com ADMSCs (Figura 27). Além disso, a média da glicemia nos animais que responderam ao tratamento foi reduzida significativamente quando comparada ao grupo não tratado, conforme mostrado na figura 27B.

Figura 27 - Terapia com ADMSCs promove a reversão da hiperglicemia em camundongos NOD recém-diabéticos.
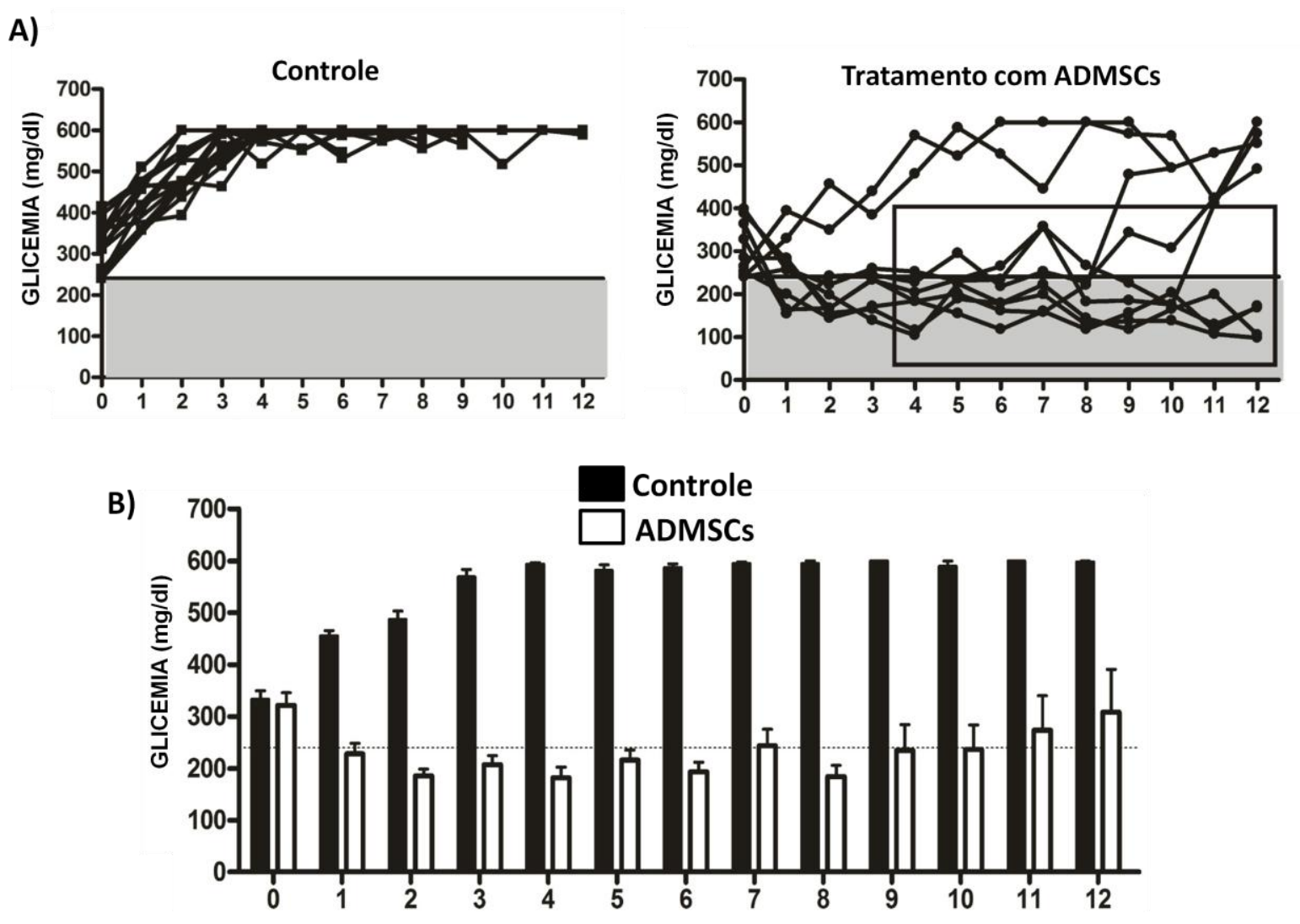

ADMSCs foram administradas intraperitonealmente em camundongos NOD fêmeas diabéticas nos dias 0,7 e 14 . A) Os níveis de glicemia $(\mathrm{mg} / \mathrm{dl})$ foram determinados semanalmente na ausência de jejum durante 12 semanas após a primeira administração de ADMSCs. A reversão da hiperglicemia pode ser mantida por até 8 semanas após o tratamento em $78 \%$ (7 de 9) dos animais tratados. B) Média \pm s.e.m. da glicemia (mg/dl) dos animais que responderam ao tratamento comparado ao grupo não tratado determinada semanalmente.

Fonte: Bassi [144]. 
A insulite nas ilhotas pancreáticas no pâncreas dos animais também foi avaliada 12 semanas após o tratamento. No grupo tratado com ADMSCs, foi observada uma diminuição no infiltrado celular inflamatório presente nas ilhotas pancreáticas quando comparado ao grupo controle (Figura 28A). Além disso, uma maior expressão de insulina pode ser detectada por imunohistoquímica nos animais que responderam ao tratamento, indicando a manutenção de ilhotas funcionais 12 semanas após o tratamento com ADMSCs.

Figura 28 - Infiltrado celular inflamatório e a expressão de insulina nas ilhotas pancreáticas de camundongos NOD 12 semanas após o tratamento com ADMSCs.

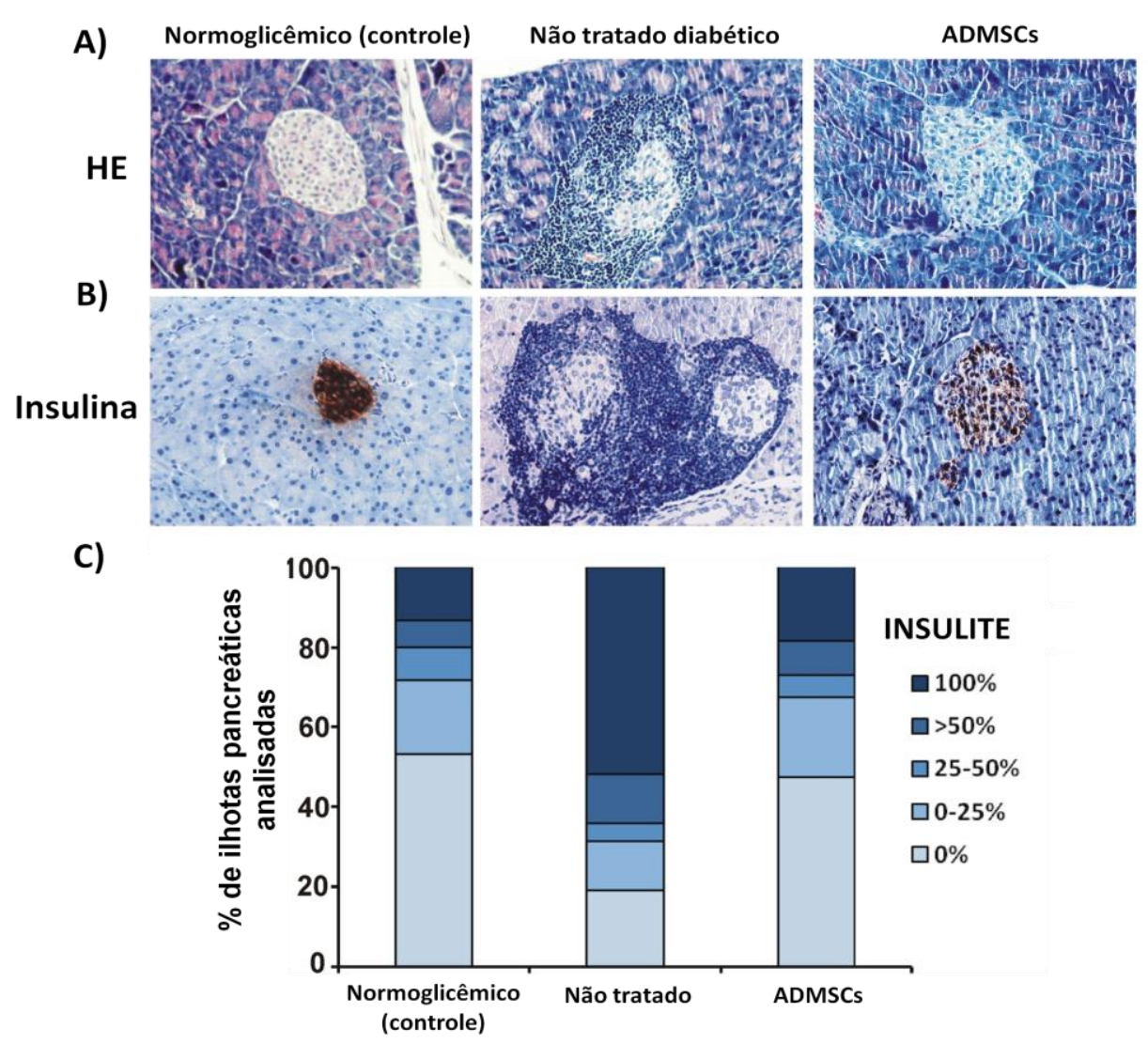

A) Análise histológica das ilhotas pancreáticas por hematoxilina-eosina (HE). B) Imunohistoquímica para insulina. Aumento de 200X. C) Quantificação do infiltrado celular inflamatório (escore de insulite) nas ilhotas pancreáticas. A quantificação da insulite foi determinada pela análise de aproximadamente 80 ilhotas/grupo experimental, de acordo com a classificação: 0 (ausência de insulite), 0-25 (peri-insulite), 25-50, >50 e 100\% de insulite em cada ilhota pancreática. $n=5 /$ grupo experimental.

Fonte: Bassi [144]. 


\subsection{Terapia com ADMSCs aumenta a frequência de células Tregs nos LPs 12 semanas após o tratamento}

Devido aos animais que responderam ao tratamento com ADMSCs apresentarem uma diminuição na insulite e uma manutenção de ilhotas pancreáticas funcionais foi interessante verificar a possibilidade de um aumento na frequência das células Tregs 12 semanas após o tratamento com ADMSCs. Conforme mostrado na figura 29, um aumento significativo na frequência de células T CD4+Foxp3+ pode ser observado no grupo tratado com ADMSC quando comparado ao grupo não tratado $(29.74 \% \pm 4.14$ vs. $14,74 \% \pm 0,72$, respectivamente; $\mathrm{p}<0,01)$. Além disso, conforme mostrado na figura 29C, uma maior frequência de células T CD4+CD25+Foxp3+ também foi observada no grupo tratado $(21,79 \% \pm 2,35)$ quando comparada tanto ao grupo não tratado $(11,13 \% \pm 0,59 ; \mathrm{p}<0,01)$ quanto ao grupo controle normoglicêmico $(14,10 \% \pm 1,80 ; \mathrm{p}<0,05)$. 
Figura 29 - Terapia com ADMSCs aumenta a frequência de células T CD4+Foxp3+e CD4+CD25+Foxp3+ nos LPs 12 semanas após o tratamento.

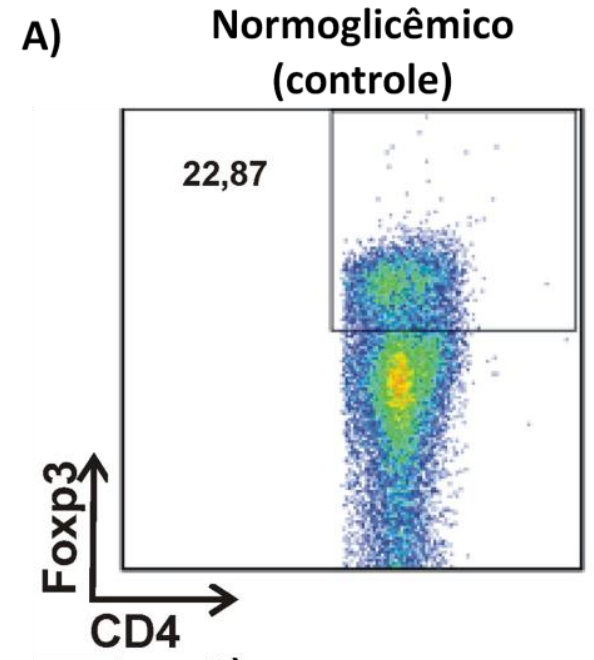

B)

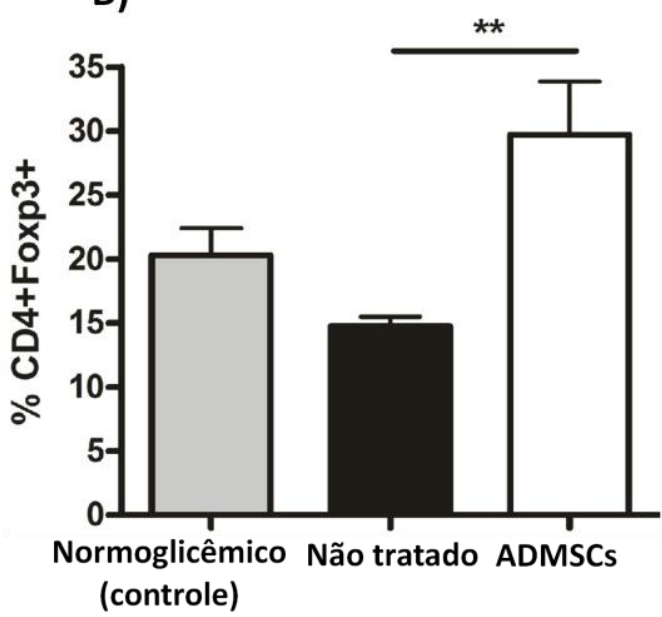

Não tratado

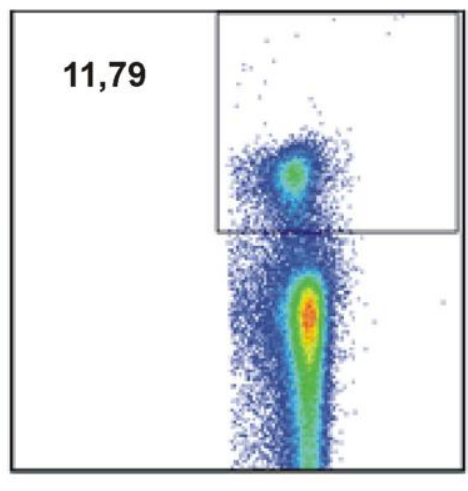

C)
ADMSCs

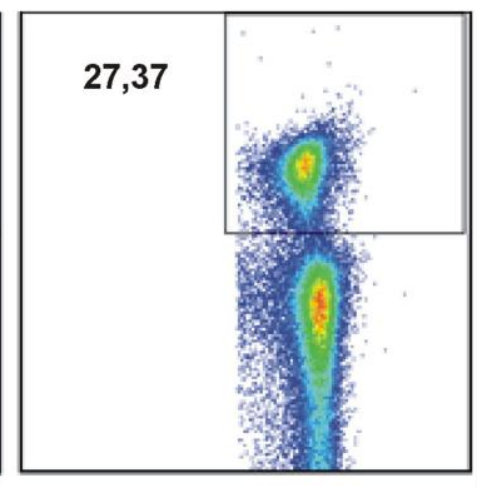

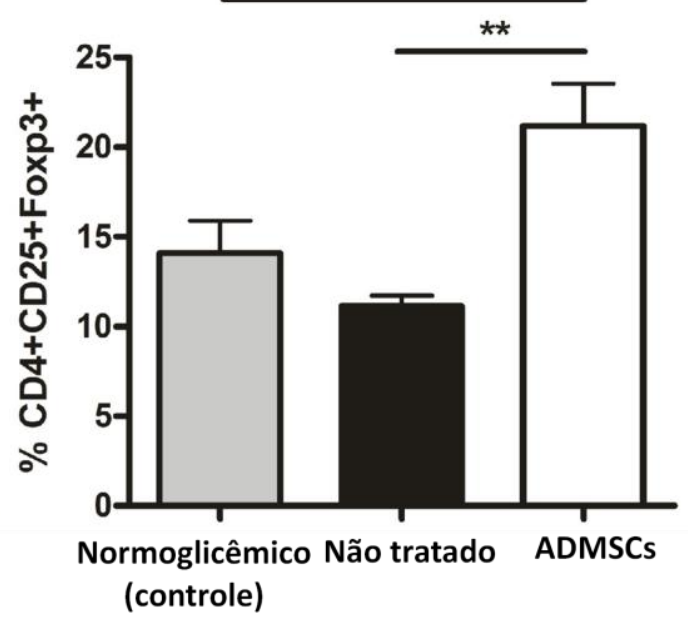

A frequência de células T CD4+Foxp3+e T CD4+CD25+Foxp3+ nos LPs foi determinada por citometria de fluxo 12 semanas após o tratamento com ADMSC. A) Dot-plot representativo da frequência de células T CD4+Foxp3+. B e C) Gráficos representativos da frequência de células T CD4+Foxp3+ e T CD4+CD25+Foxp3+, respectivamente (média \pm s.e.m.). n=5/grupo experimental. ${ }^{*} \mathrm{p}<0,05 .{ }^{* *} \mathrm{p}<0,001$.

Fonte: Bassi [144].

Recentemente, o fator de transcrição Helios tem sido sugerido como um potencial marcador para células Tregs naturais timo-derivadas, devido à ausência deste marcador em células Tregs Foxp3+ induzidas [150]. Assim, avaliamos a presença deste marcador nas células T CD4+Foxp3+ após o tratamento com ADMSCs. De forma interessante, uma maior frequência de células $T$ CD4+Foxp3+Helios+ foi observada 12 semanas após o tratamento com ADMSCs 
(Figura 20), indicando que as células Tregs Foxp3+ que aumentaram nos LPs dos animais que responderam ao tratamento seriam principalmente células Tregs naturais.

Figura 30 - Aumento da frequência de células Tregs CD4+Foxp3+Helios+ nos LPs 12 semanas após o tratamento com ADMSCs.
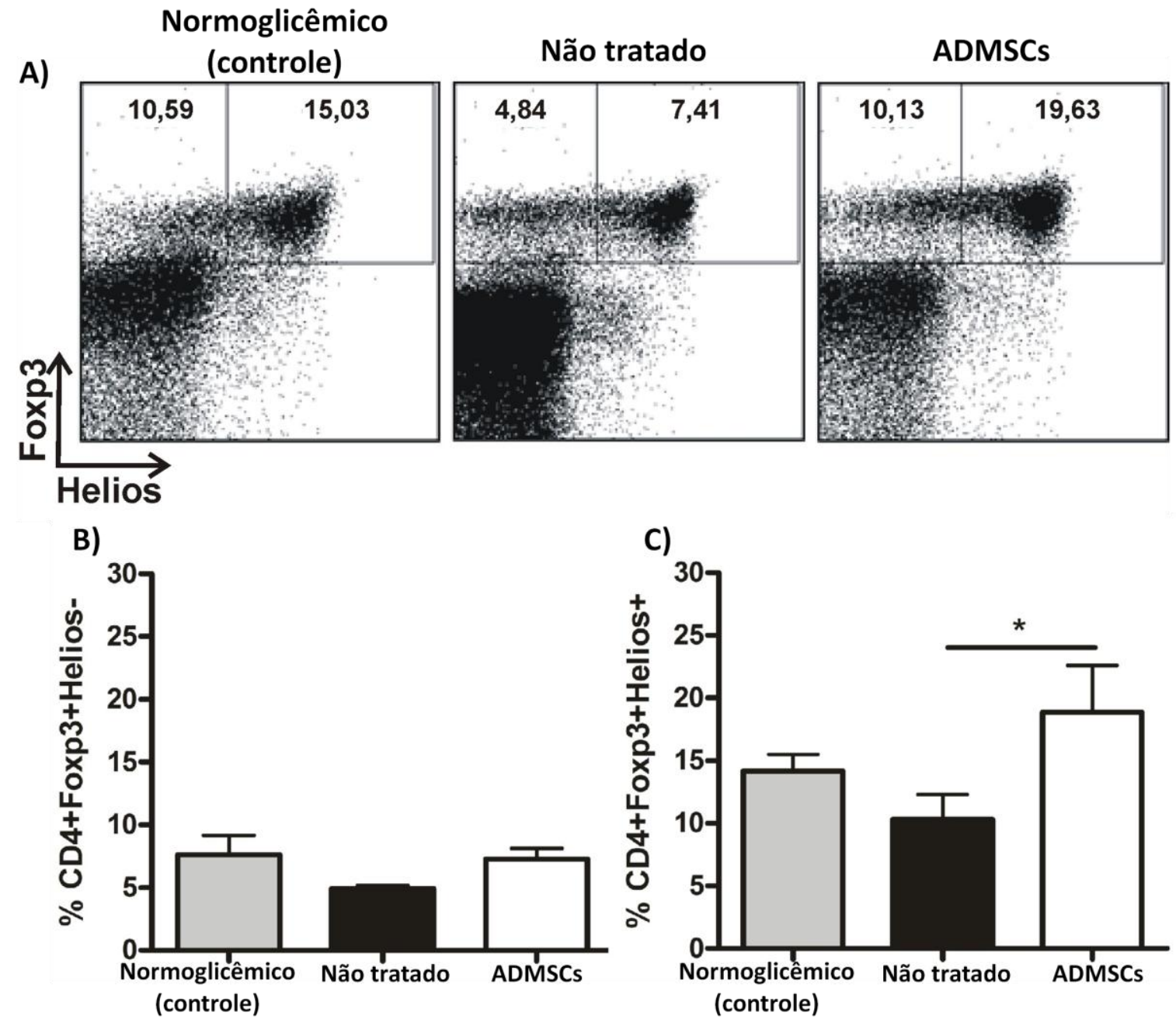

A frequência de células $\mathrm{T}$ CD4+Foxp3+Helios+ e T CD4+Foxp3+Helios- nos LPs foi determinada por citometria de fluxo 12 semanas após o tratamento com ADMSC. A) Dot-plot representativo da frequência de células T CD4+Foxp3+Helios+ e CD4+Foxp3+Helios-. B e C) Gráficos representativos da frequência de células $T$ CD4+Foxp3+Helios+ $\mathrm{e} T$ CD4+Foxp3+Helios-, respectivamente (média \pm s.e.m.). $\mathrm{n}=5$ /grupo experimental. ${ }^{*} \mathrm{p}<0,05$.

Fonte: Bassi [144].

Para uma melhor caracterização da subpopulação de células Tregs observada 12 semanas após o tratamento com ADMSCs, a frequência de células 
CD4+CD25+Foxp3+Helios+ e CD4+CD25+Foxp3+Helios- foi investigada nos animais que responderam ao tratamento. Conforme mostrado na figura 31, um aumento significativo na frequência das células T CD4+CD25+Foxp3+Helios+ combinado a uma diminuição na frequência de células T CD4+CD25+Foxp3+Helios- pode ser constatado, sugerindo a expansão de células Helios+ promovida pelo tratamento com ADMSCs.

Figura 31 - Frequência de células Helios+ e Helios- em células CD4+CD25+Foxp3+ nos linfonodos pancreáticos 12 semanas após o tratamento com ADMSCs.
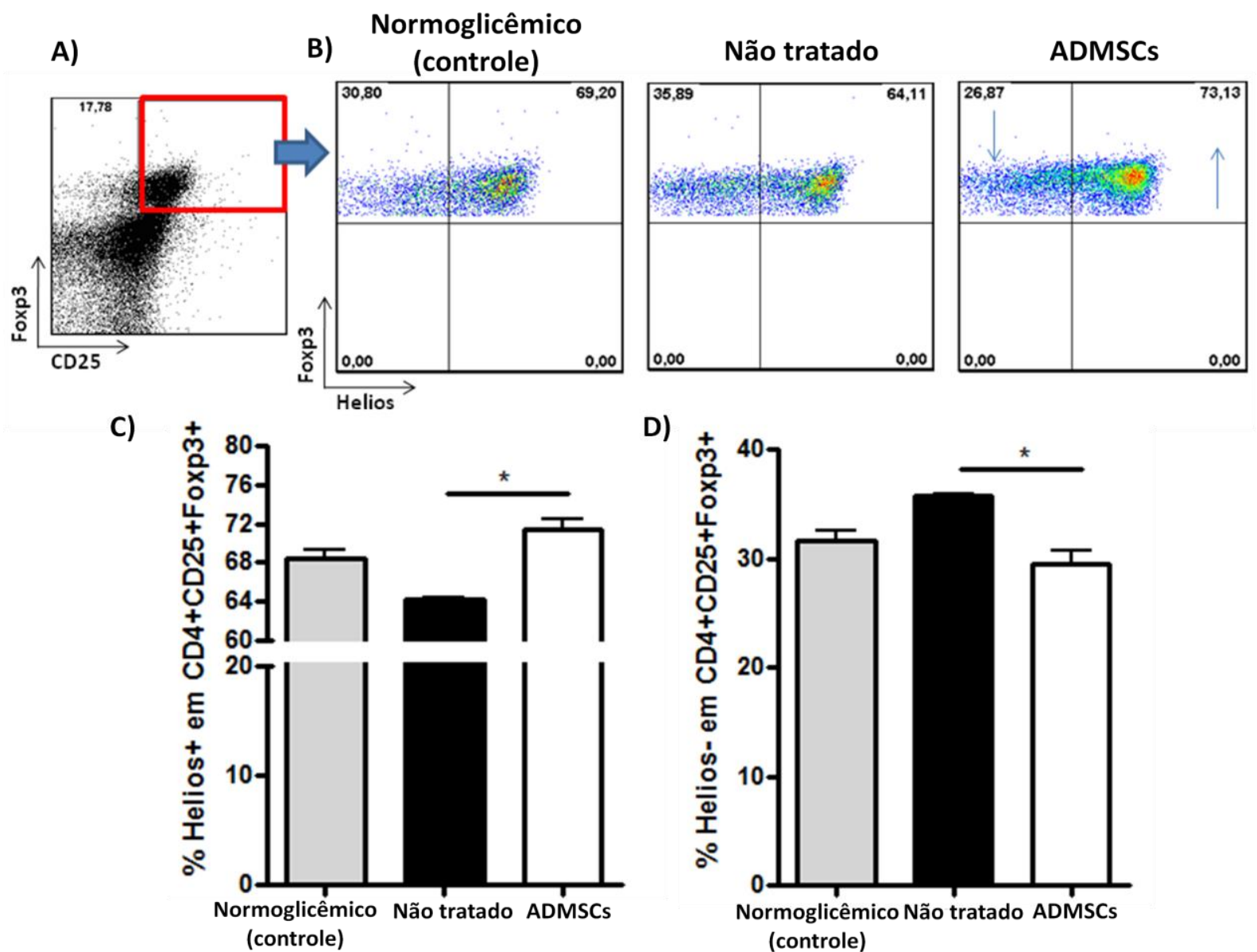

A frequência de células Helios+ e Helios- na população CD4+CD25+Foxp3+ foi determinada por citometria de fluxo 12 semanas após o tratamento. A) Dot-plot representativo da frequência de células T CD25+Foxp3+ no gate de linfócitos CD4+. B) Dot-plot representativo da frequência de células Helios+Foxp3+ e Helios-Foxp3+ em células CD4+CD25+Foxp3+. C e D) Gráficos representativos da frequência de células CD4+CD25+Foxp3+Helios+ e T CD4+CD25+Foxp3+Helios-, respectivamente (média \pm s.e.m.). n=5/grupo experimental. ${ }^{*} \mathrm{p}<0,05$.

Fonte: Bassi [144]. 


\section{DISCUSSÃO}

A incidência do DMT1 tem aumentado no decorrer dos últimos anos fazendo desta doença um importante problema de saúde pública mundial estimulando a pesquisa de novas terapias que sejam seguras e eficazes para controlar, reverter ou até mesmo prevenir o desenvolvimento desta doença [151, 152]. Neste sentido, as terapias celulares tornaram-se alternativas promissoras para a prevenção e $\mathrm{o}$ tratamento do diabetes autoimune. O transplante de ilhotas pancreáticas humanas consiste em um tratamento promissor para esta doença, no entanto, a ausência de doadores suficientes, os custos elevados e a necessidade de terapia com imunossupressores para evitar a rejeição das células transplantadas, tem limitado a ampla utilização deste procedimento $[153,154]$. Nos últimos anos, tem-se sugerido que a imunossupressão utilizada em pacientes recém-diagnosticados com DMT1 pode manter as células $\beta$ pancreáticas residuais funcionais, reduzindo assim, a necessidade da utilização de insulina posteriormente. Dessa forma, foi mostrado que o transplante de células-tronco hematopoiéticas após indução de imunossupressão com ciclofosfamida em pacientes recém-diagnosticados com DMT1 pôde promover a manutenção de células $\beta$ funcionais [155]. Neste estudo, 15 pacientes foram monitorados por um período de até 36 meses após o tratamento, sendo que 14 pacientes tornaram-se livres da utilização de insulina por uma média de aproximadamente 18 meses (dentre eles, 1 por 35 meses, 4 por 21 meses e 7 por 6 meses) [155].

Durante o início do desenvolvimento do DMT1, as células $\beta$ residuais ainda produzem insulina, oferecendo assim, uma possibilidade de intervenção terapêutica para bloquear/atenuar a destruição autoimune, recuperando assim a função das células $\beta$ remanescentes. Nos últimos anos, diversos estudos tem mostrado que as MSCs podem modular a resposta autoimune e inflamatória envolvida em diversas doenças, principalmente devido ao seu efeito imunossupressor, apresentando assim, um potencial terapêutico para diversas doenças autoimunes, incluindo o DMT1 [36]. 
Embora testes clínicos envolvendo MSCs para o tratamento de diversas doenças tenham sido iniciados, os mecanismos de ação dessas células em doenças autoimunes somente começaram a ser elucidados.

O camundongo NOD é um modelo experimental de diabetes autoimune onde uma combinação da disfunção do sistema imune associada a fatores genéticos e ambientais levam a uma resposta autoimune Th1 pró-inflamatória, culminando na perda da manutenção da tolerância às células $\beta$ pancreáticas [156]. No presente estudo, nós confirmamos a presença de uma resposta imune de perfil Th1 associada à infiltração celular (insulite) nas ilhotas pancreáticas, destruição das células $\beta$ e hiperglicemia neste modelo experimental. Estudos recentes mostraram um perfil Th1 $(\mathrm{IFN}-\gamma)$ no diabetes autoimune experimental em camundongos NOD, corroborando com os nossos resultados [145, 146]. Martin-Orozco et al. [145] diferenciaram in vitro células T com TCR transgênico para um autoantígeno das células $\beta$ (clone BDC 2.5) em células Th17, um tipo celular associado com autoimunidade órgão-específica presente em diversas doenças autoimunes como colite, encefalomielite autoimune experimental e artrite reumatóide. As células Th17 foram então transferidas para camundongos NOD/SCID (onde há ausência de linfócitos $\mathrm{T}$ e B). Após a transferência, observou-se um rápido desenvolvimento da doença com intenso infiltrado celular inflamatório e destruição das ilhotas pancreáticas. No entanto, o resultado interessante deste estudo foi que as células BDC 2.5+ recuperadas dos camundongos NOD/SCID expressaram maiores quantidades de IFN- $\gamma$ do que IL-17, indicando assim que as células Th17 transferidas para os animais se diferenciaram em células Th1 no indivíduo linfopênico, sendo essas, as responsáveis pelo desenvolvimento da doença [145]. Em outro estudo, células BDC 2.5+ Th17 não secretoras de IFN- $\gamma$ foram isoladas e transferidas para camundongos NOD/SCID [146]. Do mesmo modo, as células se converteram em células secretoras de IFN- $\gamma$ no receptor. Além disso, o desenvolvimento da doença nos animais não foi devido a IL17, pois o tratamento dos animais com um anticorpo que bloqueia esta citocina não surtiu nenhum efeito benéfico. Por outro lado, a indução do diabetes pela 
transferência de células Th1 foi prevenida pelo tratamento com anticorpo neutralizante para IFN- $\gamma$, destacando um papel crucial para células Th1 na indução do diabetes neste modelo experimental [146].

Nos últimos anos, diversos estudos mostraram o potencial imunossupressor das ADMSCs sobre a resposta imune de perfil Th1 combinada a capacidade de expandir células Tregs em vários modelos de doença autoimune, como esclerose múltipla, artrite reumatóide e colite experimental [81, 86, 134]. Assim, no presente estudo, a nossa hipótese foi que as ADMSCs poderiam melhorar o desenvolvimento recente do diabetes autoimune em camundongos NOD diabéticos promovendo seu efeito terapêutico via inibição da resposta mediada por células T CD4+ de perfil Th1 pró-inflamatório concomitantemente a expansão de células Tregs. Embora estudos anteriores tenham obtido sucesso na utilização de MSCs derivadas da medula óssea (BM-MSCs) para o tratamento e prevenção do diabetes autoimune neste modelo experimental [127-130], o potencial terapêutico das ADMSCs no tratamento desta doença, avaliando e explorando seu efeito imunomodulador, permanece totalmente inexplorado.

No estudo de Fiorina et al. [127], MSCs alogênicas isoladas a partir da medula óssea de camundongos Balb/c não diabéticos administradas por via endovenosa em camundongos NOD diabéticos migraram para o pâncreas e LPs, revertendo temporariamente a hiperglicemia em $90 \%$ dos animais após o tratamento. Por outro lado, foi mostrado que a transferência de MSCs autólogas derivadas de camundongos NOD não resultou no mesmo efeito terapêutico observado para células alogênicas, causando ainda a formação de tumores viscerais em diferentes órgãos em $20 \%$ dos camundongos NOD tratados. Esse resultado foi correlacionado com a expressão aumentada de genes ligados a proliferação e ciclo celular nas MSCs derivadas de camundongos NOD em comparação com as MSCs de Balb/c [127].

Assim, visto que utilizamos camundongos NOD neste estudo, optamos pela utilização de células ADMSCs alogênicas derivadas de camundongos Balb/c, embora o efeito benéfico do tratamento com células ADMSCs singênicas não possa ser 
descartado. Neste sentido, MSCs congênitas isoladas a partir da medula óssea de camundongos NOR ("non-obese resistant") reverteram a hiperglicemia de camundongos NOD diabéticos, diminuindo a frequência de células $\mathrm{T}$ efetoras nos linfonodos pancreáticos [129]. No tratamento de ratos diabéticos com BM-MSCs autólogas, as células migraram para o pâncreas, aumentaram os níveis de insulina e promoveram uma normoglicemia sustentada por 60 dias após o tratamento. Ainda, no grupo tratado, foi observada uma maior expressão de PDX-1 e insulina e uma maior frequência de células T CD4+Foxp3+ após o tratamento [125]. Vale ressaltar que o fator de transcrição PDX-1 tem um papel importante na diferenciação/desenvolvimento e manutenção da homeostasia das células $\beta$, regulando ainda a expressão do gene da insulina [157].

No presente estudo, uma redução na glicemia acompanhada de uma melhora significativa no teste de tolerância à glicose e aumento dos níveis de insulina no soro foram observados após o tratamento com ADMSCs. Além disso, uma diminuição da insulite combinada a uma acentuada expressão de insulina e PDX-1 nas ilhotas pancreáticas, indicando a manutenção de células $\beta$ funcionais, foram observadas nos camundongos NOD diabéticos tratados com ADMSCs.

De forma interessante, níveis mais elevados de hormônios que contribuem para a melhora do DMT1, como a amilina e GLP-1, foram observados no soro dos camundongos tratados com ADMSCs. A amilina é um hormônio peptídico secretado pelas células $\beta$ simultaneamente a secreção de insulina que atua melhorando o controle glicêmico em pacientes com DMT1 [158]. No caso do GLP-1, foi mostrado que o tratamento com a combinação desse hormônio juntamente a gastrina pôde restaurar a normoglicemia em camundongos NOD diabéticos devido principalmente ao aumento na massa de células $\beta$ pancreáticas e inibição da resposta autoimune [159]. Recentemente, mostrou-se que a sinalização do receptor de GLP-1 pode regular a proliferação linfocitária mantendo células Tregs periféricas em camundongos NOD [160]. Neste estudo, observamos um aumento nos níveis de GLP-1 e na frequência de 
células Tregs nos camundongos tratados com ADMSCs, sugerindo uma contribuição desse hormônio na melhora do diabetes autoimune observada após o tratamento.

No modelo experimental de artrite reumatóide e colite, o tratamento com ADMSCs pôde modular a resposta autoimune mediada por células T CD4+ [81, 161]. $\mathrm{Na}$ doença inflamatória intestinal, o tratamento de camundongos com ADMSCs tanto de origem murina como humana, administradas pela via intraperitoneal, melhorou significativamente a severidade da doença, diminuindo a perda de peso, diarréia e a inflamação [86, 161]. Além disso, o efeito terapêutico foi associado com uma inibição da resposta inflamatória de perfil Th1 na mucosa intestinal e linfonodos drenantes concomitante a expansão de células Tregs [86, 161].

No DMT1, as células Tregs são essenciais para manutenção da tolerância imunológica podendo ainda atenuar a autoimunidade órgão específica. Essas células têm sido alvo de intensas pesquisas nos últimos anos [53], exibindo uma potente atividade reguladora tanto in vivo como in vitro, inibindo células $\mathrm{T}$ auto-reativas e mantendo a tolerância imunológica. As Tregs possuem uma elevada expressão do fator de transcrição Foxp3, que tem papel central no desenvolvimento e função das Tregs CD25+, sendo o marcador mais específico para essas células [56].

No presente estudo, as ADMSCs foram detectadas no pâncreas e nos LPs 72h após a administração intraperitoneal em camundongos NOD diabéticos. Além disso, uma maior frequência de células CD4+CD25+Foxp3+ concomitante a uma diminuição na frequência de células T CD4+ produtoras de IFN- $\gamma$ e TNF- $\alpha$ foram detectadas nos LPs dos animais tratados, um importante sítio de regulação imunológica nesse modelo experimental. Weber et al. [162] mostraram que a transferência de células Tregs em camundongos NOD pré-diabéticos pode prevenir o desenvolvimento do diabetes autoimune, devido à diminuição do infiltrado celular inflamatório no pâncreas e ao bloqueio da resposta imune Th1 efetora nos LPs. Interessantemente, a administração de BM-MSCs alogênicas em camundongos NOD fêmeas pré-diabéticas com 4 semanas de idade preveniu o desenvolvimento da insulite espontânea e o desenvolvimento do diabetes com o decorrer da idade nestes 
animais [128]. Foi mostrado ainda que as MSCs administradas tanto pela via intraperitoneal como endovenosa migraram para os LPs e preveniram a destruição autoimune das células $\beta$ pela indução de células Tregs [128].

A propriedade das MSCs em migrar ("homing") para sítios lesionados ou inflamatórios e restaurar a função de tecidos injuriados tem sido relatada em diversos estudos $[19,163,164]$. No ano de 2006, Lee e colaboradores, mostraram que BM-MSCs humanas quando transplantadas em camundongos NOD/SCID tornados diabéticos pela administração de estreptozotocina puderam migrar para o pâncreas e glomérulos renais, reparando esses tecidos lesados [126]. Além disso, após a administração das MSCs humanas, a glicemia dos animais diabéticos foi normalizada e a concentração de insulina no soro aumentou em relação aos animais não tratados, embora a presença de insulina humana não tenha sido detectada após o tratamento [126]. Em outro estudo, MSCs alogênicas migraram para o pâncreas e LPs ao serem injetadas por via endovenosa em camundongos NOD diabéticos e reverteram temporariamente a hiperglicemia [127].

A citocina IFN- $\gamma$ é a citocina predominante em uma resposta imune com perfil Th1. Esta citocina pode ativar macrófagos amplificando a resposta imune envolvida no diabetes autoimune ou ainda sensibilizar as células $\beta$ pancreáticas, aumentando a expressão de MHC classe I nessas células, tornando-as então mais susceptíveis a citotoxicidade mediada in vivo pelos linfócitos T CD8+ [165]. Tanto os linfócitos T CD4+ quando $\mathrm{T}$ CD8+ produzem IFN- $\gamma$ durante a destruição das células $\beta$ pancreáticas em camundongos NOD [166]. O TNF- $\alpha$, por sua vez, é uma importante citocina pró-inflamatória envolvida na resposta autoimune e na indução de apoptose nas células $\beta$ pancreáticas [167-169]. Recentemente, no modelo de diabetes induzido por estreptozotocina em camundongos, a administração de BM-MSCs pode reverter a hiperglicemia por um período de até 90 dias após o tratamento, diminuindo a frequência de células $\mathrm{T}$ autoreativas e aumentando a frequência de células Tregs [170], corroborando com os nossos resultados, visto que observamos uma diminuição na frequência de células T CD4+IFN- $\gamma$ e CD4+TNF- $\alpha+$ nos LPs após o tratamento. 
É importante ressaltar que nos diversos estudos utilizando MSCs no tratamento de doenças autoimunes, o efeito terapêutico dessas células não parece estar associado com sua transdiferenciação nas células que foram danificadas, como por exemplo, as células $\beta$ pancreáticas. Geralmente, o efeito terapêutico das MSCs é relacionado ao seu potencial antiinflamatório e imunossupressor, além da produção de citocinas e fatores de crescimento por essas células, estimulando, assim, a sobrevivência e proliferação das células residentes e mantendo um microambiente favorável para o processo regenerativo. A citocina TGF- $\beta 1$ é uma importante citocina supressora no DMT1, sendo que nas ilhotas pancreáticas, pode contribuir para a proteção contra os linfócitos T CD4+ e CD8+ efetores [171]. Em camundongos NOD diabéticos, foi mostrado que as células Tregs migram para o interior do pâncreas durante a supressão do diabetes autoimune e inibem células T efetoras e macrófagos em uma maneira dependente de TGF- $\beta 1$ [172]. Em nosso estudo, no pâncreas, uma diminuição nos níveis de IFN- $\gamma$ combinado ao aumento da expressão de TGF- $\beta 1$ biologicamente ativo foram detectados após o tratamento com ADMSCs, contribuindo para a manutenção de ilhotas funcionais. Corroborando com nossos resultados, foi mostrado que a administração de BM-MSCs em camundongos NOD recém-diabéticos pode aumentar os níveis de TGF- $\beta 1$ no soro dos animais 35 dias após o tratamento [130].

A capacidade das ADMSCs em expandir células Tregs foi confirmada no presente estudo por meio de experimentos realizados in vitro. Uma maior frequência e proliferação de células T CD4+CD25+Foxp3+ foram detectadas quando linfócitos T CD4+ foram co-cultivados com as ADMSCs em uma maneira dose-dependente. Além disso, foi mostrado o papel do contato ADMSC: linfócito T CD4+ neste processo, pois quando as células foram cultivadas separadas por uma membrana (transwell), uma menor frequência e proliferação de células T CD4+CD25+Foxp3+ pode ser observada. Corroborando com nossos resultados, o papel do contato celular no mecanismo de expansão de Tregs por MSCs alogênicas foi mostrado previamente para BM-MSCs humanas [73]. Por outro lado, em outro estudo foi mostrado que a expansão de 
células Tregs por MSCs humanas in vitro foi dependente da secreção de HLA-G5 solúvel por essas células [74]. No entanto, o contato celular entre MSCs e células T estimuladas foi necessário para obtenção de uma maior secreção desse fator solúvel e conseguinte uma maior imunomodulação [74].

Além da expansão de Tregs por MSCs, BM-MSCs podem ainda recrutar as células Tregs de uma população de células CD3+ (linfócitos) in vitro e manter a expressão de Foxp3 e a atividade supressora dessas células por até 15 dias, enquanto na ausência dessas células esse efeito foi perdido em apenas 5 dias de cultura [72]. De forma interessante, no presente estudo, verificamos que as ADMSCs puderam manter um fenótipo regulador em uma população de células CD4+Foxp3+, verificado por uma maior expressão de Foxp3 nessas células quando co-cultivadas na presença de ADMSCs, corroborando com estes resultados.

A molécula co-estimuladora PD-1 e seu ligantes, PD-L1 e PD-L2 constituem um importante mecanismo regulador inibitório da resposta imune nos mecanismos de tolerância e autoimunidade, sendo que a ativação deste receptor leva a inibição da proliferação e secreção de citocinas pelos linfócitos [149]. A molécula PD-L1 é expressa constitutivamente em células do sistema imune como linfócitos B, células dendríticas, macrófagos e linfócitos $\mathrm{T}$ além de uma variedade de células nãohematopoiéticas, como célula endotelial vascular, astrócitos, célula epitelial e em locais imunoprivilegiados como trofoblasto na placenta, células epiteliais do pigmento da retina e neurônios no olho [149].

Estudos recentes mostraram a expressão do receptor PD-L1 na superfície de BM-MSCs [127, 129] e o papel crucial dessa molécula na inibição da proliferação de linfócitos T e B promovida por essas células [173, 174]. Além disso, foi mostrado que a citocina IFN- $\gamma$ pode aumentar a expressão de PD-L1 em BM-MSCs, ativando ("priming") o efeito supressor dessas células sobre os linfócitos T [174]. Em experimentos in vitro, BM-MSCs inibiram a proliferação de linfócitos $\mathrm{T}$ diabetogênicos em um mecanismo dependente de PD-L1, visto que a inibição da 
expressão dessa molécula nas BM-MSCs utilizando RNA de interferência pode reverter esse efeito imunossupressor [129].

No presente estudo, verificamos uma elevada expressão de PD-L1 em ADMSCs. Corroborando com estes resultados, uma elevada expressão constitutiva de PD-L1 também foi verificada em MSCs isoladas a partir do cordão umbilical humano e a adição de um anticorpo bloqueador para essa molécula reverteu a atividade imunossupressora de inibição da proliferação de linfócitos $\mathrm{T}$ por essas células [175].

Devido o papel de PD-L1 na regulação do desenvolvimento, manutenção e função de células Tregs [148], investigamos o papel dessa molécula na expansão dessas células promovida pelo co-cultivo in vitro com ADMSCs. Interessantemente, a expansão de células Tregs por ADMSCs foi inibida na presença de um anticorpo neutralizante para essa molécula de uma maneira dose-dependente, indicando um papel crucial dessa molécula no efeito imunussupressor dessas células in vitro sobre células Tregs. De acordo com Francisco et al. [148] APCs isoladas de animais PD-L1induzem uma menor conversão de linfócitos T CD4+ näive em células Tregs quando comparado a APCs WT (do inglês, “wild type"). Além disso, microesferas recobertas com PD-L1 puderam induzir células Tregs, na presença de TGF- $\beta 1$, aumentando e sustentando a expressão de Foxp3 e a função supressora dessas células in vitro [148]. Em nosso estudo, observamos um aumento dos níveis de TGF- $\beta 1$ quando as ADMSCs foram co-cultivadas com linfócitos T CD4+, indicando que provavelmente essa citocina poderia auxiliar na expansão das células Tregs promovida por PD-L1.

Embora o tratamento com ADMSCs tenha melhorado significativamente o desenvolvimento do diabetes autoimune em camundongos NOD recém-diabéticos, foi interessante avaliar por quanto tempo este efeito benéfico poderia ser mantido. Para isso, um novo tratamento foi realizado, seguido de um acompanhamento por 12 semanas após o tratamento. Nesse sentido, o estudo de Fiorina et al. [127] mostrou uma reversão temporária da hiperglicemia por um período de aproximadamente 41 dias após o tratamento de camundongos NOD diabéticos com BM-MSCs alogênicas. 
Posteriormente, em outro estudo, a administração de BM-MSCs congênitas isoladas de camundongos NOR manteve a reversão da hiperglicemia por até 12 semanas após o tratamento [129]. No presente estudo, observamos que a reversão da hiperglicemia após o tratamento de camundongos NOD recém-diabéticos pode ser mantida por até 8 semanas após o tratamento com ADMSCs alogênicas em $78 \%$ dos animais e por 12 semanas em 4 animais, sugerindo que provavelmente mais administrações seriam necessárias para manutenção do efeito terapêutico por um maior período de tempo. Além disso, uma menor insulite e maior expressão de insulina nas ilhotas pancreáticas foram observadas no grupo tratado com ADMSCs 12 semanas após o tratamento.

Interessantemente, nos linfonodos pancreáticos dos animais tratados com ADMSCs, verificou-se uma maior frequência de células Tregs CD4+CD25+Foxp3+. Para uma melhor fenotipagem dessas células, o fator de transcrição Helios, recentemente sugerido como um potencial marcador para células Tregs naturais foi então utilizado [150]. Inicialmente, foi mostrado que células Foxp3+ obtidas a partir da diferenciação de linfócitos T naïve estimuladas in vitro na presença de TGF- $\beta$ não expressavam esse marcador [150]. Embora esse fator de transcrição tenha sido apontado como um potencial marcador específico para células Tregs naturais timoderivadas, esse assunto ainda não é consenso na literatura, visto que recentemente um estudo mostrou a expressão de Helios em células Tregs induzidas em determinadas condições in vitro [176]. Estudos recentes mostraram que células Tregs Helios+ expressam maiores níveis de TGF- $\beta 1$, não secretam citocinas efetoras e proliferam mais in vivo, indicando que as células Foxp3+Helios+ representariam uma subpopulação funcional com características mais supressoras comparada a Tregs Foxp3+Helios- [177-179]. De forma interessante, uma maior frequência de células Tregs CD4+Foxp3+Foxp3+Helios+ foi observada nos linfonodos pancreáticos 12 semanas após o tratamento com ADMSCs, indicando a expansão de células Tregs in vivo com importantes propriedades imunossupressoras em situações de autoimunidade. 
Em resumo, o tratamento com ADMSCs pode modular de forma eficiente a resposta imune mediada por células T CD4+ e melhorar o diabetes autoimune em camundongos NOD diabéticos atenuando a resposta imune Th1 e favorecendo a expansão de células Tregs, contribuindo para a manutenção/regeneração de células $\beta$ pancreáticas funcionais. Embora novos estudos sejam necessários para confirmação da segurança e potencial terapêutico das ADMSCs e suas propriedades imunomoduladoras em doenças autoimunes experimentais, essas células possuem muitas vantagens em comparação a outras fontes celulares para aplicação em medicina regenerativa como o alto rendimento e processo de obtenção minimamente invasivo, podendo ser obtidas a partir do lipoaspirado de doadores saudáveis e expandidas in vitro. Assim, os resultados obtidos nesse estudo são promissores, revelando novas perspectivas terapêuticas para o desenvolvimento futuro de novas estratégias de terapia celular baseadas em ADMSCs para o tratamento do DMT1. 


\section{CONCLUSÕES}

- O modelo de diabetes autoimune experimental em camundongos NOD foi caracterizado por uma hiperglemia, infiltrado celular inflamatório nas ilhotas pancreáticas e resposta imune de perfil Th1 nos linfonodos pancreáticos;

- o tratamento de camundongos NOD recém-diabéticos com ADMSCs pode reverter a hiperglicemia, glicosúria e melhorar o teste de tolerância a glicose intraperitoneal;

- diversos hormônios relacionados à melhora do DMT1, como insulina, amilina e GLP-1 foram aumentados no soro dos animais após o tratamento;

- o tratamento com ADMSCs diminuiu o infiltrado celular inflamatório (insulite) nas ilhotas pancreáticas contribuindo para manutenção/regeneração de células $\beta$ funcionais expressando insulina e PD-X1;

- uma maior frequência de células Tregs CD4+CD25+Foxp3+ combinada a uma diminuição na frequência de células CD4+IFN $\gamma+$ e TNF- $\alpha+$ (perfil Th1) foi observada nos linfonodos pancreáticos;

- no pâncreas, o tratamento com ADMSCs atenuou a resposta imune Th1 (IFN$\gamma)$ combinada ao aumento da expressão de TGF- $\beta 1$ ativo;

- as ADMSCs foram detectadas no lavado peritoneal, linfonodos pancreáticos o pâncreas $72 \mathrm{~h}$ após administração em camundongos NOD diabéticos;

- a reversão da hiperglicemia em camundongos NOD recém-diabéticos foi mantida em $78 \%$ dos animais por um período de até 8 semanas após o tratamento;

- uma maior frequência de células Tregs CD4+CD25+Foxp3+Helios+ nos linfonodos pancreáticos assim como uma diminuição do infiltrado celular inflamatório foi constatada 12 semanas após o tratamento; e

- in vitro, ADMSCs promoveram a expansão/proliferação de células $\mathrm{T}$ CD4+CD25+Foxp3+ quando co-cultivadas com linfócitos T CD4+ em um mecanismo dependente de contato celular e mediado pela molécula PD-L1. 


\section{REFERÊNCIAS ${ }^{*}$}

1. Becker AJ, Mc CE, Till JE. Cytological demonstration of the clonal nature of spleen colonies derived from transplanted mouse marrow cells. Nature. 1963;197:452-4.

2. Owen RD. Immunogenetic Consequences of Vascular Anastomoses between Bovine Twins. Science. 1945;102(2651):400-1.

3. Ryan JM, Barry FP, Murphy JM, Mahon BP. Mesenchymal stem cells avoid allogeneic rejection. J Inflamm (Lond). 2005;2:8.

4. Thomson JA, Itskovitz-Eldor J, Shapiro SS, Waknitz MA, Swiergiel JJ, Marshall VS, et al. Embryonic stem cell lines derived from human blastocysts. Science. 1998;282(5391):1145-7.

5. Evans MJ, Kaufman MH. Establishment in culture of pluripotential cells from mouse embryos. Nature. 1981;292(5819):154-6.

6. Luria EA, Panasyuk AF, Friedenstein AY. Fibroblast colony formation from monolayer cultures of blood cells. Transfusion. 1971;11(6):345-9.

7. Friedenstein AJ, Gorskaja JF, Kulagina NN. Fibroblast precursors in normal and irradiated mouse hematopoietic organs. Exp Hematol. 1976;4(5):267-74.

8. Friedenstein AJ, Petrakova KV, Kurolesova AI, Frolova GP. Heterotopic of bone marrow. Analysis of precursor cells for osteogenic and hematopoietic tissues. Transplantation. 1968;6(2):230-47.

9. Owen M, Friedenstein AJ. Stromal stem cells: marrow-derived osteogenic precursors. Ciba Found Symp. 1988;136:42-60.

10. Haynesworth SE, Baber MA, Caplan AI. Cell surface antigens on human marrow-derived mesenchymal cells are detected by monoclonal antibodies. Bone. 1992;13(1):69-80.

11. Caplan AI. Mesenchymal stem cells. J Orthop Res. 1991;9(5):641-50.

12. Goshima J, Goldberg VM, Caplan AI. The osteogenic potential of cultureexpanded rat marrow mesenchymal cells assayed in vivo in calcium phosphate ceramic blocks. Clin Orthop Relat Res. 1991;262:298-311.

"De acordo com International Comittee of Medical Journal Editors. Uniform Requirements for manuscripts submitted to Biomedical Journal: sample references. [updated 2011 Jul 15]. Available from http://www.icmje.org. 
13. Haynesworth SE, Goshima J, Goldberg VM, Caplan AI. Characterization of cells with osteogenic potential from human marrow. Bone.1992;13(1):81-8.

14. Deans RJ, Moseley AB. Mesenchymal stem cells: biology and potential clinical uses. Experimental hematology. 2000;28(8):875-84.

15. Pittenger MF, Mackay AM, Beck SC, Jaiswal RK, Douglas R, Mosca JD, et al. Multilineage potential of adult human mesenchymal stem cells. Science. 1999;284(5411):143-7.

16. Gnecchi M, Melo LG. Bone marrow-derived mesenchymal stem cells: isolation, expansion, characterization, viral transduction, and production of conditioned medium. Methods Mol Biol. 2009;482:281-94.

17. da Silva Meirelles L, Chagastelles PC, Nardi NB. Mesenchymal stem cells reside in virtually all post-natal organs and tissues. Journal of cell science. 2006;119(Pt 11):2204-13.

18. Abdallah BM, Kassem M. Human mesenchymal stem cells: from basic biology to clinical applications. Gene Ther. 2008;15(2):109-16.

19. Ding S, Schultz PG. A role for chemistry in stem cell biology. Nature biotechnology. 2004;22(7):833-40.

20. Kumar S, Chanda D, Ponnazhagan S. Therapeutic potential of genetically modified mesenchymal stem cells. Gene Ther. 2008;15(10):711-5.

21. Kassem M. Mesenchymal stem cells: biological characteristics and potential clinical applications. Cloning Stem Cells. 2004;6(4):369-74.

22. Bassi EJ, Aita CA, Camara NO. Immune regulatory properties of multipotent mesenchymal stromal cells: Where do we stand? World J Stem Cells. 2011;3(1):1-8.

23. Dominici M, Le Blanc K, Mueller I, Slaper-Cortenbach I, Marini F, Krause D, et al. Minimal criteria for defining multipotent mesenchymal stromal cells. The International Society for Cellular Therapy position statement. Cytotherapy. 2006;8(4):315-7.

24. Chapel A, Bertho JM, Bensidhoum M, Fouillard L, Young RG, Frick J, et al. Mesenchymal stem cells home to injured tissues when co-infused with hematopoietic cells to treat a radiation-induced multi-organ failure syndrome. J Gene Med. 2003;5(12):1028-38.

25. Meirelles Lda S, Fontes AM, Covas DT, Caplan AI. Mechanisms involved in the therapeutic properties of mesenchymal stem cells. Cytokine Growth Factor Rev. 2009;20(5-6):419-27. 
26. Zuk PA, Zhu M, Ashjian P, De Ugarte DA, Huang JI, Mizuno H, et al. Human adipose tissue is a source of multipotent stem cells. Molecular biology of the cell. 2002;13(12):4279-95.

27. Zuk PA, Zhu M, Mizuno H, Huang J, Futrell JW, Katz AJ, et al. Multilineage cells from human adipose tissue: implications for cell-based therapies. Tissue engineering. 2001;7(2):211-28.

28. Casteilla L, Planat-Benard V, Laharrague P, Cousin B. Adipose-derived stromal cells: Their identity and uses in clinical trials, an update. World J Stem Cells. 2011;3(4):25-33.

29. Strem BM, Hicok KC, Zhu M, Wulur I, Alfonso Z, Schreiber RE, et al. Multipotential differentiation of adipose tissue-derived stem cells. Keio J Med. 2005;54(3):132-41.

30. Rada T, Reis RL, Gomes ME. Adipose Tissue-Derived Stem Cells and Their Application in Bone and Cartilage Tissue Engineering. Tissue Eng Part B Rev. 2009;15(00):1-13.

31. Bartholomew A, Sturgeon C, Siatskas M, Ferrer K, McIntosh K, Patil S, et al. Mesenchymal stem cells suppress lymphocyte proliferation in vitro and prolong skin graft survival in vivo. Experimental hematology. 2002;30(1):42-8.

32. Tse WT, Pendleton JD, Beyer WM, Egalka MC, Guinan EC. Suppression of allogeneic T-cell proliferation by human marrow stromal cells: implications in transplantation. Transplantation. 2003;75(3):389-97.

33. Eliopoulos N, Stagg J, Lejeune L, Pommey S, Galipeau J. Allogeneic marrow stromal cells are immune rejected by MHC class I- and class II-mismatched recipient mice. Blood. 2005;106(13):4057-65.

34. Grinnemo KH, Mansson A, Dellgren G, Klingberg D, Wardell E, Drvota V, et al. Xenoreactivity and engraftment of human mesenchymal stem cells transplanted into infarcted rat myocardium. J Thorac Cardiovasc Surg. 2004;127(5):1293-300.

35. Jones BJ, McTaggart SJ. Immunosuppression by mesenchymal stromal cells: from culture to clinic. Experimental hematology. 2008;36(6):733-41.

36. Abdi R, Fiorina P, Adra CN, Atkinson M, Sayegh MH. Immunomodulation by mesenchymal stem cells: a potential therapeutic strategy for type 1 diabetes. Diabetes. 2008;57(7):1759-67.

37. Le Blanc K, Tammik L, Sundberg B, Haynesworth SE, Ringden O. Mesenchymal stem cells inhibit and stimulate mixed lymphocyte cultures and mitogenic responses independently of the major histocompatibility complex. Scandinavian journal of immunology. 2003;57(1):11-20. 
38. Chen X, Armstrong MA, Li G. Mesenchymal stem cells in immunoregulation. Immunol Cell Biol. 2006;84(5):413-21.

39. Krampera M, Cosmi L, Angeli R, Pasini A, Liotta F, Andreini A, et al. Role for interferon-gamma in the immunomodulatory activity of human bone marrow mesenchymal stem cells. Stem cells (Dayton, Ohio). 2006;24(2):386-98.

40. Meisel R, Zibert A, Laryea M, Gobel U, Daubener W, Dilloo D. Human bone marrow stromal cells inhibit allogeneic T-cell responses by indoleamine 2,3dioxygenase-mediated tryptophan degradation. Blood. 2004;103(12):4619-21.

41. Bassi EJ, de Almeida DC, Moraes-Vieira PM, Camara NO. Exploring the Role of Soluble Factors Associated with Immune Regulatory Properties of Mesenchymal Stem Cells. Stem Cell Rev. 2012;8(2):329-42.

42. Bassi EJ, de Almeida DC, Moraes-Vieira PM, Camara NO. Exploring the Role of Soluble Factors Associated with Immune Regulatory Properties of Mesenchymal Stem Cells. Stem Cell Rev. 2011. (In press).

43. Aggarwal S, Pittenger MF. Human mesenchymal stem cells modulate allogeneic immune cell responses. Blood. 2005;105(4):1815-22.

44. Klyushnenkova E, Mosca JD, Zernetkina V, Majumdar MK, Beggs KJ, Simonetti DW, et al. T cell responses to allogeneic human mesenchymal stem cells: immunogenicity, tolerance, and suppression. J Biomed Sci. 2005;12(1):47-57.

45. Krampera M, Glennie S, Dyson J, Scott D, Laylor R, Simpson E, et al. Bone marrow mesenchymal stem cells inhibit the response of naive and memory antigenspecific T cells to their cognate peptide. Blood. 2003;101(9):3722-9.

46. Zappia E, Casazza S, Pedemonte E, Benvenuto F, Bonanni I, Gerdoni E, et al. Mesenchymal stem cells ameliorate experimental autoimmune encephalomyelitis inducing T-cell anergy. Blood. 2005;106(5):1755-61.

47. Deng W, Han Q, Liao L, You S, Deng H, Zhao RC. Effects of allogeneic bone marrow-derived mesenchymal stem cells on $\mathrm{T}$ and $\mathrm{B}$ lymphocytes from BXSB mice. DNA and cell biology. 2005;24(7):458-63.

48. Corcione A, Benvenuto F, Ferretti E, Giunti D, Cappiello V, Cazzanti F, et al. Human mesenchymal stem cells modulate B-cell functions. Blood. 2006;107(1):367-72.

49. Beyth S, Borovsky Z, Mevorach D, Liebergall M, Gazit Z, Aslan H, et al. Human mesenchymal stem cells alter antigen-presenting cell maturation and induce T-cell unresponsiveness. Blood. 2005;105(5):2214-9. 
50. Nauta AJ, Kruisselbrink AB, Lurvink E, Willemze R, Fibbe WE. Mesenchymal stem cells inhibit generation and function of both CD34+-derived and monocytederived dendritic cells. J Immunol. 2006;177(4):2080-7.

51. Zhang W, Ge W, Li C, You S, Liao L, Han Q, et al. Effects of mesenchymal stem cells on differentiation, maturation, and function of human monocyte-derived dendritic cells. Stem cells and development. 2004;13(3):263-71.

52. Gershon RK, Kondo K. Infectious immunological tolerance. Immunology. 1971;21(6):903-14.

53. Sakaguchi S, Sakaguchi N, Asano M, Itoh M, Toda M. Immunologic selftolerance maintained by activated $\mathrm{T}$ cells expressing IL-2 receptor alpha-chains (CD25). Breakdown of a single mechanism of self-tolerance causes various autoimmune diseases. J Immunol. 1995;155(3):1151-64.

54. Setoguchi R, Hori S, Takahashi T, Sakaguchi S. Homeostatic maintenance of natural Foxp3(+) CD25(+) CD4(+) regulatory $\mathrm{T}$ cells by interleukin (IL) 2 and induction of autoimmune disease by IL-2 neutralization. J Exp Med. 2005;201(5):72335.

55. Jonuleit H, Schmitt E, Stassen M, Tuettenberg A, Knop J, Enk AH. Identification and functional characterization of human CD4(+)CD25(+) T cells with regulatory properties isolated from peripheral blood. The Journal of experimental medicine. 2001;193(11):1285-94.

56. Fontenot JD, Gavin MA, Rudensky AY. Foxp3 programs the development and function of CD4+CD25+ regulatory T cells. Nature immunology. 2003;4(4):330-6.

57. Bacchetta R, Passerini L, Gambineri E, Dai M, Allan SE, Perroni L, et al. Defective regulatory and effector $\mathrm{T}$ cell functions in patients with FOXP3 mutations. J Clin Invest. 2006;116(6):1713-22.

58. Baecher-Allan C, Hafler DA. Human regulatory $\mathrm{T}$ cells and their role in autoimmune disease. Immunol Rev. 2006;212:203-16.

59. Randolph DA, Fathman CG. Cd4+Cd25+ regulatory $\mathrm{T}$ cells and their therapeutic potential. Annu Rev Med. 2006;57:381-402.

60. Chen W, Jin W, Hardegen N, Lei KJ, Li L, Marinos N, et al. Conversion of peripheral CD4+CD25- naive $\mathrm{T}$ cells to $\mathrm{CD} 4+\mathrm{CD} 25+$ regulatory $\mathrm{T}$ cells by TGF-beta induction of transcription factor Foxp3. The Journal of experimental medicine. 2003;198(12):1875-86.

61. Zheng SG, Wang JH, Gray JD, Soucier H, Horwitz DA. Natural and induced CD4+CD25+ cells educate CD4+CD25- cells to develop suppressive activity: the role of IL-2, TGF-beta, and IL-10. J Immunol. 2004;172(9):5213-21. 
62. Mangan PR, Harrington LE, O'Quinn DB, Helms WS, Bullard DC, Elson CO, et al. Transforming growth factor-beta induces development of the $\mathrm{T}(\mathrm{H}) 17$ lineage. Nature. 2006;441(7090):231-4.

63. Kingsley CI, Karim M, Bushell AR, Wood KJ. CD25+CD4+ regulatory T cells prevent graft rejection: CTLA-4- and IL-10-dependent immunoregulation of alloresponses. J Immunol. 2002;168(3):1080-6.

64. Read S, Greenwald R, Izcue A, Robinson N, Mandelbrot D, Francisco L, et al. Blockade of CTLA-4 on CD4+CD25+ regulatory $\mathrm{T}$ cells abrogates their function in vivo. J Immunol. 2006;177(7):4376-83.

65. You S, Leforban B, Garcia C, Bach JF, Bluestone JA, Chatenoud L. Adaptive TGF-beta-dependent regulatory $\mathrm{T}$ cells control autoimmune diabetes and are a privileged target of anti-CD3 antibody treatment. Proc Natl Acad Sci U S A. 2007;104(15):6335-40.

66. Pandiyan P, Zheng L, Ishihara S, Reed J, Lenardo MJ. CD4+CD25+Foxp3+ regulatory $\mathrm{T}$ cells induce cytokine deprivation-mediated apoptosis of effector CD4+ T cells. Nat Immunol. 2007;8(12):1353-62.

67. Deaglio S, Dwyer KM, Gao W, Friedman D, Usheva A, Erat A, et al. Adenosine generation catalyzed by CD39 and CD73 expressed on regulatory T cells mediates immune suppression. J Exp Med. 2007;204(6):1257-65.

68. Engela AU, Baan CC, Dor FJ, Weimar W, Hoogduijn MJ. On the interactions between mesenchymal stem cells and regulatory $\mathrm{T}$ cells for immunomodulation in transplantation. Front Immunol. 2012;3:126.

69. Maccario R, Podesta M, Moretta A, Cometa A, Comoli P, Montagna D, et al. Interaction of human mesenchymal stem cells with cells involved in alloantigenspecific immune response favors the differentiation of CD4+ T-cell subsets expressing a regulatory/suppressive phenotype. Haematologica. 2005;90(4):516-25.

70. Prevosto C, Zancolli M, Canevali P, Zocchi MR, Poggi A. Generation of CD4+ or CD8+ regulatory $\mathrm{T}$ cells upon mesenchymal stem cell-lymphocyte interaction. Haematologica. 2007;92(7):881-8.

71. Ye Z, Wang Y, Xie HY, Zheng SS. Immunosuppressive effects of rat mesenchymal stem cells: involvement of $\mathrm{CD} 4+\mathrm{CD} 25+$ regulatory $\mathrm{T}$ cells. Hepatobiliary Pancreat Dis Int. 2008;7(6):608-14.

72. Di Ianni M, Del Papa B, De Ioanni M, Moretti L, Bonifacio E, Cecchini D, et al. Mesenchymal cells recruit and regulate $\mathrm{T}$ regulatory cells. Exp Hematol. 2008;36(3):309-18. 
73. English K, Ryan JM, Tobin L, Murphy MJ, Barry FP, Mahon BP. Cell contact, prostaglandin $\mathrm{E}(2)$ and transforming growth factor beta 1 play non-redundant roles in human mesenchymal stem cell induction of CD4+CD25(High) forkhead box P3+ regulatory T cells. Clinical and experimental immunology. 2009;156(1):149-60.

74. Selmani Z, Naji A, Zidi I, Favier B, Gaiffe E, Obert L, et al. Human leukocyte antigen-G5 secretion by human mesenchymal stem cells is required to suppress $\mathrm{T}$ lymphocyte and natural killer function and to induce CD4+CD25highFOXP3+ regulatory T cells. Stem cells (Dayton, Ohio). 2008;26(1):212-22.

75. Ge W, Jiang J, Arp J, Liu W, Garcia B, Wang H. Regulatory T-cell generation and kidney allograft tolerance induced by mesenchymal stem cells associated with indoleamine 2,3-dioxygenase expression. Transplantation. 2010;90(12):1312-20.

76. Ghannam S, Pene J, Torcy-Moquet G, Jorgensen C, Yssel H. Mesenchymal stem cells inhibit human Th17 cell differentiation and function and induce a $\mathrm{T}$ regulatory cell phenotype. J Immunol. 2010;185(1):302-12.

77. Tatara R, Ozaki K, Kikuchi Y, Hatanaka K, Oh I, Meguro A, et al. Mesenchymal stromal cells inhibit Th17 but not regulatory T-cell differentiation. Cytotherapy. 2011;13(6):686-94.

78. Kavanagh H, Mahon BP. Allogeneic mesenchymal stem cells prevent allergic airway inflammation by inducing murine regulatory T cells. Allergy. 2011;66(4):52331.

79. Bai L, Lennon DP, Eaton V, Maier K, Caplan AI, Miller SD, et al. Human bone marrow-derived mesenchymal stem cells induce Th2-polarized immune response and promote endogenous repair in animal models of multiple sclerosis. Glia. 2009;57 (11):1192-203.

80. Mohajeri M, Farazmand A, Mohyeddin Bonab M, Nikbin B, Minagar A. FOXP3 gene expression in multiple sclerosis patients pre- and post mesenchymal stem cell therapy. Iran J Allergy Asthma Immunol. 2011;10(3):155-61.

81. Gonzalez MA, Gonzalez-Rey E, Rico L, Buscher D, Delgado M. Treatment of experimental arthritis by inducing immune tolerance with human adipose-derived mesenchymal stem cells. Arthritis and rheumatism. 2009;60(4):1006-19.

82. Zhou B, Yuan J, Zhou Y, Ghawji M, Jr., Deng YP, Lee AJ, et al. Administering human adipose-derived mesenchymal stem cells to prevent and treat experimental arthritis. Clin Immunol. 2011;141(3):328-37.

83. Augello A, Tasso R, Negrini SM, Cancedda R, Pennesi G. Cell therapy using allogeneic bone marrow mesenchymal stem cells prevents tissue damage in collageninduced arthritis. Arthritis and rheumatism. 2007;56(4):1175-86. 
84. Gonzalez-Rey E, Gonzalez MA, Varela N, O'Valle F, Hernandez-Cortes P, Rico $\mathrm{L}$, et al. Human adipose-derived mesenchymal stem cells reduce inflammatory and $\mathrm{T}$ cell responses and induce regulatory $\mathrm{T}$ cells in vitro in rheumatoid arthritis. Ann Rheum Dis. 2010;69(1):241-8.

85. Akiyama K, Chen C, Wang D, Xu X, Qu C, Yamaza T, et al. Mesenchymalstem-cell-induced immunoregulation involves FAS-ligand-/FAS-mediated $\mathrm{T}$ cell apoptosis. Cell Stem Cell. 2012;10(5):544-55.

86. Gonzalez-Rey E, Anderson P, Gonzalez MA, Rico L, Buscher D, Delgado M. Human adult stem cells derived from adipose tissue protect against experimental colitis and sepsis. Gut. 2009;58(7):929-39.

87. Zhou K, Zhang H, Jin O, Feng X, Yao G, Hou Y, et al. Transplantation of human bone marrow mesenchymal stem cell ameliorates the autoimmune pathogenesis in MRL/lpr mice. Cellular \& molecular immunology. 2008;5(6):417-24.

88. Choi EW, Shin IS, Park SY, Park JH, Kim JS, Yoon EJ, et al. Reversal of serologic, immunologic, and histologic dysfunction in mice with systemic lupus erythematosus by long-term serial adipose tissue-derived mesenchymal stem cell transplantation. Arthritis and rheumatism. 2012;64(1):243-53.

89. Itakura S, Asari S, Rawson J, Ito T, Todorov I, Liu CP, et al. Mesenchymal stem cells facilitate the induction of mixed hematopoietic chimerism and islet allograft tolerance without GVHD in the rat. Am J Transplant. 2007;7(2):336-46.

90. Le Blanc K, Rasmusson I, Sundberg B, Gotherstrom C, Hassan M, Uzunel M, et al. Treatment of severe acute graft-versus-host disease with third party haploidentical mesenchymal stem cells. Lancet. 2004;363(9419):1439-41.

91. Ringden O, Uzunel M, Rasmusson I, Remberger M, Sundberg B, Lonnies H, et al. Mesenchymal stem cells for treatment of therapy-resistant graft-versus-host disease. Transplantation. 2006;81(10):1390-7.

92. Tian Y, Deng YB, Huang YJ, Wang Y. Bone marrow-derived mesenchymal stem cells decrease acute graft-versus-host disease after allogeneic hematopoietic stem cells transplantation. Immunological investigations. 2008;37(1):29-42.

93. Le Blanc K, Frassoni F, Ball L, Locatelli F, Roelofs H, Lewis I, et al. Mesenchymal stem cells for treatment of steroid-resistant, severe, acute graft-versushost disease: a phase II study. Lancet. 2008;371(9624):1579-86.

94. Todd JA. Etiology of type 1 diabetes. Immunity. 2010;32(4):457-67.

95. Lukic ML, Stosic-Grujicic S, Shahin A. Effector mechanisms in low-dose streptozotocin-induced diabetes. Dev Immunol. 1998;6(1-2):119-28. 
96. Incidence and trends of childhood Type 1 diabetes worldwide 1990-1999. Diabet Med. 2006;23(8):857-66.

97. National Diabetes Fact Sheet. Center for Disease Control and Prevention. [homepage on internet]. Estados Unidos: 2005. Disponível em: <http://wwwcdcgov/diabetes/pubs/pdf/ndfs_2005pdf>. [Acesso em: 2012/08/02].

98. Karvonen M, Viik-Kajander M, Moltchanova E, Libman I, LaPorte R, Tuomilehto J. Incidence of childhood type 1 diabetes worldwide. Diabetes Mondiale (DiaMond) Project Group. Diabetes Care. 2000;23(10):1516-26.

99. Kantarova D, Buc M. Genetic susceptibility to type 1 diabetes mellitus in humans. Physiol Res. 2007;56(3):255-66.

100. Notkins AL. Immunologic and genetic factors in type 1 diabetes. J Biol Chem. 2002;277(46):43545-8.

101. Gomes MB, Dib AS, editors. Tratamento e acompanhamento do diabetes mellitus. Diretrizes da Sociedade Brasileira de Diabetes. Sociedade Brasileira de Diabetes. 2006;1-154.

102. Roep BO. The role of T-cells in the pathogenesis of Type 1 diabetes: from cause to cure. Diabetologia. 2003;46(3):305-21.

103. Gepts W, Lecompte PM. The pancreatic islets in diabetes. Am J Med. 1981;70(1):105-15.

104. Shimizu J, Kanagawa O, Unanue ER. Presentation of beta-cell antigens to CD4+ and CD8+ T cells of non-obese diabetic mice. J Immunol. 1993;151(3):1723-30.

105. Mathis D, Vence L, Benoist C. beta-Cell death during progression to diabetes. Nature. 2001;414(6865):792-8.

106. Pujol-Borrell R, Todd I, Doshi M, Bottazzo GF, Sutton R, Gray D, et al. HLA class II induction in human islet cells by interferon-gamma plus tumour necrosis factor or lymphotoxin. Nature. 1987;326(6110):304-6.

107. Gagnerault MC, Luan JJ, Lotton C, Lepault F. Pancreatic lymph nodes are required for priming of beta cell reactive $\mathrm{T}$ cells in NOD mice. J Exp Med. 2002;196(3):369-77.

108. Debray-Sachs M, Carnaud C, Boitard C, Cohen H, Gresser I, Bedossa P, et al. Prevention of diabetes in NOD mice treated with antibody to murine IFN gamma. J Autoimmun. 1991;4(2):237-48.

109. Sarvetnick N, Liggitt D, Pitts SL, Hansen SE, Stewart TA. Insulin-dependent diabetes mellitus induced in transgenic mice by ectopic expression of class II MHC and interferon-gamma. Cell. 1988;52(5):773-82. 
110. Corbett JA, McDaniel ML. Intraislet release of interleukin 1 inhibits beta cell function by inducing beta cell expression of inducible nitric oxide synthase. J Exp Med. 1995;181(2):559-68.

111. Wachlin G, Augstein P, Schroder D, Kuttler B, Kloting I, Heinke P, et al. IL1beta, IFN-gamma and TNF-alpha increase vulnerability of pancreatic beta cells to autoimmune destruction. J Autoimmun. 2003;20(4):303-12.

112. Willcox A, Richardson SJ, Bone AJ, Foulis AK, Morgan NG. Analysis of islet inflammation in human type 1 diabetes. Clin Exp Immunol. 2009;155(2):173-81.

113. Moriwaki M, Itoh N, Miyagawa J, Yamamoto K, Imagawa A, Yamagata K, et al. Fas and Fas ligand expression in inflamed islets in pancreas sections of patients with recent-onset Type I diabetes mellitus. Diabetologia. 1999;42(11):1332-40.

114. Eizirik DL, Mandrup-Poulsen T. A choice of death--the signal-transduction of immune-mediated beta-cell apoptosis. Diabetologia. 2001;44(12):2115-33.

115. Christie MR, Hollands JA, Brown TJ, Michelsen BK, Delovitch TL. Detection of pancreatic islet $64,000 \mathrm{M}(\mathrm{r})$ autoantigens in insulin-dependent diabetes distinct from glutamate decarboxylase. J Clin Invest. 1993;92(1):240-8.

116. Kaufman FR. Type 1 diabetes mellitus. Pediatr Rev. 2003;24(9):291-300.

117. Juedes AE, von Herrath MG. Regulatory T-cells in type 1 diabetes. Diabetes Metab Res Rev. 2004;20(6):446-51.

118. Salomon B, Lenschow DJ, Rhee L, Ashourian N, Singh B, Sharpe A, et al. B7/CD28 costimulation is essential for the homeostasis of the CD4+CD25+ immunoregulatory $\mathrm{T}$ cells that control autoimmune diabetes. Immunity. 2000;12(4):431-40.

119. Green EA, Gorelik L, McGregor CM, Tran EH, Flavell RA. CD4+CD25+ T regulatory cells control anti-islet CD8+ T cells through TGF-beta-TGF-beta receptor interactions in type 1 diabetes. Proc Natl Acad Sci U S A. 2003;100(19):10878-83.

120. Gregori S, Giarratana N, Smiroldo S, Uskokovic M, Adorini L. A 1alpha,25dihydroxyvitamin $\mathrm{D}(3)$ analog enhances regulatory T-cells and arrests autoimmune diabetes in NOD mice. Diabetes. 2002;51(5):1367-74.

121. Mukherjee R, Chaturvedi P, Qin HY, Singh B. CD4+CD25+ regulatory T cells generated in response to insulin B:9-23 peptide prevent adoptive transfer of diabetes by diabetogenic T cells. J Autoimmun. 2003;21(3):221-37.

122. Grinberg-Bleyer Y, Baeyens A, You S, Elhage R, Fourcade G, Gregoire S, et al. IL-2 reverses established type 1 diabetes in NOD mice by a local effect on pancreatic regulatory T cells. J Exp Med. 2010;207(9):1871-8. 
123. Robertson P, Davis C, Larsen J, Stratta R, Sutherland DE. Pancreas transplantation in type 1 diabetes. Diabetes Care. 2004;27 Suppl 1:S105.

124. Shapiro AM, Lakey JR, Ryan EA, Korbutt GS, Toth E, Warnock GL, et al. Islet transplantation in seven patients with type 1 diabetes mellitus using a glucocorticoid-free immunosuppressive regimen. N Engl J Med. 2000;343(4):230-8.

125. Boumaza I, Srinivasan S, Witt WT, Feghali-Bostwick C, Dai Y, Garcia-Ocana A, et al. Autologous bone marrow-derived rat mesenchymal stem cells promote PDX-1 and insulin expression in the islets, alter $\mathrm{T}$ cell cytokine pattern and preserve regulatory $\mathrm{T}$ cells in the periphery and induce sustained normoglycemia. J Autoimmun. 2009;32(1):33-42.

126. Lee RH, Seo MJ, Reger RL, Spees JL, Pulin AA, Olson SD, et al. Multipotent stromal cells from human marrow home to and promote repair of pancreatic islets and renal glomeruli in diabetic NOD/scid mice. Proc Natl Acad Sci U S A. 2006;103(46):17438-43.

127. Fiorina P, Jurewicz M, Augello A, Vergani A, Dada S, La Rosa S, et al. Immunomodulatory function of bone marrow-derived mesenchymal stem cells in experimental autoimmune type 1 diabetes. J Immunol. 2009;183(2):993-1004.

128. Madec AM, Mallone R, Afonso G, Abou Mrad E, Mesnier A, Eljaafari A, et al. Mesenchymal stem cells protect NOD mice from diabetes by inducing regulatory $\mathrm{T}$ cells. Diabetologia. 2009;52(7):1391-9.

129. Jurewicz M, Yang S, Augello A, Godwin JG, Moore RF, Azzi J, et al. Congenic mesenchymal stem cell therapy reverses hyperglycemia in experimental type 1 diabetes. Diabetes. 2010;59(12):3139-47.

130. Zhao W, Wang Y, Wang D, Sun B, Wang G, Wang J, et al. TGF-beta expression by allogeneic bone marrow stromal cells ameliorates diabetes in NOD mice through modulating the distribution of CD4+ T cell subsets. Cell Immunol. 2008;253(1-2):2330.

131. Ezquer FE, Ezquer ME, Parrau DB, Carpio D, Yanez AJ, Conget PA. Systemic administration of multipotent mesenchymal stromal cells reverts hyperglycemia and prevents nephropathy in type 1 diabetic mice. Biol Blood Marrow Transplant. 2008;14(6):631-40.

132. Hess D, Li L, Martin M, Sakano S, Hill D, Strutt B, et al. Bone marrow-derived stem cells initiate pancreatic regeneration. Nat Biotechnol. 2003;21(7):763-70.

133. Urban VS, Kiss J, Kovacs J, Gocza E, Vas V, Monostori E, et al. Mesenchymal stem cells cooperate with bone marrow cells in therapy of diabetes. Stem cells (Dayton, Ohio). 2008;26(1):244-53. 
134. Constantin G, Marconi S, Rossi B, Angiari S, Calderan L, Anghileri E, et al. Adipose-derived mesenchymal stem cells ameliorate chronic experimental autoimmune encephalomyelitis. Stem Cells. 2009;27(10):2624-35.

135. Cho KS, Park HK, Park HY, Jung JS, Jeon SG, Kim YK, et al. IFATS Series: Immunomodulatory Effects of Adipose Tissue-Derived Stem Cells in an Allergic Rhinitis Mouse Model. Stem cells (Dayton, Ohio). 2008;27(1):259-65.

136. Jaiswal N, Haynesworth SE, Caplan AI, Bruder SP. Osteogenic differentiation of purified, culture-expanded human mesenchymal stem cells in vitro. J Cell Biochem. 1997;64(2):295-312.

137. Anderson MS, Bluestone JA. The NOD mouse: a model of immune dysregulation. Annual review of immunology. 2005;23:447-85.

138. Suarez-Pinzon WL, Yan Y, Power R, Brand SJ, Rabinovitch A. Combination therapy with epidermal growth factor and gastrin increases beta-cell mass and reverses hyperglycemia in diabetic NOD mice. Diabetes. 2005;54(9):2596-601.

139. Yoon JW, Yoon CS, Lim HW, Huang QQ, Kang Y, Pyun KH, et al. Control of autoimmune diabetes in NOD mice by GAD expression or suppression in beta cells. Science. 1999;284(5417):1183-7.

140. Sakuishi K, Apetoh L, Sullivan JM, Blazar BR, Kuchroo VK, Anderson AC. Targeting Tim-3 and PD-1 pathways to reverse T cell exhaustion and restore antitumor immunity. J Exp Med. 2010;207(10):2187-94.

141. Bunnell BA, Flaat M, Gagliardi C, Patel B, Ripoll C. Adipose-derived stem cells: isolation, expansion and differentiation. Methods. 2008;45(2):115-20.

142. Phinney DG, Kopen G, Isaacson RL, Prockop DJ. Plastic adherent stromal cells from the bone marrow of commonly used strains of inbred mice: variations in yield, growth, and differentiation. J Cell Biochem. 1999;72(4):570-85.

143. Horwitz EM, Le Blanc K, Dominici M, Mueller I, Slaper-Cortenbach I, Marini FC, et al. Clarification of the nomenclature for MSC: The International Society for Cellular Therapy position statement. Cytotherapy. 2005;7(5):393-5.

144. Bassi EJ. Propriedades imunomoduladoras das células-tronco mesenquimais do tecido adiposo no tratamento do diabetes autoimune experimental. [tese (Doutorado em Ciências). São Paulo: Instituto de Ciências Biomédicas, Universidade de São Paulo; 2012.

145. Martin-Orozco N, Chung Y, Chang SH, Wang YH, Dong C. Th17 cells promote pancreatic inflammation but only induce diabetes efficiently in lymphopenic hosts after conversion into Th1 cells. Eur J Immunol. 2009;39(1):216-24. 
146. Bending D, De La PeÃ $\pm a$ H, Veldhoen M, Phillips JM, Uyttenhove C, Stockinger B, et al. Highly purified Th17 cells from BDC2.5NOD mice convert into Th1-like cells in NOD/SCID recipient mice. The Journal of Clinical Investigation. 2009;119(3):565-72.

147. Piccirillo CA, Shevach EM. Cutting edge: control of CD8+ T cell activation by CD4+CD25+ immunoregulatory cells. J Immunol. 2001;167(3):1137-40.

148. Francisco LM, Salinas VH, Brown KE, Vanguri VK, Freeman GJ, Kuchroo VK, et al. PD-L1 regulates the development, maintenance, and function of induced regulatory T cells. J Exp Med. 2009;206(13):3015-29.

149. Francisco LM, Sage PT, Sharpe AH. The PD-1 pathway in tolerance and autoimmunity. Immunol Rev. 2010;236:219-42.

150. Thornton AM, Korty PE, Tran DQ, Wohlfert EA, Murray PE, Belkaid Y, et al. Expression of Helios, an Ikaros transcription factor family member, differentiates thymic-derived from peripherally induced Foxp3+ $\mathrm{T}$ regulatory cells. J Immunol. 2010;184(7):3433-41.

151. Patterson CC, Dahlquist GG, Gyurus E, Green A, Soltesz G. Incidence trends for childhood type 1 diabetes in Europe during 1989-2003 and predicted new cases 2005-20: a multicentre prospective registration study. Lancet. 2009;373(9680):2027-33.

152. The global challenge of diabetes. Lancet. 2008;371(9626):1723.

153. Rother KI, Harlan DM. Challenges facing islet transplantation for the treatment of type 1 diabetes mellitus. J Clin Invest. 2004;114(7):877-83.

154. Ricordi C, Strom TB. Clinical islet transplantation: advances and immunological challenges. Nat Rev Immunol. 2004;4(4):259-68.

155. Voltarelli JC, Couri CE, Stracieri AB, Oliveira MC, Moraes DA, Pieroni F, et al. Autologous nonmyeloablative hematopoietic stem cell transplantation in newly diagnosed type 1 diabetes mellitus. JAMA. 2007;297(14):1568-76.

156. Delovitch TL, Singh B. The nonobese diabetic mouse as a model of autoimmune diabetes: immune dysregulation gets the NOD. Immunity. 1997;7(6):727-38.

157. Melloul D, Marshak S, Cerasi E. Regulation of pdx-1 gene expression. Diabetes. 2002;51 Suppl 3:S320-5.

158. Ceriello A, Piconi L, Quagliaro L, Wang Y, Schnabel CA, Ruggles JA, et al. Effects of pramlintide on postprandial glucose excursions and measures of oxidative stress in patients with type 1 diabetes. Diabetes Care. 2005;28(3):632-7. 
159. Suarez-Pinzon WL, Power RF, Yan Y, Wasserfall C, Atkinson M, Rabinovitch A. Combination therapy with glucagon-like peptide-1 and gastrin restores normoglycemia in diabetic NOD mice. Diabetes. 2008;57(12):3281-8.

160. Hadjiyanni I, Siminovitch KA, Danska JS, Drucker DJ. Glucagon-like peptide-1 receptor signalling selectively regulates murine lymphocyte proliferation and maintenance of peripheral regulatory T cells. Diabetologia. 2010;53(4):730-40.

161. Gonzalez MA, Gonzalez-Rey E, Rico L, Buscher D, Delgado M. Adiposederived mesenchymal stem cells alleviate experimental colitis by inhibiting inflammatory and autoimmune responses. Gastroenterology. 2009;136(3):978-89.

162. Weber SE, Harbertson J, Godebu E, Mros GA, Padrick RC, Carson BD, et al. Adaptive islet-specific regulatory CD4 $\mathrm{T}$ cells control autoimmune diabetes and mediate the disappearance of pathogenic Th1 cells in vivo. J Immunol. 2006;176(8):4730-9.

163. Hall B, Dembinski J, Sasser AK, Studeny M, Andreeff M, Marini F. Mesenchymal stem cells in cancer: tumor-associated fibroblasts and cell-based delivery vehicles. International journal of hematology. 2007;86(1):8-16.

164. Tomchuck SL, Zwezdaryk KJ, Coffelt SB, Waterman RS, Danka ES, Scandurro AB. Toll-like receptors on human mesenchymal stem cells drive their migration and immunomodulating responses. Stem cells (Dayton, Ohio). 2008;26(1):99-107.

165. Kay TW, Campbell IL, Oxbrow L, Harrison LC. Overexpression of class I major histocompatibility complex accompanies insulitis in the non-obese diabetic mouse and is prevented by anti-interferon-gamma antibody. Diabetologia. 1991;34(11):779-85.

166. Suarez-Pinzon W, Rajotte RV, Mosmann TR, Rabinovitch A. Both CD4+ and CD8+ T-cells in syngeneic islet grafts in NOD mice produce interferon-gamma during beta-cell destruction. Diabetes. 1996;45(10):1350-7.

167. Dunger A, Cunningham JM, Delaney CA, Lowe JE, Green MH, Bone AJ, et al. Tumor necrosis factor-alpha and interferon-gamma inhibit insulin secretion and cause DNA damage in unweaned-rat islets. Extent of nitric oxide involvement. Diabetes. 1996;45(2):183-9.

168. Suk K, Kim S, Kim YH, Kim KA, Chang I, Yagita H, et al. IFN-gamma/TNFalpha synergism as the final effector in autoimmune diabetes: a key role for STAT1/IFN regulatory factor-1 pathway in pancreatic beta cell death. J Immunol. 2001;166(7):4481-9.

169. Kim KA, Lee MS. Recent progress in research on beta-cell apoptosis by cytokines. Front Biosci. 2009;14:657-64. 
170. Ezquer FE, Ezquer ME, Contador D, Ricca M, Simon V, Conget PA. MSC AntiDiabetic Effect is Unrelated to Their Trans-Differentiation Potential but to their Capability to Restore Th1/Th2 Balance and to Modify the Pancreatic Microenvironment. Stem cells (Dayton, Ohio). 2012;30(8):1664-74.

171. Moritani M, Yoshimoto K, Wong SF, Tanaka C, Yamaoka T, Sano T, et al. Abrogation of autoimmune diabetes in nonobese diabetic mice and protection against effector lymphocytes by transgenic paracrine TGF-beta1. J Clin Invest. 1998;102(3):499-506.

172. Tonkin DR, Haskins K. Regulatory $\mathrm{T}$ cells enter the pancreas during suppression of type 1 diabetes and inhibit effector T cells and macrophages in a TGFbeta-dependent manner. Eur J Immunol. 2009;39(5):1313-22.

173. Augello A, Tasso R, Negrini SM, Amateis A, Indiveri F, Cancedda R, et al. Bone marrow mesenchymal progenitor cells inhibit lymphocyte proliferation by activation of the programmed death 1 pathway. Eur J Immunol. 2005;35(5):1482-90.

174. Sheng H, Wang Y, Jin Y, Zhang Q, Zhang Y, Wang L, et al. A critical role of IFNgamma in priming MSC-mediated suppression of T cell proliferation through upregulation of B7-H1. Cell Res. 2008;18(8):846-57.

175. Tipnis S, Viswanathan C, Majumdar AS. Immunosuppressive properties of human umbilical cord-derived mesenchymal stem cells: role of B7-H1 and IDO. Immunology and cell biology. 2010;88(8):795-806.

176. Gottschalk RA, Corse E, Allison JP. Expression of Helios in peripherally induced Foxp3+ regulatory T cells. J Immunol. 2012;188(3):976-80.

177. Kim YC, Bhairavabhotla R, Yoon J, Golding A, Thornton AM, Tran DQ, et al. Oligodeoxynucleotides stabilize Helios-expressing Foxp3+ human T regulatory cells during in vitro expansion. Blood. 2012;119(12):2810-8.

178. Elkord E. Comment on "expression of helios in peripherally induced foxp3+ regulatory T cells". J Immunol. 2012;189(2):500.

179. Zabransky DJ, Nirschl CJ, Durham NM, Park BV, Ceccato CM, Bruno TC, et al. Phenotypic and functional properties of Helios+ regulatory $\mathrm{T}$ cells. PLoS One. 2012;7(3):e34547. 


\section{APÊNDICES - Artigos científicos publicados}

APÊNDICE A - Bassi ÊJ, Moraes-Vieira PMM, Vieira LM, Cunha CS, Hiyane MI, Basso AS, Pacheco-Silva A, Câmara NOS. Immune regulatory properties of allogeneic adipose-derived mesenchymal stem cells in the treatment of experimental autoimmune diabetes. Diabetes, 2012. (In press)

APÊNDICE B - Bassi ÊJ, ALMEIDA DC, Moraes-Vieira PMM, Câmara NOS. Exploring the role of soluble factors associated with immune regulatory properties of mesenchymal stem cells. Stem Cell Reviews and Reports, 8: 329-42, 2012.

APÊNDICE C - Bassi ÊJ, Aita CAM, Câmara NOS. Immune regulatory properties of multipotent mesenchymal stromal cells: Where do we stand? World Journal of Stem Cells, 3:1-8, 2011.

APÊNDICE D - Moraes-Vieira PMM, Bassi ÊJ, Araujo RC, Câmara NOS. Leptin as a link between the immune system and kidney-related diseases: leading actor or just a coadjuvant?. Obesity Reviews, 2012. (In press).

APÊNDICE E - Castoldi A, Braga TT, Correa-Costa M, Aguiar CF, Bassi ÊJ, CorreaSilva R, Elias RM, Salvador F, Moraes-Vieira P, Cenedeze MA, Reis MA, Hiyane MI, Pacheco-Silva A, Gonçalves GM, Câmara NOS. TLR2, TLR4 and the MYD88 Signaling Pathway Are Crucial for Neutrophil Migration in Acute Kidney Injury Induced by Sepsis. Plos One. , v.7, p.e37584 - , 2012. (In press). 


\title{
Immune Regulatory Properties of Allogeneic Adipose-Derived Mesenchymal Stem Cells in the Treatment of Experimental Autoimmune Diabetes
}

\author{
Êtuo J. Bassi, ${ }^{2}$ Pedro M.M. Moraes-Vieira, ${ }^{2}$ Carh S.R. Moreira Si, ${ }^{2}$ Danilo C. Ameida, \\ Leonardo M. Vieira, ${ }^{2}$ Cláud h S. Cunha, ${ }^{2}$ Meire 1. Hiyane, ${ }^{2}$ Akxandre S. Basso, \\ Alvaro Pacheco-Sika, ${ }^{2}$ and Niek OS. Câmara ${ }^{2}$
}

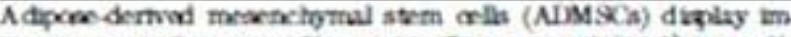

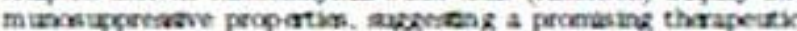

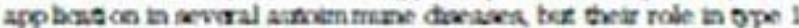
dibates (T1D) remains lurgoty unerplored. The asm of thas iedy was is imosegas the inenune regulivery pecportim of allogenes

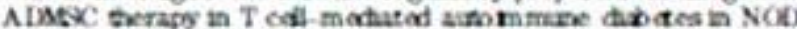

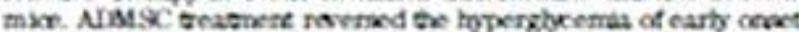

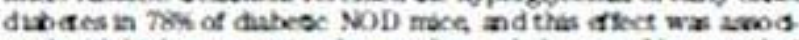
atad with hegher sarum thathin, arrytan, and glocapoen 1 ke pegeide 1

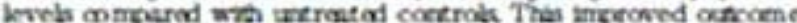
was avocixed wre downrgulason of the CT4' Thi baxd irs mime rearote and exponicon of regulutory $T$ olls (Tregs) in the

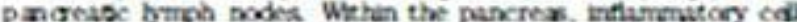
in tilsaboe and anterterce $\gamma$ lavels were redoced whale thalle, pan crease daodenal bomobox $x$, and ace ve transfoming growe.

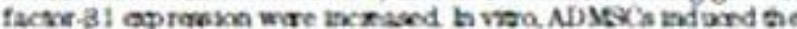

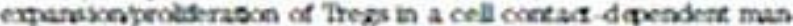
ax matued by progarren ad dexh heand 1. h suremary A Dist: thenpy etticintly amelorats auterien une dabetes pathogeneid

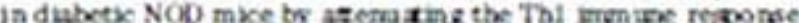
concoen zare wrth the expansice/proluferas on of 'Tregs thereby

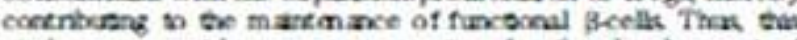
seaty mas provide a now parpacove for the davelopenene of

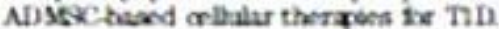
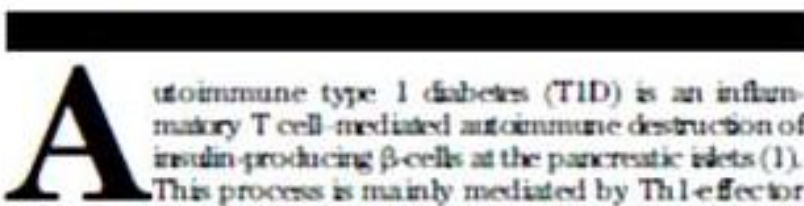

(toimmune tyge 1 dabets (TID) is at influn matry $T$ crll frediated ant cienmune destructoon of invilin groducins $\beta$-ellk at the parcrestic idets (1)

This procress is mainly mediated by Thleffechor CD4 cells and by proinflammatory groling, such $a$ in

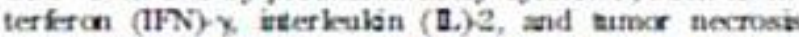
factor (TNF) $\alpha$ (2). Some studies show that the treatnent of nonobese dabetic (NOD) mice with anti- $5 \mathrm{~N}$ y anti body prevents the development of diahetes (3), and the trambenic expresuan of this cyvicine in dibetestesitat mice rosulis in drase development (4) bi addion, the in vitro combination of $I I, 1 \beta, 1 F N-\gamma$, and TNFa has bersi

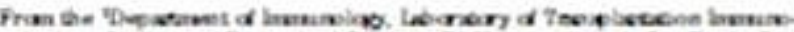

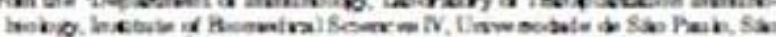

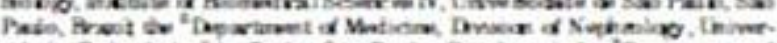

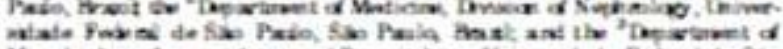

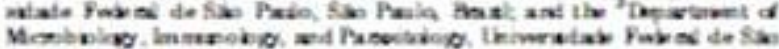

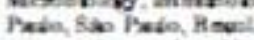

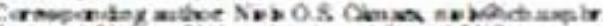

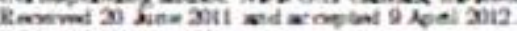

DOt rezmuthoil

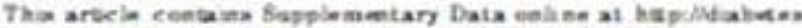

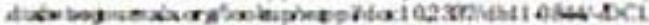

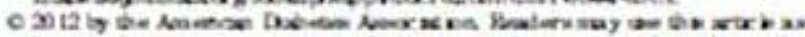

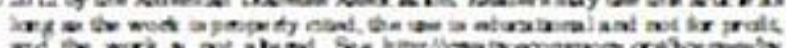
exedio is dacti.
}

shown bo ixrease the Beell vulherablity to antainame de snxtion (5). The artammine process in TID is abo com poed of resulutary componerts anch as $\mathrm{CD}^{*}$ (T)es Foxp $3^{*}$ rigulatory $T$ celk (Tregs), wlech are important for sup pressing the activation of the immune systern and therebs maintauing bomeostasis and toknace ob selfanbigens (6). The reduction of Treg frequency by disnuping the in/CDOS pitiway could accelende the onsed of autoinmune di abetes in NOD mice (7), while the e aparasion of these celk in parcreatic buph nodes (PLNs) was correlated with drease resatzice (8). Several sucossful experinertal therapies for TID show a comelation between a betser outcome and an increased frequency of these cells (9-11).

As a nsult of their inmure supprosue/regulatory and roperentive porenbal meserchymal aem cells (MSCs) have etnerged as a poksibally new therapy for TID. Several stad ies from the past fw yeans show thet MSCs are capalie of

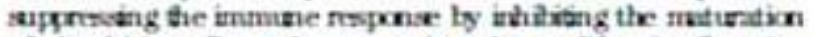
of dentritic cells and nupresuang the prodefendorvfuntion d T celk, B celk and NK crlts (12-15). Monower, MSCs have

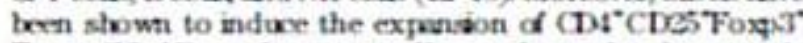
Tress (16-18), and some sudies evaluate the thenapertic effect of alogesieic of syngeneic bone mamow-dertived MQCs in the prevention or nevenion of matcimmune di abetes in sevenal experimental modek $(19-26)$. I is im. portant that adiporederived (AD)MSCs which can be acolated from fat tisue after liposuction and earily $e x$ panded in culture, have becotne an attractive source of MSCs for coll therapy. In additon, it has been nhown that ADMSCs can sapprew in vino Teell matcimmute reaponses in gnafversushont disewe and some experinental modk of atsoimsmue diseares such as edlugen indoced arthntis, experinental colitis, and anvinumure encepted anyelitis (27 -29). How ever, the intnumosuppreanie effect of ADMSCs in the treatment of TID remains bugely unexplored In this study, we evaluated the thenapeitic potentid of ADMSO $\mathrm{s}$ in ane liorating the recent onses of expeninental atoimmune diabeses in a NOD mouse model with recart to their imsnune regulabry properses. Therefore, we in vestigated the pokential of ADMSC therapy to samula neoudy suppress the Th1 CD4 T cell-mediated immure respotse invohed in this divense and promate the exparson d Trogs.

\section{EESEARCH DESIGN AND METHODS}

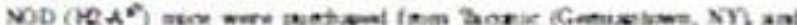

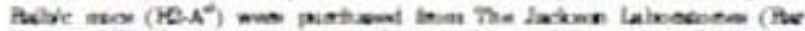

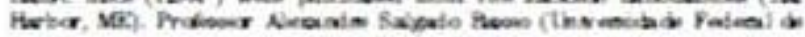

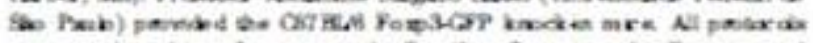

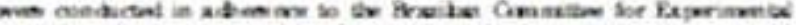

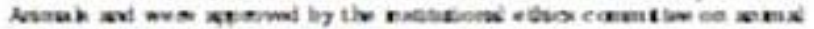

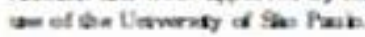




\title{
Exploring the Role of Soluble Factors Associated with Immune Regulatory Properties of Mesenchymal Stem Cells
}

\author{
Enio Josk Bassi- Danillo Candido de N meida . \\ Redre Maneel Meades Moras-Vleira . \\ Niek Olace Saralva Caman
}

Rulibal ouline: I Sermke 211

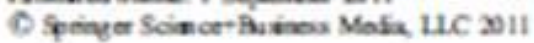

\begin{abstract}
Nitract Mesenchymal stem cells (MSCs) are chraster. ined as multipotest stovena cells with the capariny for bot selfeenewal and differentiation inso mendermal cell

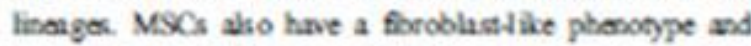
can be isolated froen several tissues. In recent yeas, zesearhers have foend thr MSCs sacrete several soluble factors that exart im manosuppossive effocts by modal aing both innase (marophagex, dendritic and NK cells) and alapeive (B cells and CD4t and CD8t $\mathrm{T}$ cells) immane rerpoesc. This nview summarizs the peincipal trophic facoes that as reled to immune regelrioe and secread by MSCs under both atoimmune and inflummeny condition. The undestanding of mechaniems the reglase imenonity in MSCs feld is important for their tature ute a a novel cellelr based immanotenpy with clinical appli. cations in several disenses.
\end{abstract}

Kegwords Mesendtymal stem cells - Immane reguleioebumune system - Solable factors - Inmunoeler fyy. Enflenmatioe

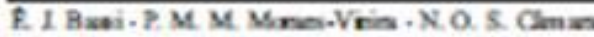

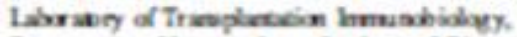

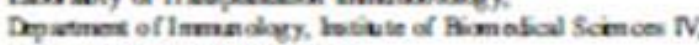

thinenible de S6a RylodSP?

assok.000 Sbo Reb, Arail

D C. de Almoila

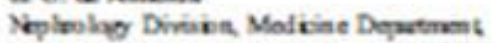

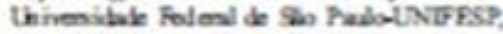

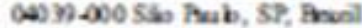

N O. S. Cimmer $(00)$

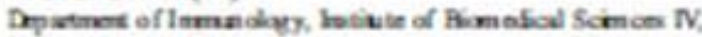

thinenit of Sba Rebs,

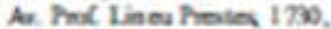

assok 000 Sbs Rab, SP, Munl

cenal nicle ah up it

\section{Intreduction}

Maltipotent stromal cells of mesaxhymal stem cells (MSC) are adalk adherent noobemzopoietic stem cells that were fiss isolsed by Friodenstein of al in 1970 foem boes marrow stroma chancterized by long-sem self. renewal [1]. In recent yers, there cells hwe been isolued from varios posental tissuch, incloding boee matrow. placesta woth palp, skin, afipone tivsoe, the nervosh system and bidney [2] Morpbologically, MSCs ane cells with fbooblass like properties (fasiform) and are chancter. irad by their ability so form fibooblast colocy-forming whits (CFUs) in their exly grouth in vitro and the potential 10 differentiate inso cateonyes, adipocytes and choodrocyes. Moroovet, there cells do not expess the bembopoienic surfice madx ars CDI4, CD45, CD84, CD133 and endothe hal marker CD31 and are poritive for CD105, CDi66, CD54, CDNo, CD55, CDi3, CD73, Stro-1 and CD44 [3]. Alboegh MSCs oan be inolsed fom several sources, aocouding to the Internaboeal Society for Cellulu Thenpy [4] every MSC should have a plasic-atherent grow th panarn exprestion of specific surfice antigens and the potential for maltilinewe differentiabion (ontoogenic, choedrogenic and adipogenic) (Fig. 1) [5]. Moorover, the sarm "maltipotest mesenchymal stromal celk" has been genes. ally usod indead of "mexenchymal stem cells" (5).

MSCs have the potential so provide effective tratemeat for a wide rage of disenses and an be wod in seveal applicabios in regeneative moticine such as ticne repur and gene delivery. h addition, MSCs were amoeg the first stem cells so be introdsoed inso clinical pactice. Hitares. ingly, there cells can modulate the immune respoese by bodh inhibiting the mrunbioeldifferentiation of dendritic cells and by suppessing the xtivrioe and lor fancioe of T and B bympocyses and NK cells in seveal ausoimmane 


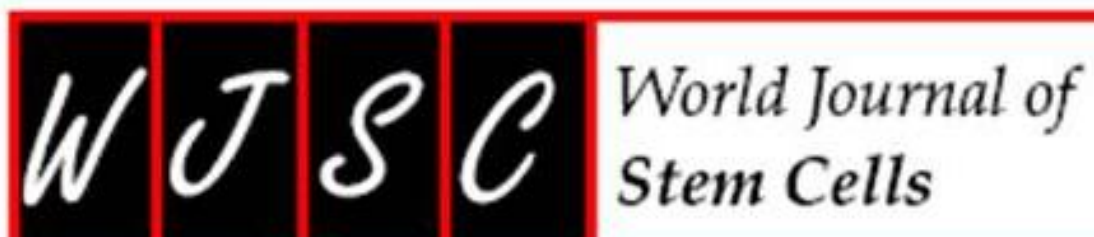

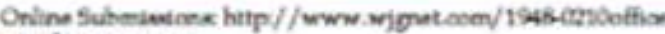

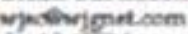

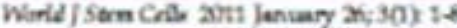
ExN rouscote janlon o zont thahidere. All righte rearval

\title{
Immune regulatory properties of multipotent mesenchymal stromal cells: Where do we stand?
}

\author{
Etrib looé Bass, Carlos Nberto Mayora Ata, Nies Olsen Saraiva Camara
}

Enio Jose Bass, Niets Oloen Sarsva Cimara, Laberaen of

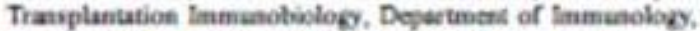

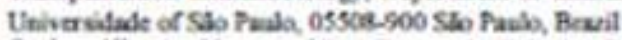
Carlos Alberto Mayora Aita, Ceatro de Cibacias Biológ. cas e A Sable, Poetificie Universibale Canblise do Furat. Beners-901 Curiolas Brwil

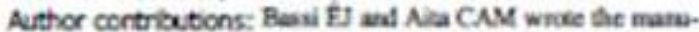
scripk Seraiva Clmisa NO wocke ad reviened de manuacript. Supported by Grants 0855447.1, 09151642-1 and 07i07139.3 from ite State of Sos Paulo Foundrion for Revearch Sappont (FAPESP, Beavilian Council or Sciencife and Techovloyje De-

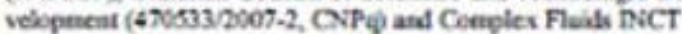
Comeroondence tox Nids Otsen Saraha CSmara, MD, Pro-

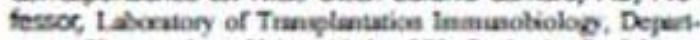

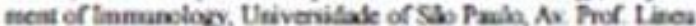

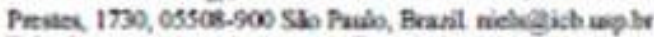
Teleohone: -35-11-3091738s Fax: +35-11-30917224

Recetved: fuly 21, $2010 \quad$ Revised: Desemler 18, 2010

Accostad: Decenber 2S, 2010

Publehed online fauary 26, 2011

\begin{abstract}
Multipotent mesenchymal stromal cols (MSC) can be bolated and effidently expanded from almost every single booy tessee and have the ability of sel'-renews and differentiation into various mesodermal cel lineages. Moreover, these cells are considered immunologcally privieged, relatad to a lodk of surface expression of costimulatory moleolies required for complete $T$ cel activision. Recently, it has been observed that MSC are capetie of suppressing the immune resporse by inhibting the maturation of dendritic colls and suppressing the function of T lymphocytes, B iymphocyes and natural kiler cels in autoimmune and infammatory diseases as a new strategy for immunosupprexsion. The undersanding of immune regulation mecharisms by MSC is necessary for their use as immunotherapy in clinical applicsions for several disease.
\end{abstract}

O2011 Bvehideng. Al ights resores.
Key word: Immunosuppression; Mesenchymal stem cel; Immune system; Imfammation; Autoimmune diseave

Peer revirwer: Guatgesea Ren, P.D. Depurtunent of Molecs: Ier Genetics, Misrobvology and Imananology, Rotert Wood

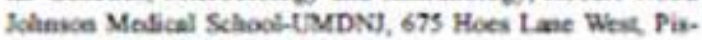
culawn, NJ Cess4, Uniad Stanes

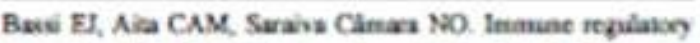
properties of multipotent mewonchymal stromal cellix Whare do

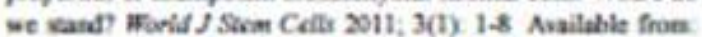
URL. hutp//ww w wignet com/1948-0210/ralt/v3/i1/t Mtm

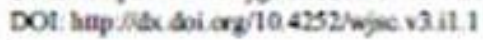

\section{INTRODUCTION}

Multipotent mesenchymed stronal cels (MSO) are adult multipotent non-hematopoietic stem cells capable of solf-tenewal and generstice of different cell lines Friedensten and colleagues in 1970 were the first to iolane and report a population of acherent stem coll from the bone-mienow strom" the bene marrow, they are now shown to roside in almost every ope of connective tisuse and can be isobated from various postetatal tissues such as boee martos, come and retina, placenta, mooth pulps shin, nervoce syseem and kidney? ${ }^{7}$. Due to the facility of isolation and extensive differentiation potental, MSC are among the first atem cells so be introduced in dirical pescice with a grest potential in cell therapy.

\section{Isolation, dfferentiation and expansion capacity}

Genendly, these cells can self-eenew and are miltipotent and therefoee hise a potential of differentiabion more hmited thas embeyonic stem cels which aee plunpotere. MSC hwe been shown to be sile to differentate is abs and in the into vericus mesodermal cel lincapes induding outoocyes, abipocytes, choodrocyses, muscle and myclo-sup- 


\title{
Obesity Comorbidity/Etiology and Pathophysiology
}

\section{Leptin as a link between the immune system and kidney-related diseases: leading actor or just a coadjuvant?}

\author{
P. M. M. Morses-Veira', E. J. Bassi', R. C. Araujo² and N. O. S. Camara'
}

\author{
Imunoog Docusnert, matite of \\ Banodcul Scunce. Unversyy of Soa Paja. \\ SP. Brast Docormuet of Bcchyecs, Fosoral \\ unvonty of Sao Paso. Sto Paib Erast \\ Fxavod 20 Doanbu 2011; novisad 2 \\ Potruar 200; accotad s Mech 2012

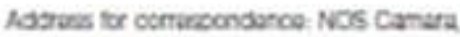 \\ Decormatt of mmuedogr. nands of

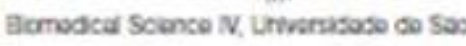 \\ Pasa, Ras Post Lnou Pratera, 1730

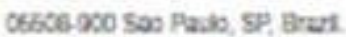 \\ Emal notocthust
}

\begin{abstract}
Summary
Food intake and nutritional satus modify the pbysiological responses of the immune sysem to illiness and infection and requlate the derelopenent of chroeic inflammutory processes, wech as kidney disease. Adipose tisue sectetes immune. related proteins called adipokines that have pleiotropic effects on both the immune and neuroendocrine syterns, linking metabolism and immune physiol. oge. Leptin, an adipose tiwaederived adipokine, displays a variety of immune and physiological functions, and participates in several immune responses. Here, we review the curtent literature on the role of leptin in kidney diseases, linking adipose tiosue and the immune system with kidney-related dosorden. The modulation of this adipose hormone may have a major impact on the treatment of several immune- and metabolic-related kidney diseass.
\end{abstract}

Keywords: Foxp3, kidncy, keptin, nephrology.

obosity roviows (2012) 13, 733-743

\section{Introduction}

Obesity, a pathological conditicn that is characterizod by excessive fat deposits, is currently a major public health isue and an important risk factor contributing to the development of muny different diseases wotldwide. Obesity is correlated with low-grade inflammation of white adipose tissee and is accompanied by chronic activation of the innate immune system, insulin resistance, impaired glucone tolerance and diabetes (1). In addition, obesity has been zwociated with hypertension, hypercholesterolaemia, cardiovascular diseases, several types of tumours and immune dysfunction that leads to hipher infoction rates and delayed wound bealing (1-3). The changes in energy homeontasis awociated with obesity have been attributed to boch physiological imbal.

Satcon the wrk was sutcontos by the Brarkan Founsabon - FAFSP

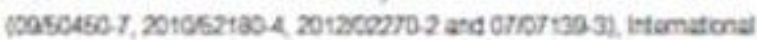
Rasodatsd Labordsy in Fanal immuncouthosg (CNPQtrouml, NCT Concler Pulds and CNete ances, which can be caused by neuroendrocrine factors, metabolic disturbances, genetic traits of other biological factors, and enviroemental influences, wuch as lifestyle changes, excosive energy intake and/or redoced physical activity (4). In this review, we will discuse the current undentanding of leptin and its complex role in modulating immune responses, with an emphasis on kidney diseass.

\section{The influence of adipose tissue on kidney diseases}

Body fat secretes a variety of soluble factors called adipok. ines, which are cytokines that are prodaced mainly by adipocytes (5). The immune-related proteins penerated by adipocytes indude leptin, adiponectin, resistin, valatin, tumcer necrosis factor (TNF), adpsin and interleukin (II.)-6, as shown in Fig. 1. Among these adipokines, leptin is considered to be a purticularly important adpocyte. generated immune-rdated protein. Adpose tiwue functions not only to store energy beat also to cuntrol immune 


\title{
TLR2, TLR4 and the MYD88 Signaling Pathway Are Crucial for Neutrophil Migration in Acute Kidney Injury Induced by Sepsis
}

\author{
Angda Castoldi '2, Tärcio Todoro Braga', Mathous Correa-Costa ${ }^{2}$, Gristhiane Fávoro Aguiar', Énio \\ José Bassí, Reinaldo Correa-Silva', Roa Maria Elias', Fabia Salvador', Pedro Manoel Moraes-Vidira', \\ Marcos Antônio Cenedeze', Marlene Antónia Rdis", Mdre boshie Hiyane ${ }^{2}$, Álvaro Pacheco-Silva ${ }^{1,2}$, \\ Giselle Martins Gonçalves ${ }^{2}$, Nids Osen Saraha Cimara ${ }^{12 .}$

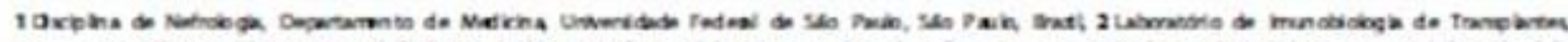

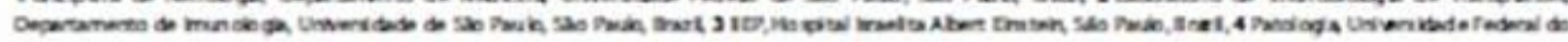

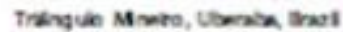

\begin{abstract}

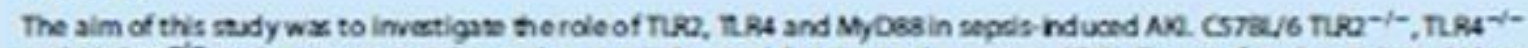

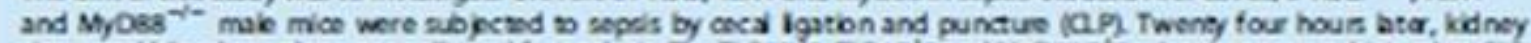

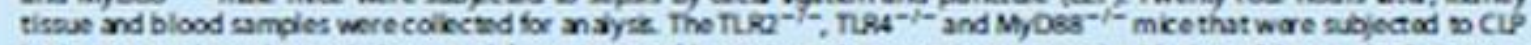

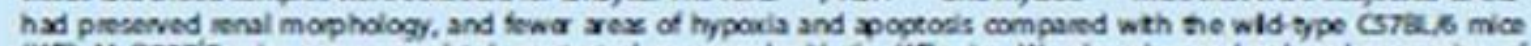

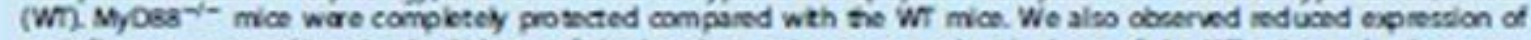
prointamm xary cycoitnes in the isdngys of the knodiout mice compand wth those of the WT mike and suberguant

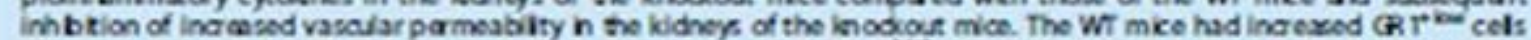

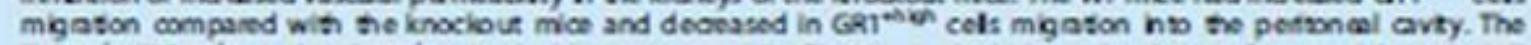

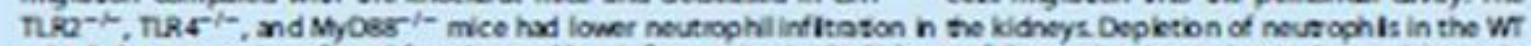
mice kd 2 protection of rend function and less $n$ trmmason in the kdneys of these mice imase immunity partidpates in

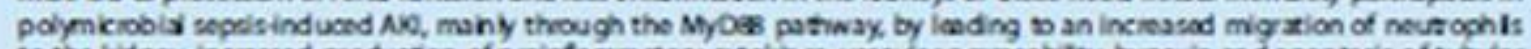
to the kidnex, inciered producton of prointamm xary cycolines, vacular pameabity, hypoxia nd apoptosis of tubular cels.

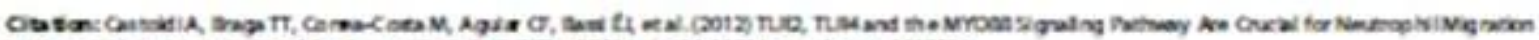

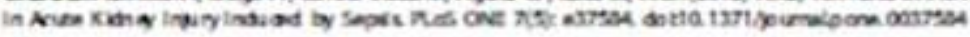

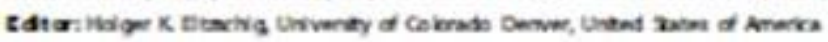

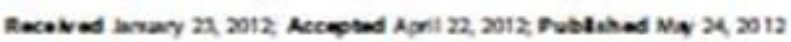

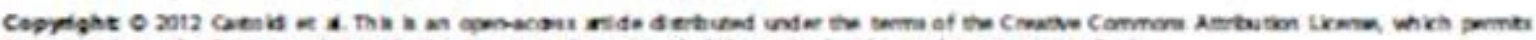

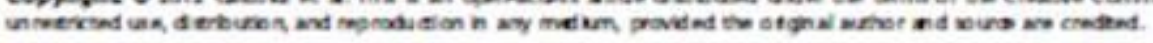

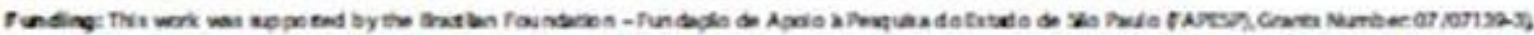

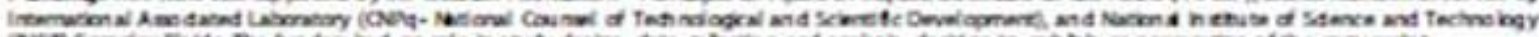

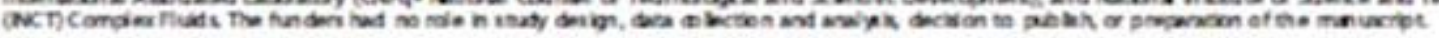

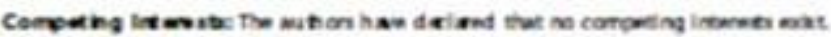

- tenal: solerhas b
\end{abstract}

\section{Introduction}

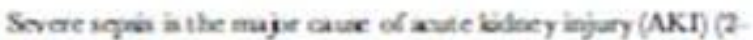
4). Dopine al clbors so beacr oompechend this puehologr, liele

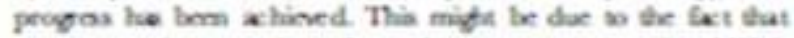
moe rocarch goupe huve boouad mere on proving the AKI is muing caund by chunges in bidney hemodynenio, while odfer

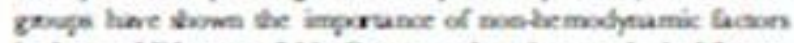

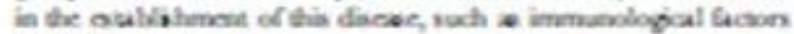

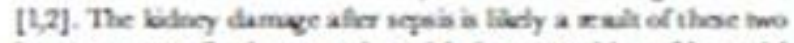

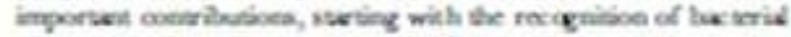

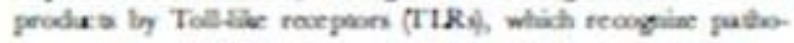

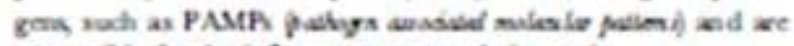

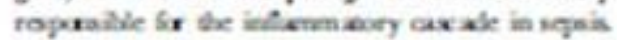

Sigul tranalasion throckh TIRs is puesialy medaved by a

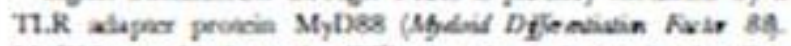
MyDes an hind os the TIK bmain and rosnit siguling

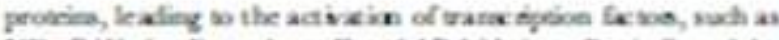

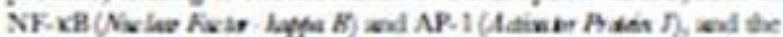

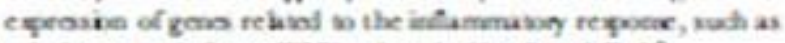

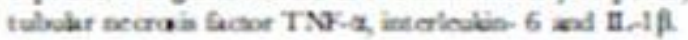

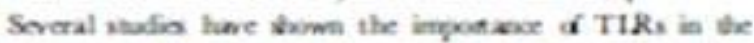

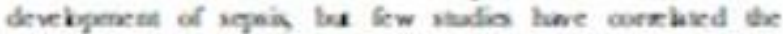

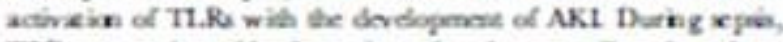

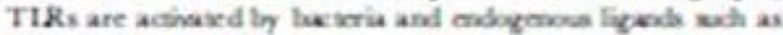

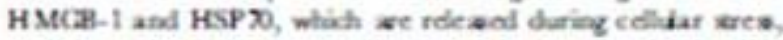
and intorad widh the immune noem in the catracelihat

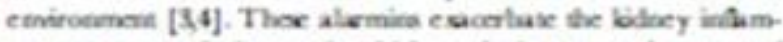
menry poscese darngngwh, which rals in greer deruge and necrusi.

Thas, we hypodiesied that mice deficont in T1.K2 and TTR4 and the alupoe procin MyDes ropoed los difoxively a

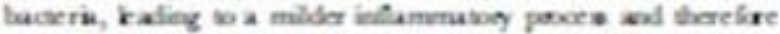

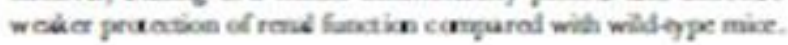

